\title{
DETERMINAÇÃO DAS CURVAS DE ISO-CONSUMO COM TRATOR OPERANDO SOBRE SOLO AGRÍCOLA
}

\section{ROGÉRIO CORRÊA BERNARDES}

Engenheiro Mecânico

Orientador: Prof. Dr. LUIZ ANTÔNIO BALASTREIRE

Dissertação apresentada à Escola Superior de Agricultura "Luiz de Queiroz", Universidade de São Paulo, para obtenção do título de Mestre em Agronomia, Área de Concentração: Máquinas Agrícolas.

PIRACICABA

Estado de São Paulo - Brasil

Agosto - 1997 
Dados Internacionais de Catalogação na Publicação (CIP) DIVISÃo DE BIBLIOTECA E DOCUMENTAÇĀO - Campus "Luiz de Queiroz"/USP

Bernardes, Rogério Corrêa

Determinaçăo das curvas de iso-consumo com trator operando sobre solo agricola / Rogério Corrêa Bernardes. . Piracicaba, 1997.

108 p. : il.

Dissertaçāo (mestrado) - - Escola Superior de Agricultura Luiz de Queiroz, 1997. Bibliografia.

1. Consumo (combustivel) 2. Ensaio de campo 3. Trator agricola I. Título 


\section{DETERMINAÇÃO DAS CURVAS DE ISO-CONSUMO COM TRATOR OPERANDO SOBRE SOLO AGRÍCOLA}

ROGÉRIO CORRÊA BERNARDES

Aprovada em: 23.09 .1997

Comissão julgadora:

Prof. Dr. Luiz Antônio Balastreire

ESALQ/USP

Prof. Dr. Oscar Antônio Braumbeck

FEAGRI/UNICAMP

Prof. Dr. Carlos Antônio Gamero

FCAVUNESP-Botucatu

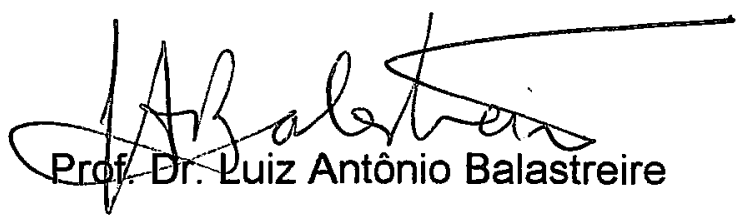

Orientador 
Ao meu pai, Calebre.

À minha mãe, Sirlei Maria

Ao meu avô André e minha avó Aparecida

Aos meus amigos

e principalmente, ao Senhor 


\section{AGRADECIMENTOS}

Ao Prof. Dr. Luiz Antônio Balastreire, Prof. Dr. Oscar Antônio Braumbeck, Prof. Dr.Carlos Antônio Gamero, Prof. Dr. Marcos Milam e ao Prof. Dr. Geraldo Mialhe pelas sugestões e apoio dados durante a realização deste trabalho.

À empresa Valmet do Brasil S.A., pela colaboração concedida.

Ao funcionário Eng. Eletrônico Juarez R. Amaral que ajudou-me de modo decisivo durante o curso e em todas as fases do trabalho.

À todos os funcionários, técnicos de laboratório e estagiários, pela ajuda prestada durante a elaboração e execução dos ensaios de campo. 


\section{SUMÁRIO}

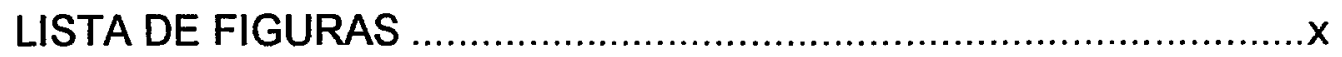

LISTA DE TABELAS .................................................................ii

LISTA DE SÍMBOLOS ...........................................................

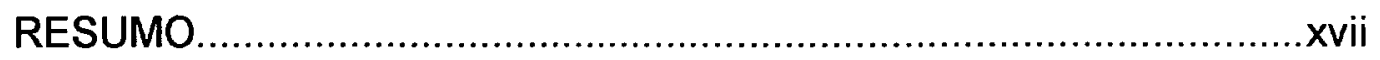

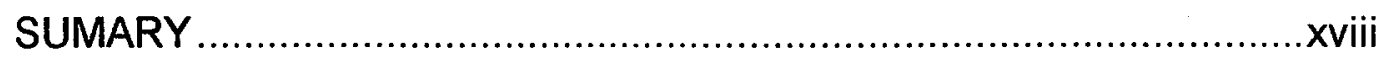

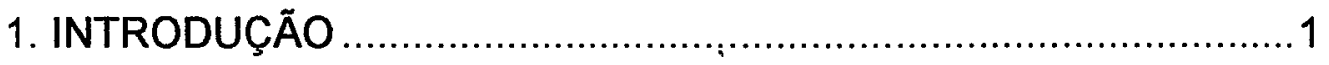

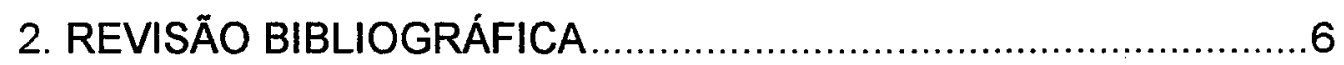

2.1 Aspectos Gerais sobre a Eficiência Global dos Tratores........6

2.1.1 Possibilidades de Economia Energética durante $\mathrm{o}$ uso do trator..................................................

A) Motor e Transmissão ........................................................

B) Órgãos Auxiliares ..................................................... 13

C) Sistema de Tração ..................................................13

2.1.2 Possibilidade de Economia Energética através da Redução de Carga .......................................15

2.2 Conceitos de Desempenho de Motores ................................ 16

2.3 Desempenho na Barra de Tração do Trator ..........................21

2.4 Modelos de Consumo de Combustível ................................24 
2.5 Curvas de Iso-Consumo ou Eficiência Global do Motor

2.6 Determinação dos Pontos Ótimos de Trabalho de um Motor Diesel

2.7 Rendimento Global de Tratores em Pista de Concreto ...........36

2.8 Seleção da Relação de Transmissão 40

2.9 Análise do Desempenho do Trator em Ensaio de Campo 47

2.10 Modelos Empíricos da Razão Dinâmica de Tração .49

3. MATERIAL E MÉTODOS

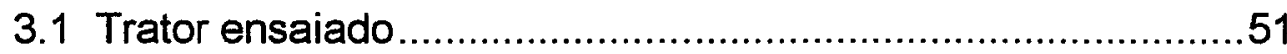

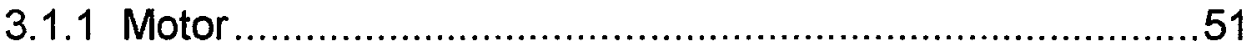

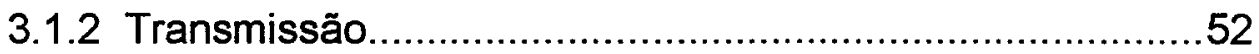

3.1.3 Características Dimensionais e Ponderais .......................53

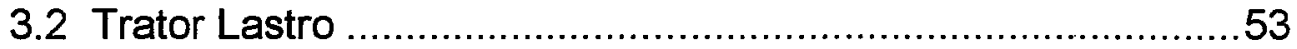

3.3 Medição do Consumo de Combustível ...................................53

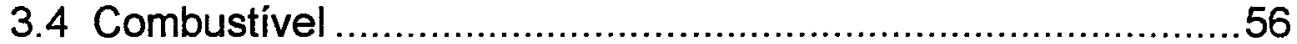

3.5 Medição das Temperaturas e Umidade Relativa .....................56

3.6 Medição da Pressão Atmosférica.........................................57

3.7 Caracterização da Área e do Solo .........................................58

3.8 Medição da Rotação do Motor .............................................60

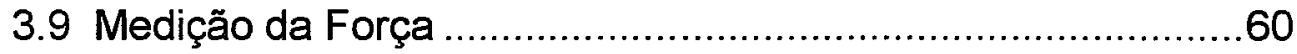

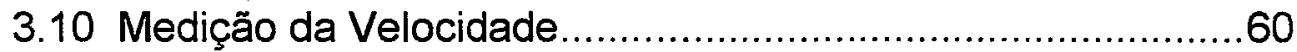




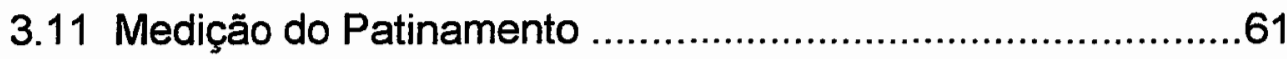

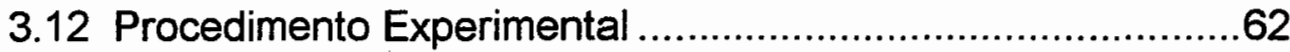

3.12.1 Campo e Condições de Tração .......................................62

3.12.2 Procedimento Geral do Ensaio ....................................64

3.13 Avaliação do Rendimento Global do Trator em Campo.........66

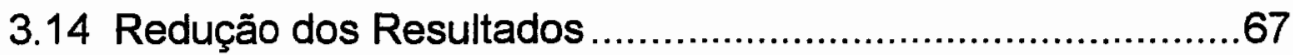

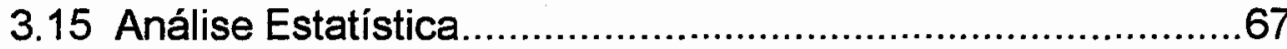

3.16 Verificação do Procedimento GUTD ...................................68

3.17 Análise da Razão Dinâmica de Tração obtida pelos dados experimentais e pelos modelos propostos 68

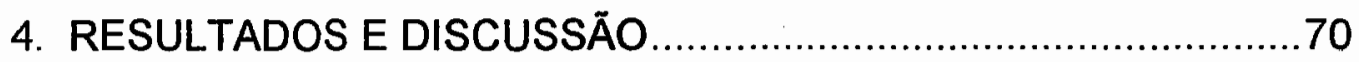

4.1 Dados Referentes às condições do Solo ...............................70

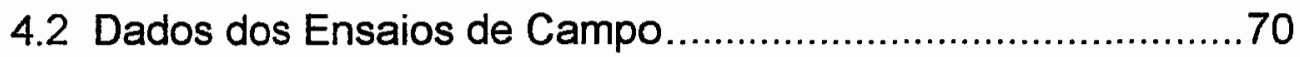

4.3 Cálculo da Força, Velocidade de Deslocamento, Potência Corrigida, Patinamento e

Eficiência Global do Trator $\left(\eta_{t}\right)$ 71

4.4 Eficiência Global Reduzido do Trator em função das variáveis Força de Tração (F) e

Velocidade de Deslocamento (V). .72

4.4.1 Para a Marcha L2R ..................................................... 72

4.4.2 Para a Marcha L2L...................................................73

4.4.3 Para a Marcha L3L.....................................................74

4.5 Estimadores dos coeficientes das equações 
envoltórias de força em função da velocidade,

para as diversas marchas utilizadas......................................75

4.6 Curvas de Iso-Consumo ou de Parâmetros Múltiplos..............76

4.6.1 Curva de Iso-Consumo do Trator

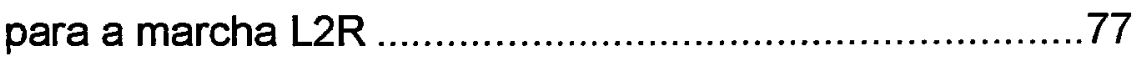

4.6.2 Curva de Iso-Consumo do Trator

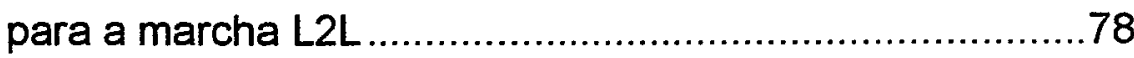

4.6.3 Curva de Iso-Consumo do Trator para a marcha L3L

4.7 Curvas de Ganho de Eficiência Global do Trator

na Troca de Marchas (procedimento Gear-Up and Throttle Down - GUTD) .80

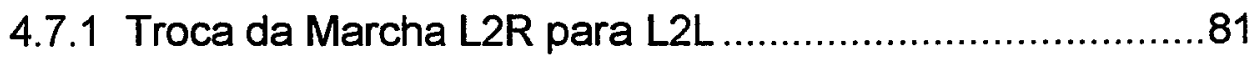

4.7.2 Troca da Marcha L2L para L3L.....................................83

4.8 Comparação dos Modelos propostos da Razão Dinâmica de Tração com os dados experimentais 86

5. CONCLUSÕES 89

Recomendações para Trabalhos Futuros 90

ANEXO A: Características do Solo na Área Ensaiada. 91

ANEXO B: Dados dos Ensaios de Campo

ANEXO C: Cálculo dos Valores de Força, Velocidade, Consumo e Patinamento 102 


\section{LISTA DE FIGURAS}

Figura 1 - Balanço energético de um trator operando em trabalho de tração.......................................................... 6

Figura 2- Curva de iso-consumo de um motor diesel..................... 8

Figura 3- Curva de iso-consumo de um motor diesel adaptado........ 10

Figura 4- Rendimento de tração de um trator agrícola em função do seu patinamento.......................................... 14

Figura 5- Curvas de potência, torque e consumo específico............ 19

Figura 6- Curvas de desempenho de um trator................................ 22

Figura 7- Curvas de modelos de consumo de combustível.............. 25

Figura 8- Curvas de iso-consumo de um motor diesel..................... 28

Figura 9- Eficiência do motor diesel a rotação constante.....................29

Figura 10- Eficiência do motor diesel a torque constante....................30

Figura 11- Duas situações de operação para um motor diesel;

a) tempos iguais gastos em cada ponto de trabalho do motor

b) tempo gasto na dependência dos diferentes pontos de trabalho do motor

Figura 12- Curva de desempenho do motor incluindo

a curva de otimização da eficiência. 34

Figura 13- Curva de desempenho do motor incluindo a reta de aproximação para otimização da eficiência 35

Figura 14- Diagrama de blocos do funcionamento do GUTD. 47 
Figura 15- Vista esquemática do medidor de combustível.................. 54

Figura 16- Vista do medidor de combustivel.................................... 54

Figura 17- Vista do painel de controle.......................................... 55

Figura 18- Vista do campo de ensaios........................................... 58

Figura 19- Esquematização dos geradores de sinal para determinação do patinamento...........................................61

Figura 20- Montagem do gerador de sinal de patinamento...................62

Figura 21- Posicionamento das estacas.............................................. 65

Figura 22- Vista lateral do comboio...........................................66

Figura 23- Curva de iso-consumo específico do trator operando em solo agrícola, em função da força na barra de tração e velocidade de deslocamento, para a marcha $L 2 R$, e os pontos experimentais obtidos dos ensaios. .77

Figura 24- Curva de iso-consumo específico do trator operando em solo agrícola, em função da força na barra de tração e velocidade de deslocamento, para a marcha $\mathrm{L} 2 \mathrm{~L}$, e os pontos experimentais obtidos dos ensaios 78

Figura 25- Curva de iso-consumo especifico do trator operando em solo agrícola, em função da força na barra de tração e velocidade de deslocamento, para a marcha $L 3 L$, e os pontos experimentais obtidos dos ensaios 79

Figura 26- Indicação da área onde se pode realizar a troca de marchas de $L 2 R$ para $L 2 L$ - área hachuriada. 
Figura 27- Curvas de iso-ganho de eficiência global do trator, na mudança da relação de transmissão de $L 2 R$ para $L 2 L$..........82

Figura 28- Indicação da área onde se pode realizar a troca de marchas de L2L para L3L - área hachuriada. .83

Figura 29- Curvas de iso-ganho de eficiência global do trator, na mudança da relação de transmissão de $L 2 L$ para $L 3 L$ 84

Figura 30- Comparação das curvas da razão dinâmica de tração obtidas através da aplicação dos modelos propostos com os dados experimentais.

Figura 31- Eficiência tratória em função do patinamento das rodas do trator 88 


\section{LISTA DE TABELAS}

Tabela 1- Tabela onde se relaciona o consumo de combustível, razão de trabalho e índice tempo-consumo à relação de transmissão e rotação do motor

Tabela 2- Relações de transmissão do trator ensaiado...................... 52

Tabela 3- Temperatura e umidade do ar no local do ensaio................55

Tabela 4- Pressão barométrica durante os dias de ensaio..................57

Tabela 5- Resultados médios de umidade e densidade do solo...........59

Tabela 6- Índice de cone médio da área do ensaio............................59

Tabela 7- Marchas e rotações utilizadas no trator lastro para impor a força necessária ao trator ensaiado..................... 64

Tabela 8- Estimadores dos coeficientes para a marcha L2R ............. 72

Tabela 9- Estimadores dos coeficientes para a marcha L2L............ 73

Tabela 10- Estimadores dos coeficientes para a marcha L3L............. 74

Tabela 11- Coeficientes das equações envoltórias de força em função da velocidade, para as diversas marchas utilizadas.

Tabela A1- Dados referentes à densidade do solo $(\mathrm{g} / \mathrm{ml})$ das amostras recolhidas em 12 pontos aleatoriamente espalhados pela área de ensaio, nas três profundidades $(0-5,5-10,10-15) \ldots .91$ 
Tabela A2- Dados referentes à umidade do solo (\%) das amostras recolhidas em 12 pontos aleatórios da área de ensaio, nas três profundidades $(0-5,5-10,10-15)$.

Tabela A3- Dados referentes à resistência à penetração $\left(\mathrm{kgf} / \mathrm{cm}^{2}\right)$ na linha do rodado do trator, antes e após a sua passagem, nas profundidades $(0-5,5-10,10-15)$

Tabela B1- Dados referentes à calibração da célula de carga, com o amplificador ajustado para $\mathbf{3 0 0 0}$ micro strain, correspondente à 36787, $5 \mathrm{~N}$ (3750 kgf), para cada intervalo de ensaio especificado através dos números extremos.

Tabela B2- Dados referentes à calibração dos contadores de pulsos de cada roda do trator, onde a tabela discrimina o número de pulsos para um deslocamento de $\mathbf{4 0}$ metros do trator, com patinamento considerado nulo.

Total de ensaios: 5

Tabela B3- Dados referentes aos parâmetros medidos durante os ensaios. Na seqüência das colunas, tem-se: número do ensaio (cronológico); tipo do ensaio (de 1 a 36); tempo total do ensaio (segundos); pulsos das rodas traseira esquerda, traseira direita, dianteira esquerda, e dianteira direita; número de pulsos da célula de carga (cc); consumo de combustível (leitura da bureta central); tempo de consumo do combustivel (segundos); temperatura do óleo diesel (em milivolts de um termopar tipo J); dia e mês, horário do ensaio. 98

Tabela C1- Cálculo dos parâmetros dinâmicos 102 


\section{LISTA DE SÍMBOLOS}

\section{Símbolo}

$a_{i}$

b

$b_{i}$

$\mathrm{Bn}$

CECG

CECL

$\mathrm{CH}$

$\mathrm{c}_{\mathrm{i}}$

CN

d

D

Dens. Comb.

$\mathrm{d}_{\mathrm{i}}$

Ea

Ee

$\mathbf{e}_{i}$

Ep

E.T.

$\mathrm{F}$

$f_{i}$

$g_{i}$

GUTD

\section{Descrição}

constante do modelo matemático

largura da secção do pneu sem carga

constante do modelo matemático

índice de mobilidade de Brixius

consumo específico de combustivel, em g/kW.h

consumo especifico de combustivel, em L/kW.h

da tomada de potência

consumo horário de combustível em $\mathrm{kg} / \mathrm{h}$

constante do modelo matemático

índice de mobilidade

diâmetro do pneu sem carga

débito de combustível por cilindro e por ciclo em $\mathrm{mg}$

densidade do combustível em $\mathrm{g} / \mathrm{dm}^{3}$

constante do modelo matemático

rendimento de engrenamento entre o motor e eixo da roda

energia especifica, em kW.h/l

constante do modelo matemático

rendimento de engrenamento entre o motor e a TDP

eficiência tratória

força na barra de tração

constante do modelo matemático

constante do modelo matemático

"gear up and throttle down"

marcha acima e aceleração reduzida 
h

$\mathrm{H}$

$h_{i}$

IC

k

$l_{i}$

Mp

N

$\mathrm{Nr}$

Pbdt

$P_{m}$

$\mathrm{R}$

RDT

$\mathrm{Ri}$

RT

$S$

SR

$\mathrm{t}$

T

TDP

$\operatorname{Tr}$

V

$\mathrm{X}$

W

$\delta$

$\eta_{\mathrm{b}}$

$\eta_{\mathrm{t}}$

secção de altura do pneu

poder calorífico do combustível

constante do modelo matemático

indice de cone médio na camada de $0-15 \mathrm{~cm}$ do solo

constante de ajuste de unidades

constante do modelo matemático

máxima potência na TDP

rotação do motor

rotação a máxima potência

potência desenvolvida na barra de tração

potência do motor

raio de rolamento das rodas de tração

razão dinâmica de tração

região de integração

reserva de torque

patinamento

redução total de velocidade (rpm do motor/ rpm do

eixo da roda)

tempo

torque do motor

tomada de potência

torque a máxima potência

velocidade de deslocamento do trator

porcentagem (ou razão) do uso da potência máxima

carga dinâmica sobre o rodado de tração

deflexão percentual do pneu (geralmente considerado 20\%)

eficiência global do motor

eficiência global do trator pela barra de tração 


\title{
DETERMINAÇÃO DAS CURVAS DE ISO-CONSUMO COM TRATOR OPERANDO SOBRE SOLO AGRÍCOLA
}

\author{
Autor: ROGÉRIO CORRÊA BERNARDES \\ Orientador: Prof. Dr. LUIZ ANTÔNIO BALASTREIRE
}

RESUMO

O custo referente ao consumo de combustivel representa aproximadamente $30 \%$ dos custos totais de um trator agrícola, sendo que tal porcentagem tem aumentado significativamente desde a década de 1970. Por este motivo, nesta pesquisa realizaram-se ensaios de campo na barra de tração de um trator de tal forma a se medir o consumo de combustível em diversas condições de esforço tratório e potência na barra de tração.

Desta maneira, foi possível calcular o consumo específico de combustível, tendo como parâmetro a potência na barra de tração, e consequentemente calcular a eficiência da transformação energética global do trator e aplicar estes dados a um modelo polinomial que correlaciona a eficiência à velocidade e força.

Observou-se que há regiões de operação do trator mais econômicas, e que estas só podem ser atingidas quando o trator dispõe de um número mínimo de marchas. 


\section{SUMMARY}

The fuel consumption cost represents about $30 \%$ of the total costs of farm tractors. This percentage has increased significantly since the 70's decade. In this research field tests of a tractor's drawbar were conducted to measure the fuel consumption in several conditions of drawbar pull and power.

The objective was to calculate the fuel specific consumption using the drawbar power, and consequently to calculate the efficiency of energy transformation using a mathematical model that correlates force and velocity with performance.

This research indicated that there are regions where the tractor operation would be more efficient in terms of energy use, and to use these regions the tractor must have a minimum of shift gears. 


\section{1- INTRODUÇÃo}

A seleção criteriosa de um trator no momento da compra vem-se tornando um comportamento cada vez mais freqüente no meio agrícola, pois é um fator que contribui no aumento da renda líquida, já que permite diminuição dos custos no setor agropecuário. Os dados para esta seleção têm como origem os ensaios oficiais que são conduzidos por entidades credenciadas, e que, segundo Mialhe (1996), podem assumir diversos aspectos, como por exemplo:

- servirem de elemento de qualidade mínima dos tratores;

- propiciarem a evolução tecnológica, já que suprem os fabricantes de dados muitas vezes não facilmente disponíveis e onerosos de serem obtidos;

- fornecer aos usuários dados mínimos para melhor seleção das máquinas e implementos através de uma linguagem simples e objetiva;

- credenciar as indústrias do país para a exportação de seus produtos, ou seja, concessão de um "certificado de conformidade".

Estes ensaios de máquinas agrícolas têm sido realizados há décadas. Os primeiros ensaios de máquinas agrícolas que se tem notícia foram realizados no final do século passado, em Uppsala, Suécia, e em Paris (França), ensaios estes que não passavam de apenas demonstrações práticas e sem qualquer caráter investigativo. $\mathrm{O}$ primeiro ensaio criterioso realizado, devido à necessidades de qualidade mínima, se deu nos EUA, mais precisamente em Nebraska, quando em 1919 foi apresentado um projeto de lei de Ensaio de Tratores de Nebraska, o qual obrigava os fabricantes que 
desejassem vender seus produtos neste Estado a passá-los por um ensaio na Universidade.

No Brasil, o primeiro ensaio de trator foi executado na Fazenda Ipanema-SP, pelo ex-CENTRI - Centro de Treinamento Rural de Ipanema, do Ministério da Agricultura. Esta medida foi de fundamental importância, já que durante o período de pós-guerra (1950-60), o Brasil passou a importar um grande número de máquinas, que, pelo fato de terem origem em países diversos, nem sempre se adaptaram ao uso nas condições brasileiras. Além disso, ao se adotar esta medida de ensaios nacionais, promoveu-se a criação e treinamento de um grupo especializado em ensaios, até então inexistente.

Deste fato em diante, procurou-se a profissionalização destes ensaios através de diversos Decretos, os quais estabeleceram novos critérios de obrigatoriedade de ensaios da maquinaria agrícola no país.

Os ensaios oficiais de tratores agrícolas no Brasil são realizados segundo a norma NBR-10400, a qual prevê os ensaios de desempenho na barra de tração sendo feitos em pista de concreto, e ainda não em campo.

A nível internacional, as normas OECD e ISO são tidas como as principais, mas também não prevêem ensaios de campo.

Segundo Mialhe (1996), estes ensaios, normalizados e sob a égide de compromisso público, devem possibilitar três tipos de confrontos:

$\left.1^{\circ}\right)$ comparação de desempenho de um espécime sob várias condições de ajuste e regulagens, dentro das especificações da máquina e sob as condições da norma;

$2^{\underline{0}}$ ) comparação do desempenho de um espécime com outros espécimes similares;

$\left.3^{\underline{0}}\right)$ comparação dos dados com um conjunto de dados que especificam um "padrão qualificador". 
No caso de interesse específico, o ensaio no qual se verifica a potência na barra de tração em função da relação de transmissão escolhida e aceleração, segundo a norma, dá uma visão geral do desempenho do trator sob determinadas condições, especificadas por ela. Este procedimento é importante na medida de que sugere internacionalização dos dados, ou seja, fixadas as condições impostas pela norma, tem-se resultados semelhantes (para não se dizer iguais) em qualquer ensaio feito com o mesmo trator, portanto permitindo comparações diretas de diversos tipos e modelos de tratores, dando ao comprador a oportunidade de escolher o tipo que mais lhe convém.

Estas condições, como pode-se verificar, está voltada para a reprodutibilidade do ensaio (Mialhe, 1996):

- pista de concreto (no caso de ensaio de trator com pneumáticos);

- condições dos pneus: devem ser aqueles indicados pelo fabricante e não ter desgaste maior de que $35 \%$;

- a linha de tração deve ser paralela ao plano de apoio e estar situada no plano longitudinal central do trator;

- não deve ocorrer uma transferência de peso do eixo dianteiro para o traseiro maior que $80 \%$ do peso estático do eixo dianteiro, quando se trata de trator $4 \times 2$.

O objetivo deste trabalho é obter as curvas de iso-consumo de um trator, de tal maneira a obter dados que se voltem mais à aplicação na propriedade rural, e por isso os ensaios devem ser realizados em condições que se encontram nas propriedades rurais. Contudo, não se pode perder a visão de normalidade dos ensaios, a qual fixa regras na sua conduta, como por exemplo, as citadas no item anterior (desgaste mínimo do pneu, condição de lastragem, medição do consumo de combustível, etc).

A mudança sugerida é quanto ao tipo de piso sobre o qual se dará o ensaio. A proposta é de realizar o ensaio sobre solo agrícola, onde realmente atua o 
rodado do trator, já que a pista de concreto, apesar de ser uniforme e reproduzível, pouco reflete a verdadeira situação do piso onde o trator trabalha. Espera-se que esta alteração não venha a prejudicar as outras condições de medição, mantendo-as sob controle e confiáveis.

Pretende-se com isto obter resultados mais condizentes com relação ao consumo e sua minimização, mas também fornecer dados a respeito da força tratória, potência, patinamento, etc, a fim de ter resultados mais voltados à aplicação do trator no meio agrícola, servindo como base de melhoria de seu desempenho e utilização mais criteriosa das possibilidades que o equipamento oferece.

Mostrará, também, a importância de se ter um número mínimo de marchas bem escalonadas disponíveis nos tratores como forma de se alcançar a melhor adaptação da fonte de potência ao meio em que se encontra e possivel aplicação do procedimento GUTD ("gear up and throttle down" - marcha acima e aceleração reduzida).

Os objetivos específicos deste trabalho, após a completa caracterização do solo, são:

Impostas três relações de marcha, as mais utilizadas nas operações agrícolas devido a velocidade que com elas se obtém, propõe-se:

- medir o patinamento médio sob diversas condições de esforço tratório;

- medir a força desenvolvida pelo trator sob as diversas condições impostas;

- medir a velocidade média em cada caso anterior, e posterior cálculo da potência desenvolvida;

- medir o consumo médio em cada condição anterior;

- calcular o consumo específico referente à potência desenvolvida na barra de tração; 
- construção das curvas de iso-consumo especifico e obtenção das áreas favoráveis para a aplicação do trabalho tratório onde se obtém maior economia;

- verificação da funcionalidade do procedimento GUTD;

- análise da razão dinâmica de tração e eficiência tratória através dos dados experimentais e modelos empiricos.

Com os resultados anteriores, espera-se obter parâmetros que auxiliem na decisão de optar pela melhor combinação de fatores que resultem em um uso racional do trator, através de uma maximização do seu rendimento como fonte de potência no meio agrícola. 


\section{2- REVISÃo BIBLIOGRÁFICA}

\section{1-Aspectos Gerais sobre a Eficiência Global de Tratores}

Segundo Steinkampf (1981), considerando que o combustível consumido componha $100 \%$ da energia total, então no máximo apenas $20 \%$ desta energia se converte em energia efetiva durante o trabalho de tração de um trator, conforme visto na figura 1 .

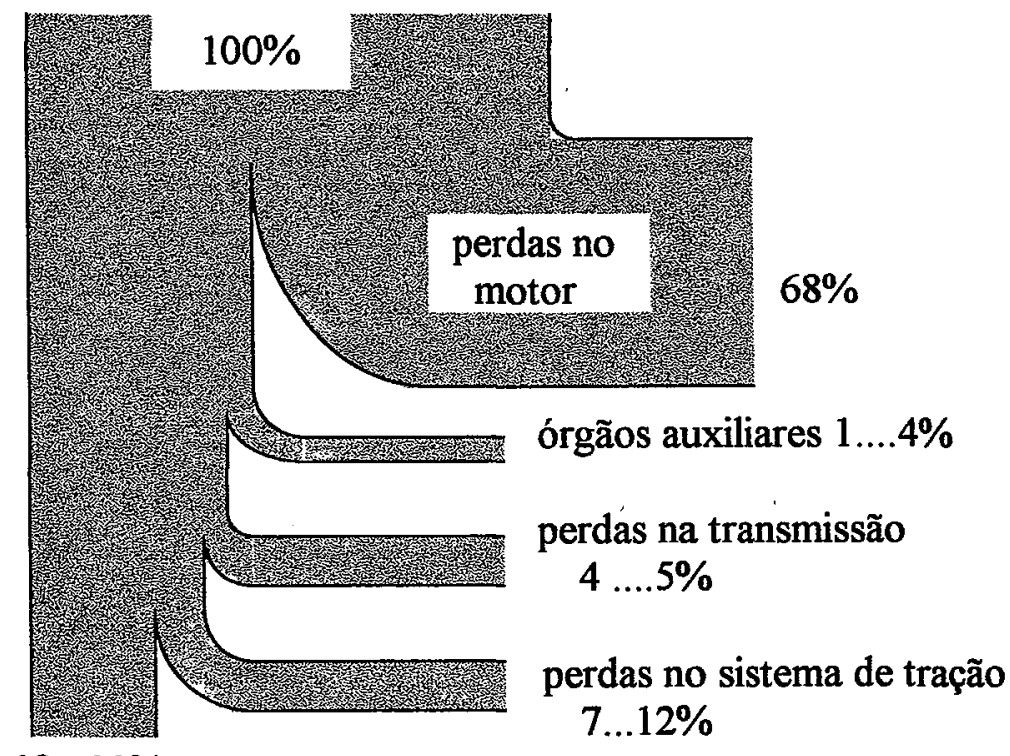

$12 . . .20 \%$

energia útil para tração

Figura 1 - Balanço energético de um trator operando em trabalho de tração (Fonte: Steinkampf, 1981) 
As razões para este pequeno aproveitamento da energia são as perdas internas do motor, perdas na transmissão, perdas devido a interação do pneu com o solo e também com o acionamento dos órgãos auxiliares.

Segundo este mesmo autor, no uso dos tratores, há duas possibilidades de reduzir o consumo de combustivel:

A. pela redução das perdas da conversão da energia do combustível para energia utilizável durante o uso do trator;

B. pela redução da energía consumida.

\subsection{1) Possibilidades de Economia Energética durante o uso do trator}

\section{A) Motor e Transmissão}

A eficiência global do motor é descrita como sendo a razão de energia que sai pelo eixo árvore do motor pela energia consumida em forma de combustivel, eficiência esta que depende de diversos fatores, como por exemplo, da razão de compressão, método de combustão interna, enchimento das câmaras de combustão, e especialmente sobre a utilização do motor e sua rotação durante a operação.

Este último fator pode ser visto claramente nas curvas de iso-consumo de um motor, como por exemplo na figura 2. Dependendo do uso do motor (rotação e potência), este pode ter uma eficiência que varia de 18 até $39,9 \%$. 


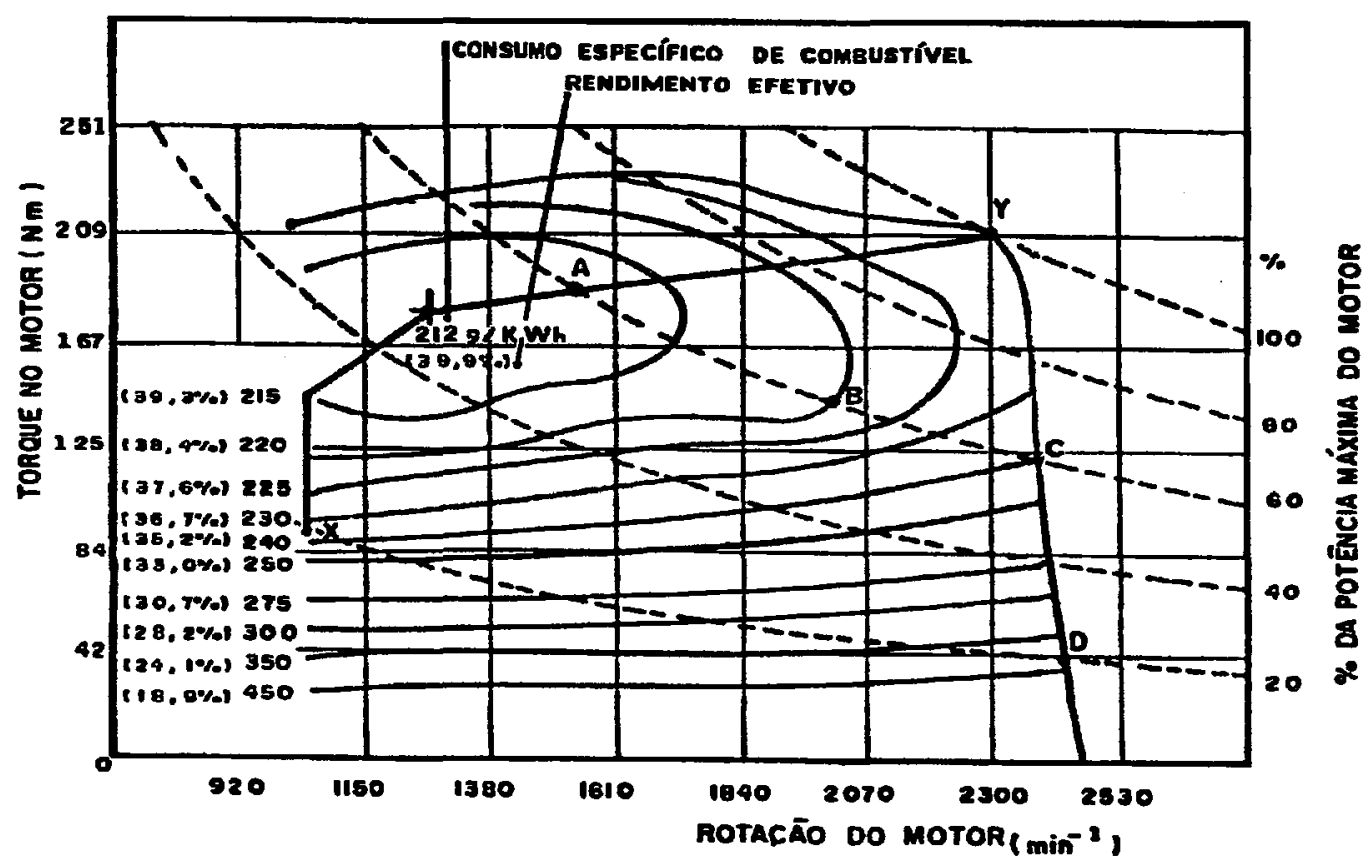

Figura 2: Curva de Iso-Consumo de um motor diesel (fonte: Souza, 1989).

As possibilidades de economia de combustivel pela utilização das áreas de consumo específico favoráveis são maiores que a redução do consumo específico do motor pela utilização de avançadas tecnologias. Lober (1981), citado por Steinkampf (1981), afirma que nos últimos 30 anos outros métodos de combustão e altas taxas de compressão (por exemplo, o uso do aspiração forçada) não têm permitido significativas reduções do consumo específico de combustível, e consequentemente aumento do rendimento, o que freqüentemente é exigido. Também, que no atual desenvolvimento de motores, um alto gasto na investigação tecnológica seria necessário para reduzir o consumo especifico e aumentar a área de consumo específico considerado pequeno.

Ainda segundo Steinkampf (1981), quanto maior for a potência empregada do motor (potência que é exigida), mais dificil fica utilizar-se das áreas econômicas das curvas de iso-consumo, já que estas se concentram nas regiões de média potência, impossibilitando o uso do motor na sua região de máximo rendimento. 
Há ainda outros aspectos a destacados por Steinkampf (1981), que influenciam na operação do motor.

1. a livre seleção da rotação do motor para as operações;

2. graduação da transmissão e cambiabilidade (facilidade de troca de marchas) devem ser compatíveis com a utilização do motor e permitir altas e também baixas velocidades de deslocamento, ou seja, ter um elevado número de marchas;

3. avanços técnicos deveriam ser implementados de tal forma que permitissem fornecer ao tratorista informações sobre a otimização do consumo através das posições da alavanca do acelerador e marchas a serem escolhidas.

Há também a questão de a velocidade do motor não ser livremente escolhida durante muitas operações onde se utiliza a TDP (tomada de potência), a qual deve manter uma velocidade controlada, ou quando se faz transporte de pequenas cargas, na qual a taxa de utilização do motor é relativamente pequena - a maneira de conduzir estas operações em que o motor é pouco exigido, é dotar o trator de pelo menos uma marcha "over-drive".

A utilização desta área favorável à economia de combustivel encontrada nas curvas de iso-consumo, como visto na figura 2 , é muito dependente da gradação de marchas, a utilidade do câmbio, mudança de marchas e respectiva tração ou potência demandada pelo equipamento. Por exemplo, para uma utilização que dependa de $60 \%$ da potência disponível do motor, é possível verificar através da figura 2 que o motor pode trabalhar em diversos pontos de rotação e portanto de torque, porém uma considerável parcela de combustível pode ser economizada pela redução da rotação de operação do motor, atingindo portanto um ponto ótimo de consumo para este regime de trabalho, conforme visto na passagem do ponto $\mathrm{C}$ para $\mathrm{o}$ ponto B, e finalmente para o ponto A. Porém, quando for exigido uma alta potência do motor, esta área de baixo consumo torna-se menor, e quando atingida, a economia que proporciona é pequena. Especialmente sob este aspecto, são desejáveis 
significantes avanços tecnológicos para otimizar o comportamento de dirigibilidade. (Steinkampf, 1981).

Além disso, uma outra possibilidade de redução do consumo de combustivel consiste em utilizar motores cujas curvas de iso-consumo sejam melhor adaptadas para a utilidade principal do trator. No caso de tratores operando com elevadas cargas e que por isso exigem altas rotações do motor, é preferivel que estes motores apresentem as áreas de baixo consumo específico em elevadas rotações, como pode ser visto na figura 3 .

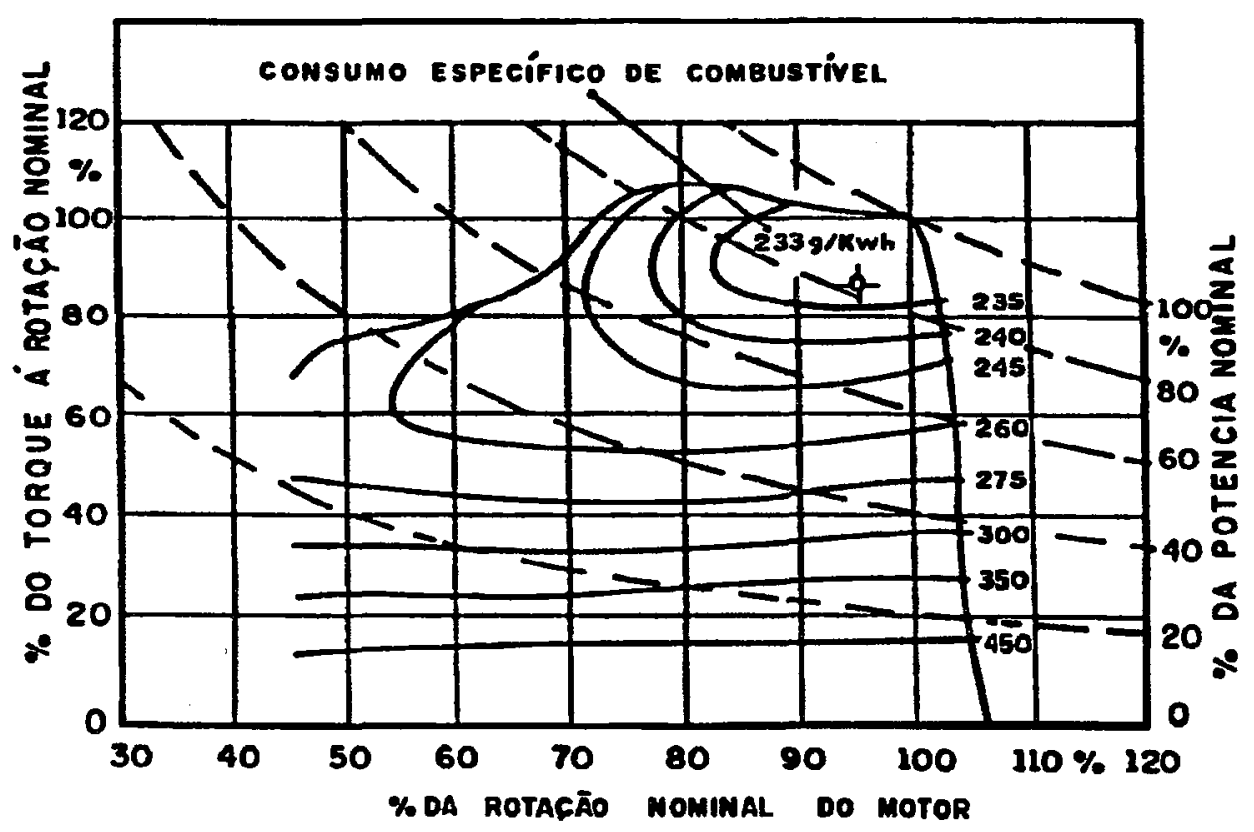

Figura 3: Curva de iso-consumo de motor diesel adaptado. (fonte: Steinkampf,1981)

Por sua vez, as perdas energéticas nas transmissões dificilmente serão reduzidas, isto por que exige-se cada vez mais um número maior de marchas e um maior conforto na sua mudança, exigências estas que levam a uma melhor exploração das áreas de baixo consumo nos tratores, situação contraditória ao aumento do rendimento da transmissão individualmente. (Steinkampf, 1981). 
Hansen et.al. (1986) trabalharam nos procedimentos para aquisição de dados. Citam que para a otimização do desempenho do trator é necessário um sistema de aquisição confiável da distribuição temporal da potência motora utilizada pelo trator. Este procedimento faz com que a indefinição a respeito da carga real sobre o motor durante as operações de campo, ainda existente entre os usuários de tratores e também fabricantes, venha a ser desfeita.

O objetivo, segundo Hansen et.al. (1986), foi de desenvolver um sistema confiável que pudesse fornecer a distribuição do tempo de operações de campo sob a curva rotação $\mathrm{x}$ potência desenvolvida pelo motor. $\mathrm{O}$ princípio utilizado no método de determinação do tempo gasto a diferentes níveis de potência do motor foi de utilizar o mapa de desempenho do motor, mapa este determinado em testes laboratoriais que relacionam o consumo de combustível, potência e rotação. Seu experimento, após a montagem do equipamento de aquisição de dados, consistiu em:

- comparar o procedimento de três tratoristas diferentes para uma determinada operação;

- comparar três tipos de operações diferentes com o mesmo tratorista;

- determinar o desempenho de campo para diferentes relações de engrenamento do sistema de tração e diferentes níveis de aceleração para um mesmo operador e operação;

Nos dois primeiros objetivos, existe uma natural diferença de condução por parte dos tratoristas, um guiando mais economicamente, outro não, e em relação à operação a ser executada, é também natural que diferenças ocorram em relação ao consumo, concluíram Hansen et.al. (1986).

Em relação à escolha da marcha e da rotação do motor, segundo Hansen et.al. (1986), foram obtidas as diferenças mais significativas. A tabela 1 mostra os resultados que se chegaram: 
Tabela 1: Tabela onde se relaciona o consumo de combustivel, razão de trabalho e índice tempo-consumo à relação de transmissão e rotação do motor. (fonte: Hansen et.al., 1986)

\begin{tabular}{|c|c|c|c|c|}
\hline $\begin{array}{c}\text { rotação do } \\
\text { motor (rpm) }\end{array}$ & $\begin{array}{c}\text { relação de } \\
\text { transmissão }\end{array}$ & $\begin{array}{c}\text { consumo de } \\
\text { combustível } \\
(\mathrm{L} / \mathrm{ha})\end{array}$ & $\begin{array}{c}\text { razão de } \\
\text { trabalho (h/ha) }\end{array}$ & $\begin{array}{c}\text { índice tempo- } \\
\text { consumo }\left(\mathrm{Lh} / \mathrm{ha}^{2}\right)\end{array}$ \\
\hline 1900 & 2 & 28 & 5.0 & 138 \\
\hline 1900 & 3 & 28 & 3.5 & 99 \\
\hline 1900 & 4 & 26 & 2.9 & 76 \\
\hline 2500 & 3 & 17 & 1.6 & 27 \\
\hline
\end{tabular}

O índice de tempo-consumo usado por Meiring e Rall (1979), citados por Hansen et.al. (1986), é o produto da razão de trabalho com o consumo de combustivel (litros.hora/hectare ${ }^{2}$ ), sendo por isso uma medida de desempenho de campo. Otimizar o desempenho de campo implica na minimização deste índice, como ocorre na mudança da segunda relação para a terceira, a 1900 rpm do motor.

Os autores verificaram que, ao fazer a troca da $3^{\mathrm{a}}$ para a $4^{\mathrm{a}}$ marcha, trabalhando a uma rotação de $1900 \mathrm{rpm}$, o motor foi carregado perto da região de máxima potência que pode desenvolver. Todavia, uma larga região de operação, acima e abaixo da esperada (1900 rpm previamente estabelecida) foi explorada pelo motor, sendo esta variação plenamente natural devido as condições do solo que faz com que a carga de tração também varie.

Ao se utilizar a $3^{\underline{a}}$ marcha, porém a $2500 \mathrm{rpm}$, observou-se que a carga esteve concentrada $80 \%$ do seu tempo na máxima desenvolvida. Da tabela 1 , verificase que houve uma redução de $64 \%$ no índice tempo-consumo comparado com o dado anterior.

Os autores concluíram, portanto, que instrumentos para aquisição de dados foram de grande importância, e que poderiam ser valiosas ferramentas para a pesquisa e gerenciamento na busca da otimização das operações agrícolas, haja visto 
que foram suficientemente precisos e confiáveis para a proposta de determinar a distribuição temporal da carga do motor e portanto melhor escolha da marcha adotada.

\section{B) Órgãos Auxiliares}

Segundo Steinkampf (1981), a energia gasta para o acionamento destes mecanismos pode variar de 1 a $4 \%$ da energia consumida em forma de combustível (as perdas por engrenamento já incluídas), ou de 3 a $15 \%$ da energia medida no eixo árvore do motor, e afirma que as possibilidades de reduzir a energia consumida por estes agregados não têm sido exploradas adequadamente.

\section{C) Sistema de Tracão}

Ainda segundo Steinkampf (1981), as perdas do sistema de tração de um trator são medidas através da soma das perdas devido à resistência ao rolamento das rodas em relação ao solo, com as perdas devido ao patinamento das rodas motrizes, sendo a causa de que apenas 50 a $80 \%$ de toda a energia dada pela transmissão às rodas motrizes ser convertida em energia eficiente para o uso. A eficiência do sistema de tração é medida através da relação entre a energia disponivel para a tração no eixo árvore das rodas com a quantidade de energia efetiva restante na barra de tração.

A figura 4 mostra uma curva que relaciona o rendimento de tração com o respectivo patinamento das rodas motrizes. 
Rendimento de

Tração

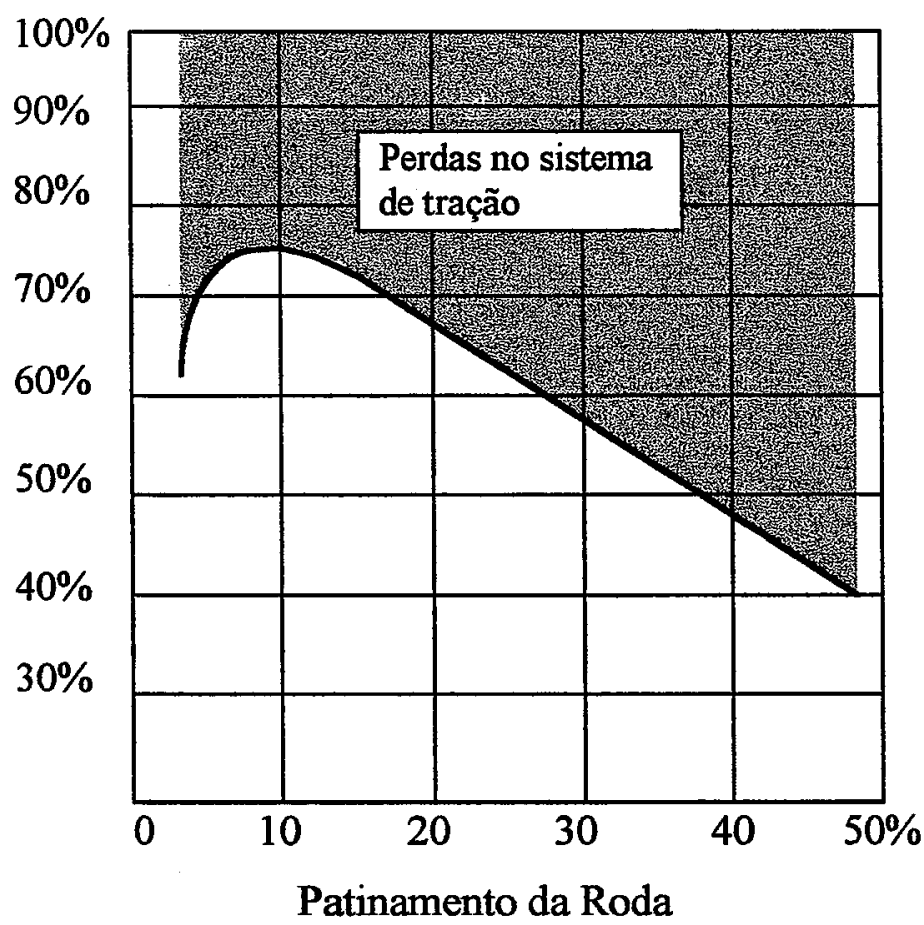

Figura 4: Rendimento de tração de um pneu agrícola em função do seu patinamento. (fonte: Steinkampf, 1981)

Fica claro que o rendimento de tração cresce rapidamente, passando por um máximo com um patinamento da ordem de $10 \%$ em solo, porém diminui após este valor. Importantes pré-requisitos para se obter uma eficiente transmissão de energia são:

- que independentemente do máximo valor de rendimento de tração, deve-se procurar trabalhar nesta condição de máximo rendimento;

- que os pneus utilizados no trator sejam adequados para solo que se está trabalhando, alcançando assim o mais alto rendimento;

- que as perdas adicionais no sistema de tração possam ser evitadas através do uso de todas as rodas de tração acionadas, pelo uso do bloqueio do diferencial e pela boa distribuição de carga nos eixos.

Para obter uma maximização do sistema de transmissão, deve-se ter sempre em vista os seguintes fatores: tipo de solo, umidade, índice de vazios do solo, 
dimensão do pneu, tipo de carcaça (diagonal ou radial), pressão do perfil do rodado e utilização do pneu.

Alta eficiência no sistema de transmissão pode ser obtido quando:

- a umidade do solo for pequena;

- o solo for do tipo argiloso;

- o índice de vazios do solo for menor, portanto um solo mais compactado;

- o pneu apresentar uma relação diâmetro-largura maior;

- a profundidade das garras do pneus for maior para solos mais úmidos;

- for explorada toda a capacidade do pneu;

Portanto, um aumento de eficiência na conversão energética, resultado de uma maior eficiência no sistema de tração e redução do consumo de combustível, pode ser conseguido pelo uso do trator em solos mais secos e duros, e também através da combinação adequada entre o implemento e o trator, condições nem sempre possíveis de serem obtidas. (Steinkampf, 1981).

\subsection{2) Possibilidade de Economia Energética através da Redução da Carga}

Ainda segundo Steinkampf (1981), o intensivo cultivo do solo tem sido utilizado como prática constante, visto que a potência do motor no decorrer das décadas teve um acréscimo substancial. Esta é uma das razões do continuo aumento dos campos de cultivo. Tal situação faz com que uma quantidade expressiva de combustível tenha sido utilizada para estas operações de cultivo, quantidade esta que poderia ser reduzida pelo uso de implementos que realizassem um cultivo menos intensivo, sem que a qualidade e a quantidade dos trabalhos nos campos fossem afetados. Estima-se que até 30\% do combustível gasto poderia ser economizado se outros implementos mais adaptados, com uma redução da profundidade e diminuição 
da freqüência de operações fossem levados em prática, como por exemplo, a adoção de implementos ou máquinas trabalhando no lado dianteiro e traseiro do trator, realizando duas operações simultaneamente.

\section{2 - Conceitos de Desempenho de Motores}

Segundo Taylor (1971), os fatores que podem ser relacionados para a avaliação de desempenho do motor de combustão interna, são:

- potência máxima disponível em cada rotação, dentro da faixa útil de operação;

- faixa de velocidade e potência na qual é possível a operação satisfatória;

- consumo de combustível em todos os pontos, dentro da faixa esperada de operação;

Para tanto, com a finalidade de melhor compreender o desempenho dos motores de combustão interna, algumas definições são feitas:

Potência Máxima Absoluta: é a maior potência que o motor pode desenvolver ao nível do mar, sem limitações arbitrárias;

Potência Nominal Máxima: é a maior potência que um motor pode desenvolver em serviço;

Potência Nominal Normal: é a maior potência especificada para operação contínua;

Rotação Nominal: é a rotação do eixo árvore à potência nominal;

Torque: é o conjugado no eixo-árvore de manivelas.

O desempenho do motor é mais facilmente mostrado através de suas curvas características. Estas curvas são, segundo Taylor (1971), as curvas de potência, 
de conjugado e consumo de combustível por unidade de tempo, obtidas em toda faixa útil de rotação e carga do motor. Este autor também faz uso de parâmetros mais generalizados que usualmente se encontra (como por exemplo, velocidade do êmbolo, potência por área do êmbolo, entre outros), o que os tornam relativamente independentes do tamanho do cilindro, fazendo com que se possa comparar motores de tamanhos diferentes.

Ainda Taylor (1971) afirma que, independentemente do tamanho do motor, todos apresentam uma região de mais baixo consumo específico de combustível. Essa região, evidentemente, é aquela que apresenta o máximo rendimento térmico e mecânico do motor. Ressalta, que apesar dos tamanhos diferentes existentes de motor, este ponto de maior economia ocorre aproximadamente à mesma velocidade do êmbolo e à mesma razão da potência fornecida com relação à máxima potência.

Os motores com aspiração forçada, ou seja, quando pelo uso de um compressor sua pressão de admissão é maior do que a da atmosfera envolvente, foram desenvolvidos a fim de que, para um mesmo peso e volume de instalação, a potência fornecida seja maior. Nos motores Diesel, a aspiração forçada resulta em uma apreciável melhora no desempenho e na economia de combustível. (Taylor, 1971).

Mialhe (1985), relata que o desempenho dos motores de combustão interna (especificamente os de tratores) pode ser analisado sob dois enfoques:

- o motor isolado do trator;

- o motor instalado no trator.

Tanto no primeiro quanto no segundo caso, o ensaio é de fundamental importância. No primeiro, o motor é submetido à ensaios efetuados de acordo com normas técnicas voltadas para ensaios de motores. No segundo, o motor é considerado como parte integrante do trator, e por isso os ensaios devem seguir de acordo com as 
normas técnicas específicas para ensaios de tratores, (neste caso, a análise do motor se faz a partir dos resultados obtidos nos ensaios da tomada de potência do trator TDP). Por isso, uma análise completa do desempenho de tratores não pode excluir considerações confrontando os dois enfoques acima, já que um determinado motor poderá ter seu comportamento, como fonte de potência, prejudicado ou otimizado num trator.

São utilizados, portanto, parâmetros que caracterizam o desempenho do motor e que interessam à análise do desempenho de tratores. Estes parâmetros são melhor descritos através de curvas construídas em gráficos cartesianos (fig.5), e são:

1- Torque (conjugado ou momento de força)

Esta curva é obtida com auxílio de dinamômetros do tipo absorção, e para isto a alimentação do motor é ajustada previamente.

\section{2- Potência Efetiva}

Esta curva é obtida através de cálculos, utilizando-se os dados de velocidade angular (rotação) e momento de força, através da seguinte equação:

$$
\mathrm{P}_{\mathrm{m}}=\mathrm{N} \cdot \mathrm{T} \cdot \mathrm{k}
$$

onde: $P_{m}=$ potência do motor, em $\mathrm{kW}$;

$\mathrm{N}$ = rotação do motor, em rpm;

$\mathrm{T}=$ momento de força do motor, em N.m;

$\mathrm{k}=$ constante de ajuste de unidades. 


\section{3- Consumo de Combustível}

A curva de consumo de combustível é obtida a partir dos dados de tempo decorrido para ser gasto um certo volume ou massa de combustivel, com o motor submetido a determinada carga pelo dinamômetro. Com estes dados, obtém-se o consumo horário, expresso em litros/hora ou quilogramas/hora. Ao relacionar este valor com a potência obtida durante o intervalo em que se mediu o consumo médio, obtém-se o "consumo específico", que é expresso nas seguintes grandezas:

massa (ou volume)/ potência.tempo

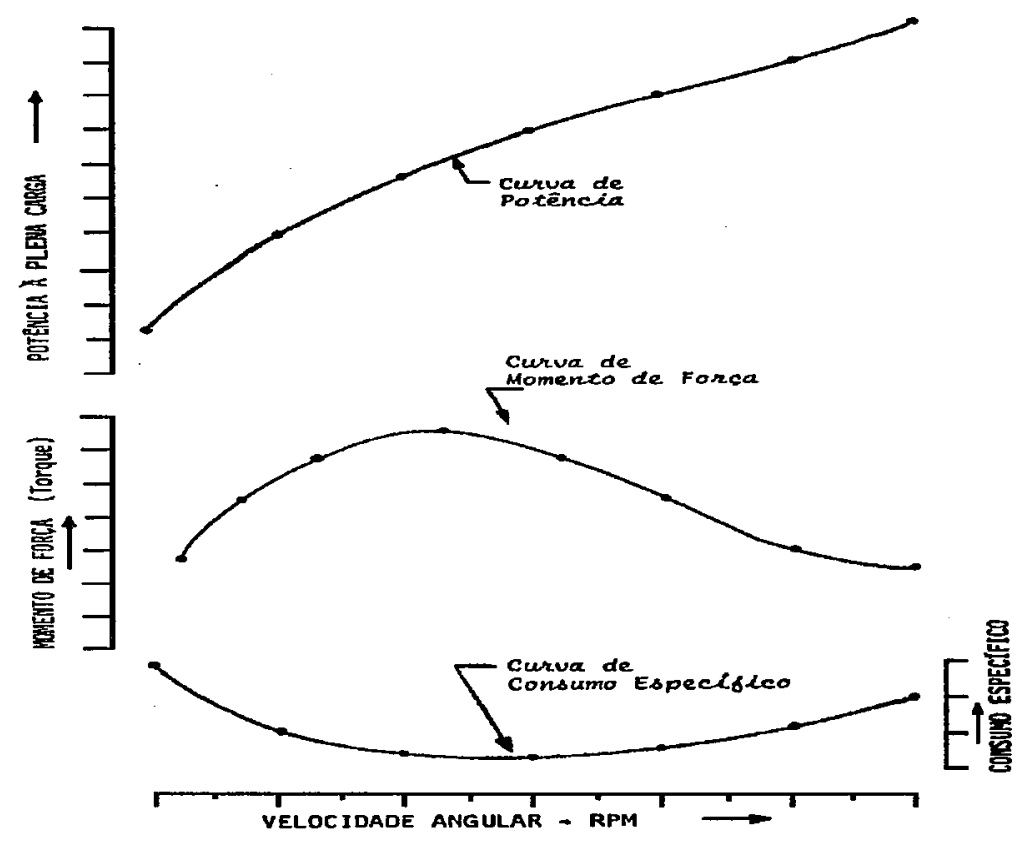

Figura 5: Curvas de potência, torque e consumo específico.

(fonte: Mialhe, 1985) 
Como observou Mialhe (1985), o consumo específico de combustível de um motor é maior, tanto a velocidades mais baixas como nas mais altas, evidenciando uma rotação de mínimo consumo.

Sobre estas três curvas da figura 5 , alguns pontos de interesse específico para aplicação em tratores agrícolas são observados por Mialhe (1985):

- potência máxima;

- torque (ou momento de força) máximo;

- consumo específico de combustível mínimo.

Ressalta Mialhe (1985), que entre o regime (rotação) de potência máxima e o de momento de força máximo situa-se a chamada "faixa de utilização a plena carga" do motor. Nesta região defini-se um outro parâmetro denominado de "reserva de torque" (RT), assim equacionado:

$$
\mathrm{RT}=\frac{\text { torque máximo }}{\text { torque à potência máxima }}-1
$$

Então, para uma rotação abaixo desta "faixa de utilização a plena carga", qualquer aumento de carga (aumento de momento resistente) leva o motor ao efeito denominado na prática de "morrer" (ou stoll), já que a reserva de torque é nula neste regime do motor.

Estes ensaios devem seguir a norma NBR 5484, a qual prevê as condições atmosféricas padrão:

- pressão barométrica $746,0 \mathrm{~mm} \mathrm{Hg}$

- pressão barométrica do ar seco $736,0 \mathrm{~mm} \mathrm{Hg}$

- temperatura do ar ambiente $30,0^{\circ} \mathrm{C}$

- pressão de vapor padrão $10,0 \mathrm{~mm} \mathrm{Hg}$

- densidade absoluto do ar seco $1,129 \mathrm{~kg} / \mathrm{m}^{3}$ 
Contudo, estas condições não são facilmente obtidas em laboratório, o que faz com que se utilize um fator de redução que conduz os resultados ao padrão e permita comparações posteriores, por mais que as condições atmosféricas diferenciem da padrão, dentro de determinados limites.

\section{3- Desempenho na Barra de Tração do Trator}

Segundo Mialhe (1985), a análise do desempenho da barra de tração dos tratores agrícolas é feita a partir dos dados obtidos em ensaios padronizados. Estes são realizados de acordo com uma metodologia preconizada em normas, numa pista de concreto em nível, com o posicionamento do acelerador na posição máxima e acoplando-se a barra de tração do trator à um carro dinamométrico capaz de desenvolver um esforço frenante controlável e equipado com os instrumentos de mensuração requeridos para a coleta das informações exigidas.

Estes ensaios são feitos sob diversas condições:

- com trator lastrado;

- com trator sem lastro.

Para cada uma destas condições, o ensaio é realizado sob diversas marchas e exigências diferentes de potência na barra de tração.

Mialhe (1985) observa também que a distribuição do peso sob a condição dinâmica é de fundamental importância para o desempenho da barra de tração do trator, já que influencia na conversão de potência do motor para a de potência de tração. Os três principais aspectos analisados são:

- características de desempenho do motor;

- características das transmissões;

- distribuição de peso e conformação do chassi do trator. 
A análise do desempenho da barra de tração pode assim assumir dois posicionamentos, dependendo do objetivo a ser atingido:

1. pode servir como comparação de comportamento de espécimes similares, visando melhor seleção;

2. como análise da adequação do motor, transmissão e do conjunto motor/transmissão, já que são fatores que influenciam diretamente no desempenho do trator.

Portanto, em relação ao desempenho na barra de tração, são fornecidos quatro gráficos para melhor apreciação dos resultados, conforme a figura 6. Estes gráficos representam:

- consumo específico em função da força de tração na barra;

- patinamento em função da força de tração;

- velocidade de deslocamento em função da força de tração;

- a potência na barra de tração em função da força de tração.

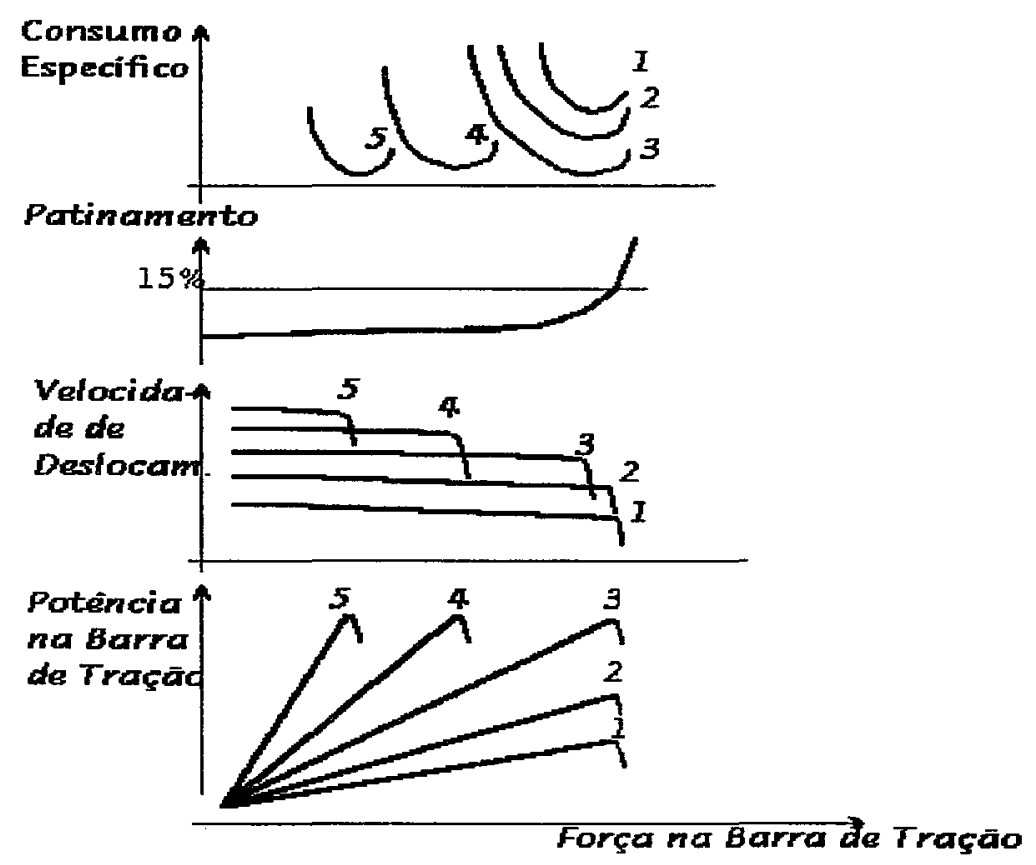

Figura 6: Curvas de desempenho de um trator. (fonte: Mialhe, 1985) 
A análise destas curvas de desempenho revela que, no caso de ensaio padronizado em pista de concreto, os seguintes pontos são destacados:

- a potência máxima de tração ocorre sempre que a velocidade de deslocamento está na iminência de ser reduzida sensivelmente, devido ao rápido incremento do patinamento, que ocorre geralmente a $15 \%$;

- o consumo específico tende a se tornar mínimo nos pontos de máximo torque, independentemente do consumo horário;

- a posição das curvas de consumo específico torna clara a importância da correta seleção das relações de transmissão em função de diferentes níveis de carga na barra de tração, visando menor consumo energético.

Uma aplicação destas curvas de desempenho na barra de tração (figura 6), segundo Mialhe (1985), se refere à escolha de qual marcha a se utilizar para uma determinada operação. Considerando-se que uma operação solicite uma dada força de tração, poder-se-ão utilizar diversas marchas com o motor a plena carga (neste caso específico, a velocidade de deslocamento não é um fator limitante). Então, a marcha a ser selecionada deve ser aquela que resulta na otimização do consumo de combustível.

Burt et.al. (1985) estudaram o efeito da velocidade de deslocamento do trator sobre o desempenho de tratores de rodas. Vários outros pesquisadores citados por Burt et.al. (1985) já realizaram diversas pesquisas nesta área, como Gee-Clough (1977) que apresentou resultados de desempenho de tração com tratores de pneus a velocidades de campo variando de 0,9 até $1,8 \mathrm{~m} / \mathrm{s}$ e concluiu que o coeficiente de tração à uma redução de velocidade na razão de $20 \%$ foi significativamente maior que na velocidade maior, e Guskov (1968) mostrando que existe uma velocidade determinada que resulta numa maximização da eficiência de tração. 
Os resultados de Burt et.al. (1985), que realizaram diversos ensaios de tração com a velocidade sendo reduzida lentamente e continuamente de 0,6 até alcançar $0,1 \mathrm{~m} / \mathrm{s}$, em solo arenoso e com pneus diagonal e radial, revelaram que a velocidade exerce um efeito muito pequeno na tração e eficiência tratória.

\section{4- Modelos de Consumo de Combustível}

A proposta de modelos de consumo de combustível para tratores agrícolas tem sido preocupação constante de diversos pesquisadores.

Segundo Khalilian et.al. (1984), o custo referente ao consumo de combustível representa aproximadamente $30 \%$ do custo total de um trator, e esta proporção vem aumentando significativamente devido ao acréscimo dos preços dos combustiveis. Afirmam, portanto, que informações relativas ao consumo de combustível seriam muito mais úteis caso fossem disponíveis equações que resultassem em fáceis cálculos do consumo para todos os níveis de carga e rotação do motor.

A ASAE prevê o consumo de combustível por alguns modelos abaixo citados, considerando um aumento no consumo de $15 \%$ para prever uma perda de eficiência sob as condições de campo. ASAE D497.2 (1994)

diesel

$$
\mathrm{CECL}=2,64 . \mathrm{X}+3,91-0,203 .(738 . \mathrm{X}+173)^{\wedge} 0,5
$$

gasolina

$$
\mathrm{CECL}=2,74 . \mathrm{X}+3,15-0,203 .(697 . \mathrm{X})^{\wedge} 0,5
$$

onde: $\mathrm{CECL}=$ consumo específico em litros/kW.h

$$
\mathrm{X}=\text { porcentagem do uso da potência máxima da tomada de potência. }
$$

Ainda segundo Khalilian et.al. (1984) citam que a ASAE prevê apenas uma equação para cada tipo de combustível, porém esta equação não mostra as 
diferenças no consumo devido a três diferentes formas de admissão do ar: aspirado naturalmente, com aspiração forçada somente e com aspiração forçada e intercooler. Estes pesquisadores, após análise dos dados de ensaio de tratores de Nebraska, afirmam que existem significativas diferenças entre o consumo dos motores diesel devido à forma de admissão de ar. As equações polinomiais para estes motores são:

para aspiração natural $\quad E e=0,29+6,41 . X-4,96 . X^{2}+1,16 . X^{3}$

para aspiração forçada $\quad E e=0,20+7,10 \cdot X+6,95 \cdot X^{2}+2,72 \cdot X^{3}$

onde: $\mathrm{Ee}=$ energia específica, em $\mathrm{kW} \cdot \mathrm{h} / \mathrm{L}$

$\mathrm{X}=$ porcentagem do uso da potência máxima da tomada de potência.

Com estes dados, foi feita uma análise de regressão para predizer a energia específica em função da porcentagem de potência máxima utilizada na TDP, resultando em equações polinomiais de segunda ordem. As curvas são mostradas na figura 7.

energia
especifica
$(\mathrm{kW} . \mathrm{h} / \mathrm{L})$

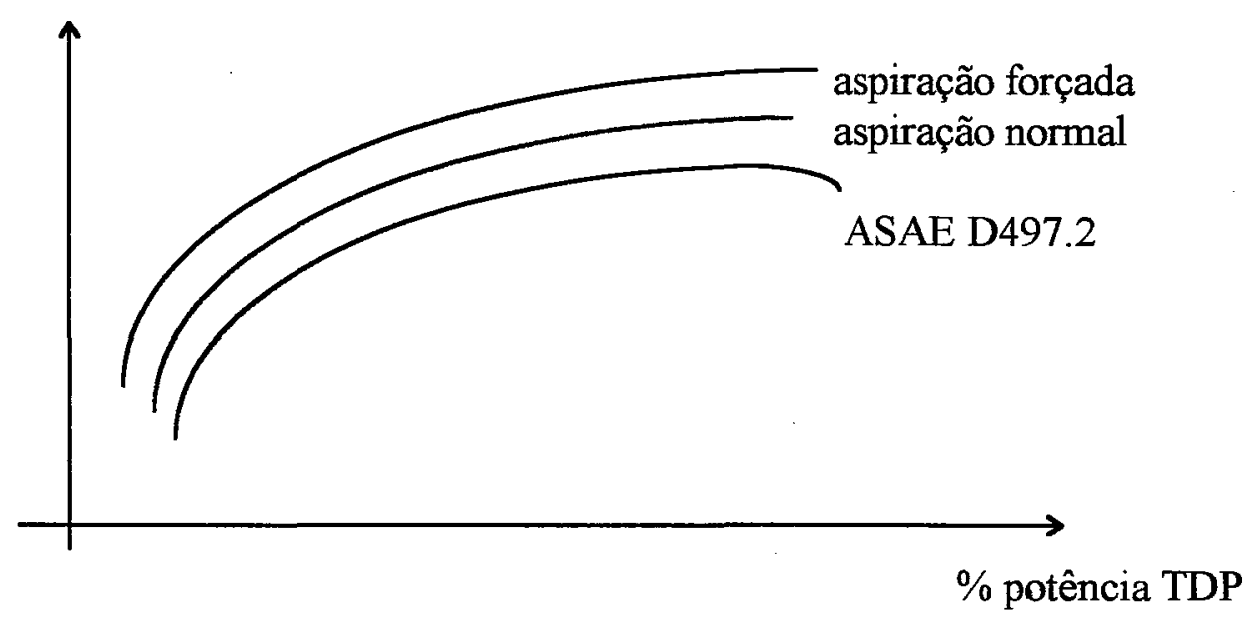

Figura 7: Curvas dos modelos de consumo de combustivel. (fonte: Khalilian et.al., 1984).

Como é possivel observar, a curva obtida seguindo o modelo da ASAE (figura 7) revela um baixo rendimento do combustivel quando comparado com as 
outras duas curvas obtidas por Khalilian et.al. (1984), as quais mostram a significativa influência do modo de admissão do ar pelo motor.

Khalilian et.al. (1984) citam ainda uma maneira de se predizer o consumo específico em operações de campo através do estudo do consumo específico de combustível referente à TDP supra citado. $O$ equacionamento é:

$$
X=\frac{F \cdot N \cdot R \cdot E p \cdot 2 \cdot \pi}{\text { Ea } \cdot S R \cdot M p \cdot 60000}
$$

onde: $\mathrm{X}=$ razão da potência equivalente na TDP pela potência máxima na TDP;

$\mathrm{F}=$ força de tração na barra $(\mathrm{N})$;

$\mathrm{N}=$ rotação do motor (rpm);

$\mathrm{R}=$ raio de rolamento das rodas de tração $(\mathrm{m})$;

$\mathrm{Ep}=$ rendimento de engrenamento entre o motor e a TDP;

$\mathrm{Ea}=$ rendimento de engrenamento entre o motor e o eixo da roda;

$\mathrm{SR}=$ redução total de velocidade (rpm do motor/rpm do eixo da roda);

$\mathrm{Mp}=$ máxima potência da TDP $(\mathrm{kW})$.

Portanto, dada a força de tração e os outros parâmetros, calculase o valor de $\mathrm{X}$, que conhecidamente está relacionado com o consumo do trator.

Um outro método citado por Khalilian et.al. (1984), trata-se do equacionamento desenvolvido por Bowers (1978), assim colocado:

$$
X=\frac{F \cdot V}{M p \cdot(0,86)^{n} \cdot 3600}
$$

onde: $F=$ força de tração (Newton);

$\mathrm{V}=$ velocidade do trator $(\mathrm{km} / \mathrm{h})$; 
$\mathrm{Mp}=$ máxima potência da TDP $(\mathrm{kW})$;

$X=$ razão da potência equivalente na TDP pela potência máxima na TDP;

$\mathrm{n}=$ constante do solo ( 2 para solos duros, 3 para solos firmes, 4 para solos arados e 5 para solos soltos e arenosos).

Este segundo método é um bom procedimento para predizer o consumo de combustível em operações de campo, diferente daquele sugerido pela ASAE, que aumenta em pelo menos $20 \%$ os dados de consumo.

Pacey et.al. (1982), com a mesma preocupação em encontrar uma equação para predizer o consumo específico do trator, analisou os dados do "Nebraska Tractor Test Data for 1982", o qual incluia o ensaio de 179 tratores diesel com TDP (tomada de potência), em seis pontos de carga, variando de zero até a potência máxima. $\mathrm{O}$ modelo proposto foi uma equação do terceiro grau, a qual resultou no menor erro para todos os dados, e num comparativo com o que determina a ASAE, observou-se que deveria ser adotada a sua proposta. O equacionamento proposto é:

$$
\mathrm{Ee}=8,24 . \mathrm{X}-8,41 \cdot \mathrm{X}^{2}+3,12 . \mathrm{X}^{3}
$$

onde: $\mathrm{Ee}=$ energia específica, em $\mathrm{kW} \cdot \mathrm{h} / \mathrm{L}$

$\mathrm{X}=$ porcentagem do uso da potência máxima da tomada de potência.

\section{5- Curvas de Iso-Consumo ou Eficiência Global do Motor}

Segundo Souza et.al. (1990), as curvas de iso-consumo (ou de parâmetros múltiplos), consistem numa familia de curvas que mostram a dependência de um ou mais parâmetros constantes com dois outros parâmetros variáveis. A figura 8 mostra um exemplo destas curvas; as linhas contínuas representam o consumo específico constante de combustível, e consequentemente valores constantes da eficiência global do motor, e as tracejadas, as de iso-potência. 


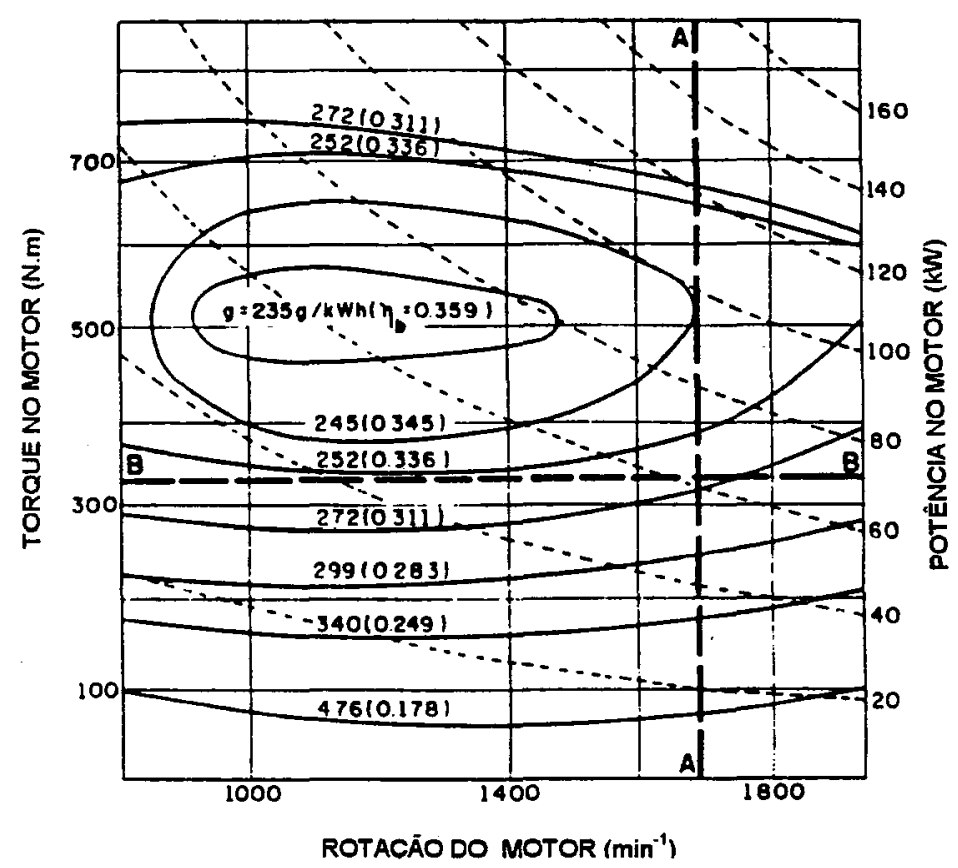

Figura 8: Curvas de iso-consumo de um motor diesel (fonte: Souza E., 1989)

Estas curvas são obtidas com o ensaio do motor em laboratório, fazendo com que se varie a rotação e também a potência exigida (ou torque) para cada rotação, de tal modo que se cubra toda a área de trabalho do motor. A cada ponto de regime, e portanto a cada rotação e potência, faz se a medição do consumo de combustível durante um determinado tempo. De posse destes dados, faz-se a relação da potência desenvolvida no motor pelo respectivo consumo de combustível no intervalo de tempo, obtendo-se então, para cada rotação, valores de consumo por unidade de potência desenvolvida e unidade de tempo considerado.

A eficiência global do motor $\left(\eta_{b}\right)$ é definido, segundo Souza E. (1989), como o grau de efetiva utilização da energia térmica pelo motor, e por isso depende do poder calorífico do combustível e do seu consumo específico. O equacionamento utilizado para se calcular a eficiência é:

$$
\eta_{\mathrm{b}}=3600 / \text { (H.CECG) }
$$

onde: $\eta_{\mathrm{b}}=$ eficiência global do motor; 
$\mathrm{H}=$ poder calorífico inferior do combustivel $(\mathrm{MJ} / \mathrm{kg})$;

$\mathrm{CECG}=$ consumo específico de combustível $(\mathrm{g} / \mathrm{kW} \cdot \mathrm{h})$.

Nesta mesma figura, tomando-se uma rotação constante como representada pela linha $\mathrm{AA}$, verifica-se como o consumo específico é alterado em função de diferentes níveis de torque. A figura 9 mostra este caso considerado (rotação constante) relacionando a eficiência em função do torque. É importante observar que a eficiência parte de zero para torque nulo, atinge um máximo e depois volta a diminuir sensivelmente. Análises estatísticas mostram que esta relação pode ser descrita na seguinte função:

$$
\eta_{b}=a_{0}+a_{1} \cdot T+a_{2} \cdot T^{2}+a_{3} \cdot T^{3}+a_{4} \cdot T^{4}
$$

onde: $a_{0} \ldots . a_{4}=$ coeficientes;

$\mathrm{T}=$ torque desenvolvido no eixo árvore.

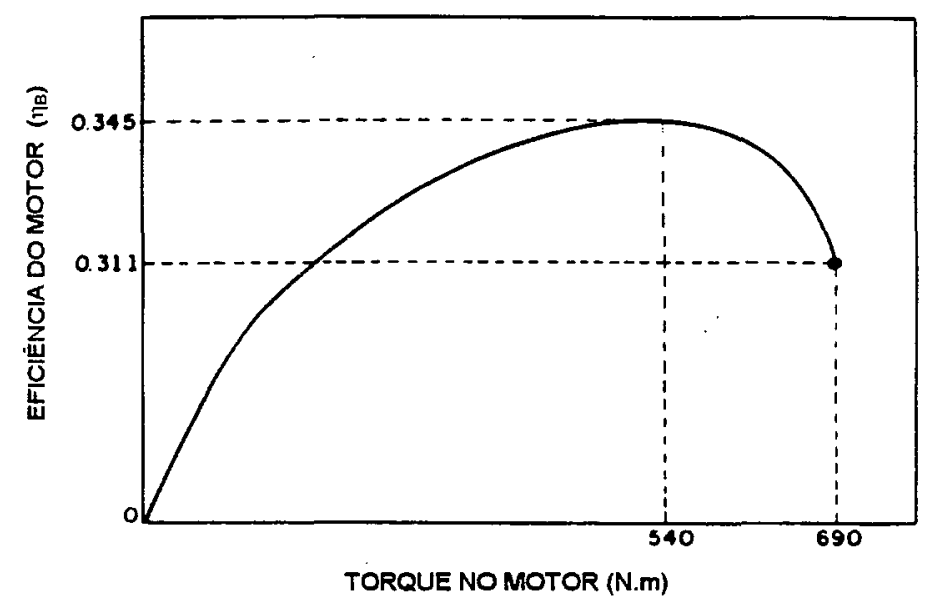

Figura 9: Eficiência do motor diesel a rotação constante (fonte: Souza E., 1989)

Na mesma figura 8, tomando-se agora torque constante, como indicado pela linha $\mathrm{BB}$, verifica-se como varia a eficiência global em função da velocidade, 
vista na figura 10. De maneira análoga ao ocorrido com a eficiência global em função do torque, o rendimento também tem um máximo para uma determinada rotação, e esta relação, após análise estatística, pode ser assim descrita:

$$
\eta_{b}=b_{o}+b_{1} . N+b_{2} \cdot N^{2}
$$

onde: $b_{0}, b_{1}, b_{2}=$ coeficientes;

$$
\mathrm{N}=\text { rotação do motor. }
$$

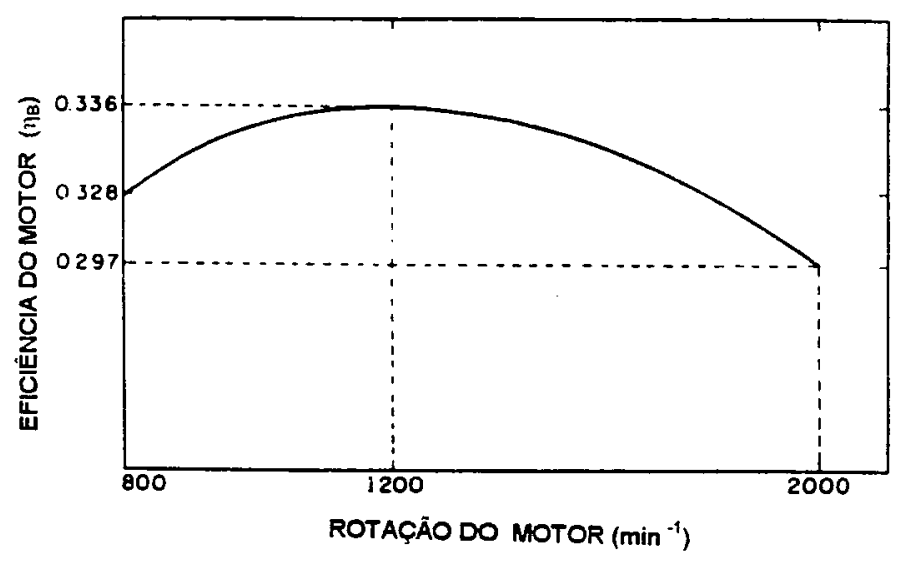

Figura 10: Eficiência do motor diesel a torque constante (fonte: Souza E., 1989)

Portanto, para qualquer variação do torque e rotação, a eficiência global do motor pode ser assim descrita:

$$
\eta_{b}=c_{1}+c_{2} \cdot T+c_{3} \cdot N+c_{4} \cdot T^{2}+c_{5} \cdot T^{3}+c_{6} \cdot T^{4}+c_{7} \cdot N^{2}+c_{8} \cdot N \cdot T
$$

onde: $c_{1} \ldots c_{8}=$ coeficientes;

$\mathrm{T}=$ torque;

$\mathrm{N}=$ rotação; 
Observa-se, nesta equação (13), a interação entre a rotação do motor e o torque, revelada pelo seu produto junto ao coeficiente $c_{8}$. Esta equação pode ser simplificada, fazendo-se os coeficientes $c_{5}$ e $c_{6}$ iguais à zero, obtendo-se com isso uma das equações cônicas (elipse, hipérbole ou parábola), função do determinante calculado como sendo o valor numérico de $4 \cdot \mathrm{c}_{4} \cdot \mathrm{c}_{7}-\mathrm{c}_{8}{ }^{2}$ (maior, menor e igual à zero, respectivamente).

Souza et.al. (1990) propôs esta relação simplificada para estudar a eficiência de um motor de combustão interna de tal modo que as condições de trabalho do motor sejam observadas para que se escolha a melhor região de operação, dada pela combinação da rotação e torque, visando minimizar o consumo de combustível.

Contudo, o uso de um dado motor freqüentemente requer que a operação se processe numa faixa de torque e velocidade. Neste caso é útil avaliar o rendimento global na zona de operação, como mostrado na figura 11. Portanto, a eficiência final acaba sendo uma média ponderada das eficiências para cada ponto da zona de operação do motor. Portanto:

$$
\eta_{\mathrm{b}}=\frac{\int_{\mathrm{Ri}} \int \eta_{\mathrm{b}}(\mathrm{N}, \mathrm{T}) \cdot \mathrm{W}(\mathrm{N}, \mathrm{T}) \cdot \mathrm{dN} \cdot \mathrm{dT}}{\int_{\mathrm{R}} \int \mathrm{W}(\mathrm{N}, \mathrm{T}) \cdot \mathrm{dN} \cdot \mathrm{dT}}
$$

onde: $\mathrm{W}(\mathrm{N}, \mathrm{T}) \ldots$ é o coeficiente de peso a ser dado em função do tempo que o motor opera no regime de rotação $\mathrm{N}$ e torque $\mathrm{T}$; Ri... região de integração 


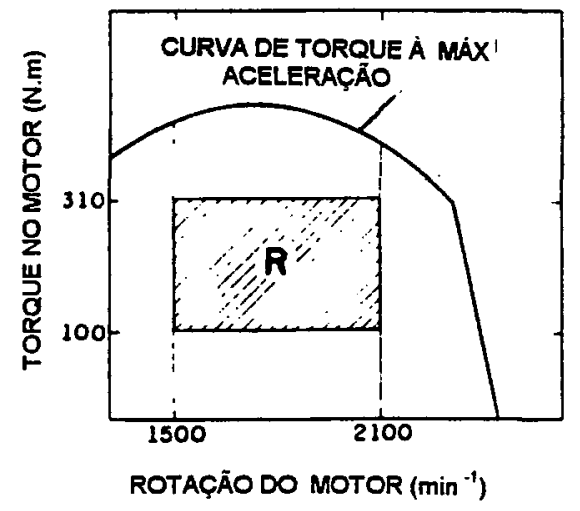

(a)

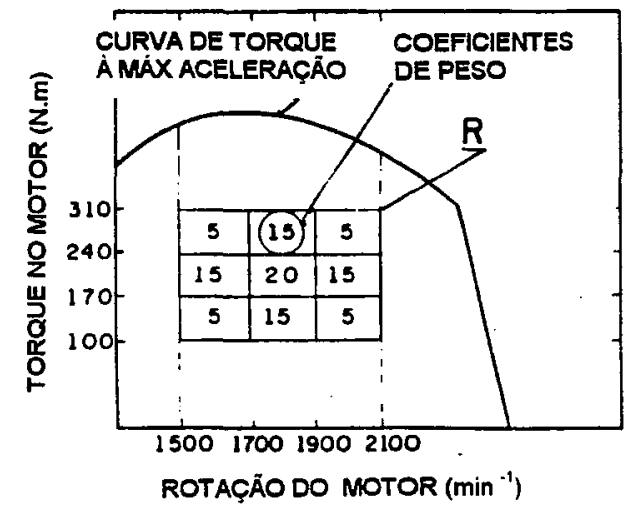

(b)

Figura 11: Duas situações de operação para um motor diesel; (a) tempos iguais gastos em cada ponto de trabalho do motor, (b) tempo gasto na dependência dos diferentes pontos de trabalho do motor. (fonte: Souza et.al., 1990).

Os resultados obtidos por Souza et.al. (1990), que ensaiaram cinco motores diferentes utilizando-se a metodologia de manter constante a rotação do motor e impondo diversas cargas pela variação da posição da alavanca da bomba injetora, desde a mínima até a máxima possível, revelaram que o correlacionamentó dos pontos experimentais à equação 13 é muito bom, com o coeficiente de correlação múltipla $\left(R^{2}\right)$ situado ente 0,960 até 0,989 . A diferença entre o coeficiente de correlação múltipla $\left(R^{2}\right)$ da equação 13 completa para a equação 13 simplificada $\left(c_{5}\right.$ e $c_{6}$ iguais à zero) foi de 0,9 a $3,9 \%$.

2.6- Determinação dos Pontos Ótimos de Trabalho de um Motor Diesel.

Wang G. e Zoerb G.C. (1989) descrevem dois métodos para determinação dos pontos ótimos de trabalho para motores diesel. Estes modelos são importantes, já que no projeto de um indicador de marchas e rotação do motor se requer o conhecimento destas regiões de baixo consumo. Estes autores citam que o procedimento GUTD é um conceito que vem se tornando comum nos últimos anos para melhorar a eficiência das operações agrícolas. Os indicadores para seleção da 
relação de transmissão (marcha) têm sido desenvolvidos segundo esta técnica, a qual tem dado resultados expressivos quando trabalham conjuntamente com sistemas automáticos de troca de marchas. Testes de campo indicam que este sistema tem conseguido uma economia de até $20 \%$ no combustível gasto, mas que, devido à complexidade do equipamento, estes indicadores de marcha ainda não se encontram disponíveis no mercado.

O primeiro, chamado de "modelo e teste", inclui um modelo de consumo. Este modelo tem 7 coeficientes para serem determinados através do ensaio do motor. O teorema de igual inclinação de curvas é utilizado para determinar este ponto de máximo rendimento.

O segundo método resulta numa relação aproximada do ótimo do torque e rotação do motor. Este método de aproximação não requer o ensaio prévio do motor. Providencia a otimização da relação torque-rotação requeridos do motor devido ao projeto de um indicador de seleção de marchas da transmissão.

Para o primeiro método, é fundamental que o ensaio do motor tenha sido realizado previamente. Segundo Wang e Zoerb (1989), para mapear o motor são necessários de 50 a 250 pontos de dados do motor, porém Jahns (1983) citado por Wang e Zoerb (1989), introduziu uma equação que define um mapa de desempenho do motor, e que portanto reduz o número de pontos a serem obtidos. A equação proposta é:

$$
\mathrm{CH}=\mathrm{d}_{1} \cdot \mathrm{N}+\mathrm{d}_{2} \cdot \mathrm{N}^{2}+\mathrm{d}_{3} \cdot \mathrm{N}^{3}+\mathrm{d}_{4} \cdot \mathrm{N} \cdot \mathrm{T}+\mathrm{d}_{5} \cdot \mathrm{N}^{2} \cdot \mathrm{T}+\mathrm{d}_{6} \cdot \mathrm{N}^{3} \cdot \mathrm{T}+\mathrm{d}_{7} \cdot \mathrm{N} \cdot \mathrm{T}^{2}+\mathrm{d}_{8} \cdot \mathrm{N}^{2} \cdot \mathrm{T}^{2}+\mathrm{d}_{9} \cdot \mathrm{N}^{3} \cdot \mathrm{T}^{2}
$$

onde: $\mathrm{CH}=$ consumo horário de combustivel $(\mathrm{kg} / \mathrm{h})$;

$$
\mathrm{N}=\text { rotação do motor }(\mathrm{rpm}) \text {; }
$$

$\mathrm{T}=$ torque do motor (N.m);

$\mathrm{d}_{\mathrm{i}}=$ coeficientes. 
Este primeiro método trata da minimização desta equação, e portanto da maximização do rendimento. $O$ teorema de igual inclinação é aplicado à derivada do torque em relação à rotação para uma determinada potência, derivada esta que deve ser igual à derivada do torque em relação à rotação para um determinado consumo. Esta igualdade resulta numa equação que representa uma linha. Em outras palavras, diz-se que, para um nível constante de potência, se a rotação do motor e seu torque são tais que o valor do consumo de combustível for o mais baixo possível, pode-se afirmar que o motor está trabalhando no seu ponto de ótimo consumo. Se a potência do motor variar de 0 até $100 \%$ da potência máxima, o ponto ótimo de trabalho seguirá uma linha, o que significa dizer que com uma dada combinação de torque e rotação, de tal forma que esteja sempre sobre esta linha, a maximização do rendimento é obtida, conforme visto na linha pontilhada CD da figura 12 .

Esta linha é representada pela seguinte equação (chamada de equação de otimização T-N):

$d_{7} \cdot T^{2}-\left(d_{5} \cdot N+2 \cdot d_{6} \cdot N^{2}\right) \cdot T-\left(d_{1}+2 \cdot d_{2} \cdot N+3 \cdot d_{3} \cdot N^{3}\right)=0$

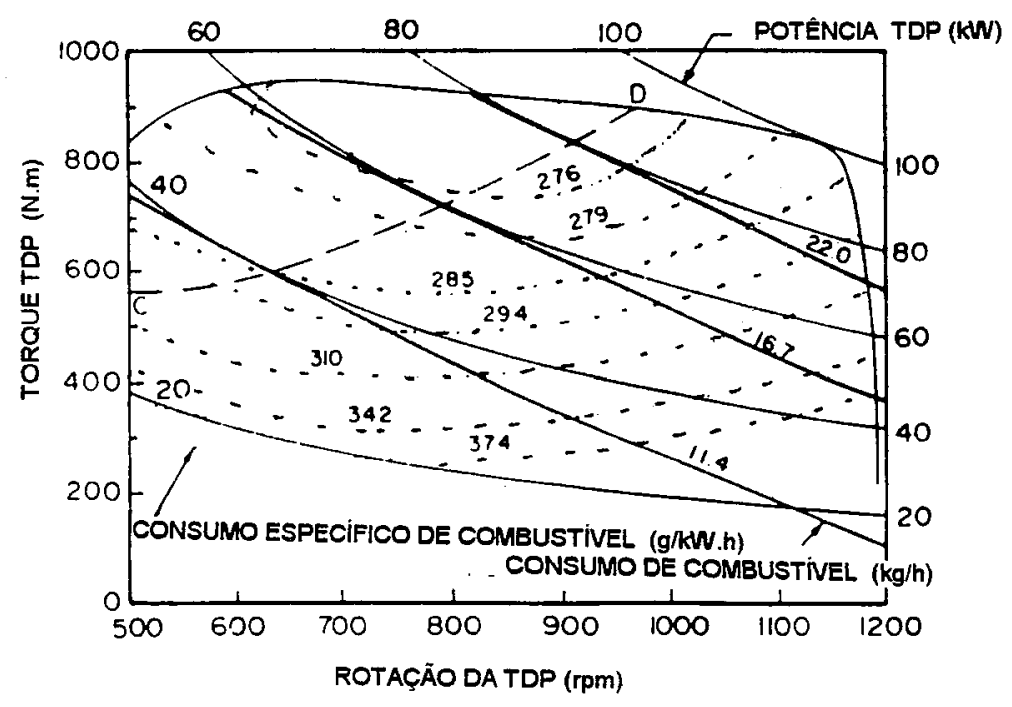

Figura 12: Curva de desempenho do motor incluindo a curva de otimização da eficiência (linha CD). (fonte: Wang e Zoerb, 1989) 
O segundo método descrito por Wang e Zoerb (1989), trata da otimização da equação T-N por aproximação. Como visto no primeiro método, a equação de otimização da curva T-N não é linear, porém uma simples aproximação que satisfaz esta não linearidade é uma reta, que pode ser definida simplesmente por apenas dois pontos.

O primeiro ponto desta reta é definido como sendo $80 \%$ da rotação nominal e $100 \%$ do torque desenvolvido na potência máxima. O segundo ponto é definido pela razão do torque em relação à velocidade, tomados do primeiro ponto; como por exemplo, se a torque for de $65 \%$, a rotação seguirá a relação $65 \%$ vezes 0,8 , que resulta em $52 \%$.

A reta pode ser então desenhada por estes dois pontos, conforme mostra a figura 13. Esta reta é uma aproximação da linha descrita pela equação 16, e pode ser utilizada com precisão suficiente para auxiliar no projeto de indicador de seleção de marchas.

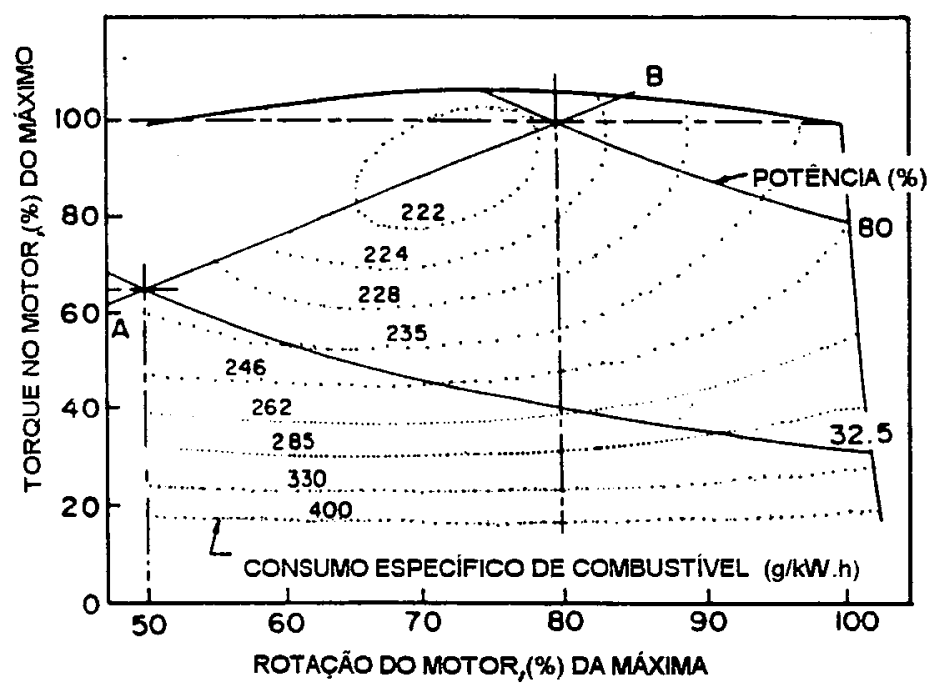

Figura 13: Curva de desempenho do motor incluindo a reta (AB) de aproximação para otimização da eficiência. (fonte: Wang e Zoerb, 1989) 
Wang e Zoerb (1989) concluem que, pelo fato do trator apresentar um número limitado de relações de transmissão (marchas), e devido a condição de uso (carga e velocidade) ser bastante variada, a equação 16, a qual dá com precisão a relação entre o torque e rotação do motor para uma otimização do consumo, raramente será respeitada. Portanto, é conveniente que se utilize do recurso da otimização da relação T-N pelo segundo método, a qual é facilmente representada pela seguinte equação:

$$
\mathrm{N} / \mathrm{Nr}=0,86 .(\mathrm{T} / \mathrm{Tr})-0,06
$$

onde: $\mathrm{Nr}=$ rotação a máxima potência;

$\operatorname{Tr}=$ torque a máxima potência;

Esta equação de aproximação não apenas simplifica a expressão matemática da relação de otimização, como também elimina os testes de motor.

\section{7- Rendimento Global de Tratores em Pista de Concreto}

Leviticus et.al. (1985) conduziram um estudo com os dados obtidos através dos testes de trator de Nebraska (Nebraska Tractor Tests), com o propósito de investigar a relação existente entre diversos parâmetros do trator com o desempenho de tração em superficie de concreto e explicar as causas da variação dos resultados dos ensaios de tração.

Há um considerável número de variáveis que podem afetar o desempenho do trator numa superficie de concreto:

- parâmetros do pneu: capacidade de carga, qualidade de borracha, tipo de construção (diagonal ou radial), preparação e pressão dos pneus;

- condições de tração: rugosidade da superficie, condições ambientais; 
- configuração do trator: trator com tração $4 \times 4,4 \times 2$ (TDA) e $4 \times 2$, com rodado simples ou duplo;

- tamanho do trator: potência, peso e sua distribuição;

- patinamento das rodas.

Concluíram que os modelos desenvolvidos por Wismer e Luth (1972) e Zoz e Brixius (1979) para predizer o desempenho aproximado (em termos de razão dinâmica de tração e eficiência de tração) dos tratores testados em Nebraska são válidos, porém ainda muito se tem a pesquisar.

Souza et.al. (1991) procuraram estabelecer uma relação do rendimento global do trator como função da velocidade de deslocamento e da força de tração e por isso pode ser avaliado por ensaios de desempenho.

Ensaios padronizados são conduzidos em pista de concreto descoberta $\mathrm{e}$ utilizando-se uma posição do acelerador que resulta na máxima rotação do motor, de acordo com a especificação do fabricante. Afirmam, contudo, que o rendimento global de um trator é função do rendimento do motor, transmissão e sistema de tração, e que estes são dependentes do torque produzido pelo motor, assim como pela rotação do mesmo, e que este rendimento global, calculado ou obtido experimentalmente, é muitas vezes mais útil que o rendimento somente do motor.

Souza et.al. (1991), desenvolveram então uma metodologia de ensaio para se determinar a dependência do rendimento global do trator como função da velocidade de deslocamento e da força de tração desenvolvidos.

A eficiência do motor é dada pela equação geral (13), a qual considera como variáveis a rotação e torque do motor, representando portanto as curvas de isoconsumo.

$O$ rendimento global do trator $\left(\eta_{t}\right)$, por sua vez, conforme estes autores, é função de vários parâmetros:

- velocidade e torque do motor; 
- seleção da relação de transmissão;

- distribuição do peso do trator;

- tipo de superficie sobre a qual se trabalha;

- tipo de rodado.

Os experimentos realizados por Souza et.al. (1991) levaram a conclusão de que o rendimento global do trator $\left(\eta_{\mathfrak{t}}\right)$ pode ser escrito analiticamente por duas relações:

- a primeira, considera o rendimento $\eta_{t}$ como função direta da rotação e do torque do motor, e da interação destes dois, como descrito abaixo:

$\eta_{t}=e_{1}+e_{2} \cdot T+e_{3} \cdot N+e_{4} \cdot T^{2}+e_{5} \cdot T^{3}+e_{6} \cdot T^{4}+e_{7} \cdot N^{2}+e_{8} \cdot N \cdot T$

onde: $\eta_{\mathrm{t}}=$ eficiência global do trator;

$\mathrm{N}=$ rotação do motor (rpm);

$\mathrm{T}=$ torque do motor (N.m);

$e_{i}=$ coeficientes.

- a segunda relação considera o rendimento como função direta da velocidade e força de tração do trator, requeridas para a operação em cada relação de transmissão, e pode ser escrita como:

$\eta_{t}=f_{1}+f_{2} \cdot F+f_{3} \cdot V+f_{4} \cdot F^{2}+f_{5} \cdot F^{3}+f_{6} \cdot F^{4}+f_{7} \cdot V^{2}+f_{8} \cdot F \cdot V$

onde: $\mathrm{V}=$ velocidade de deslocamento do trator ;

$\mathrm{F}=$ força na barra de tração;

$f_{i}=$ coeficientes.

Como é possível observar, a equação (18) é similar à (13), diferenciando apenas pelas constantes; tem sua aplicação favorável quando se deseja 
fazer uma análise das perdas de potência devido à tração e transmissão, já que suas variáveis independentes são as mesmas. A equação (19), semelhante à (18), tendo alterado apenas as variáveis independentes e seus coeficientes, tem sua razão de ser estudada pelo fato da grande dependência entre a eficiência global do trator com a velocidade e força, para uma determinada relação de transmissão, e também quando se faz comparações diretas do rendimento de diversos tratores, ou quando um mesmo trator opera sob condições diferentes. Novamente, sendo os coeficientes de índices 5 e 6 das equações 18 e 19 iguais à zero, a equação torna-se uma cônica.

Os resultados observados por Souza et.al. (1991) dos testes em pista de concreto, foram que as correlações das equações (18) e (19) feitas para diversos tipos de tratores se mostraram bastante precisas, com coeficiente de determinação múltipla ao redor de 0,981 até 0,993 .

Observaram, também, numa comparação feita entre os tratores $4 \times 4$ TDA (tração dianteira auxiliar) ligada, $4 \times 4$ TDA desligada e $4 \times 2$, que o primeiro trator, para a $7^{\mathrm{a}}$ marcha na qual foram feitos os ensaios, tem um rendimento maior que os outros dois. Ao realizarem uma análise das perdas de transmissão e tração, concluíram que a razão para este elevado rendimento do trator $4 \times 4$ TDA ligada é devido ao balanço positivo de rendimento quando se contabiliza as perdas ligadas ao sistema de transmissão mais complexo com o ganho de eficiência de conversão do peso do trator para a força na barra de tração. Já o trator $4 \times 4$ TDA desligada, não apresenta este acréscimo de rendimento, porém as perdas de transmissão estão presentes. Ao compararem o trator $4 \times 4$ TDA desligada com o trator $4 \times 2$, verificaram que este último apresentou um maior rendimento que o primeiro, pelo mesmo motivo citado anteriormente; o trator $4 \times 4$ TDA desligada apresenta balanço negativo de rendimento. 
As curvas envoltórias das curvas de iso-consumo, como apresentada na figura 8, podem ser traçadas, segundo Almeida (1990), utilizando-se as seguintes correlações:

a) correlação para a região de corte do regulador de rotação:

$$
\mathrm{F}=\mathrm{g}_{0}+\mathrm{g}_{1} \cdot \mathrm{V}+\mathrm{g}_{2} . \mathrm{V}^{2}
$$

b) correlação para a região fora do corte do regulador de rotação:

$$
F=h_{0}+h_{1} . V+h_{2} . V^{2}+h_{3} . V^{3}
$$

onde: $F$... força na barra de tração;

V... velocidade de deslocamento do trator;

$\mathrm{g}_{\mathrm{i}}, \mathrm{h}_{\mathrm{i}} \ldots$ coeficientes.

\section{8- Seleção da Relacão de Transmissão}

$\mathrm{O}$ rendimento global de um trator, como visto, depende de diversos parâmetros. Um destes parâmetros a serem abordados é a relação de transmissão escolhida para uma especifica operação no campo.

Souza L. (1989), com estudos preliminares foi constatado que, em trabalhos realizados com um trator Valmet $9804 \times 4$ com aspiração forçada, uma substancial economia de combustivel foi conseguida somente com o artificio de operar o trator com marchas mais altas e rotações do motor mais baixas, deixando o motor de trabalhar próximo ao ponto de máxima potência e passando a trabalhar próximo ao ponto de máximo torque. Por este motivo, transmissões melhor adaptadas ao motor e para o uso no meio agrícola deverão ser estudadas de tal forma que permita que o motor trabalhe a uma rotação de maior economia de combustivel, prevendo sempre uma significativa reserva de torque. 
Uma abordagem sobre o melhor aproveitamento energético também é feito por Lyne et.al. (1984). Consideram que, apesar do esforço do desenvolvimento de combustíveis alternativos e mais econômicos, há ainda muito para se pesquisar e um considerável potencial de redução no consumo nos motores diesel quando empregados em qualquer operação agrícola específica. Citam que se o operador selecionar melhor a rotação do motor e a relação de transmissão, poderá minimizar o consumo específico de combustivel, e se este procedimento for acompanhado do aumento do rendimento de tração, consideráveis acréscimos podem ser somados ao rendimento global.

Nos resultados que obtiveram, Lyne et.al. (1984) concluíram que a relação de transmissão pode ser aumentada (por exemplo de uma terceira para quarta) com uma correspondente redução da rotação do motor porém nenhuma mudança significativa em relação à tração das rodas, obtendo-se por isso expressiva economia de combustível. Nas suas pesquisas, onde trataram sobre a utilização do motor e relação de transmissão, assim como a lastragem do trator e pressão dos pneus, algumas relações podem ser deduzidas:

1 - que baixos valores de consumo específico para operações de campo podem ser alcançados com altos níveis de saída de potência, otimizando o desempenho do motor e rendimento de tração;

2- o rendimento de tração pode ser otimizado pela apropriada seleção da carga dinâmica e pressão dos pneus;

3- aumentando-se a lastragem, a potência na barra aumenta significativamente, com a correspondente diminuição do consumo específico de combustível;

4- a otimização do rendimento global do trator requer um sistema automático de controle para selecionar adequadamente parâmetros do motor (rotação e torque), relação de transmissão, lastragem e pressão dos pneus, e sugere que este 
rendimento pode ser medido em termos de quantidade de combustivel por unidade de velocidade de deslocamento como um parâmetro a ser usado no sistema de controle.

Segundo Chancellor et.al. (1984), em testes preliminares com tratores operados por dois tratoristas, comprovou que uma redução no consumo de combustível na ordem de 5 a $12 \%$ pode ser obtido com operações conduzidas de maneira mais econômica.

Vários outros pesquisadores têm estudado este aspecto. Citados por Chancellor et.al. (1984) temos: Schrock et.al. (1982) que em seus ensaios obteve na média uma economia de 19,8\% no consumo quando comparado com práticas normais; Castelli e Morello (1980), que afirmam ter conseguido uma economia de $25 \%$ no consumo com o uso de controle automático da rotação do motor e da transmissão continua por correia em "V", em automóveis; e Chancellor (1981), que observou que um ajuste adequado da relação de transmissão permite uma economia de $10 \%$ no consumo seguido de um aumento médio de $17 \%$ na força de tração.

Em seu trabalho, Chancellor et.al. (1984) equiparam um trator com diversos sensores para medir o torque do eixo da roda, rotação do motor, posicionamento da alavanca de troca de marchas, velocidade, consumo de combustível, entre outros, e chegaram a conclusão de que, ao se adotar um procedimento que explore melhor os regimes econômicos do motor através das diversas relações de transmissão, comprovou-se que uma redução no consumo de combustível é obtido na ordem de 5 a $12 \%$ em operações agrícolas, quando comparado com operações idênticas realizadas por um experiente operador, e ainda permitir um aumento no desempenho da barra de tração. 
Schrock et.al. (1986) em seus estudos, reafirmam que o procedimento de "gear up and throttle down" (alta relação de transmissão e baixa rotação, mantendo-se a velocidade de deslocamento) é uma técnica de operação de tratores que permite economia quando o trabalho não exigir elevadas cargas do motor. Este procedimento depende de diversos fatores, como:

- nível de potência exigido;

- variabilidade da condição do campo;

- características da curva de torque do motor;

- da utilização da tomada de potência.

Um trabalho citado por Schrock et.al. (1986) que evidencia a dependência do consumo em relação ao nível de potência exigido foi feito por Stephens et.al. (1981), o qual revela que uma economia de 13\% pode ser alcançada quando se trabalha com uma potência média exigida de $48 \mathrm{~kW}$, porém pode chegar à $25 \%$ quando o trabalho exigir apenas $25 \mathrm{~kW}$.

Schrock et.al. (1986) citam três observações adicionais que aumentam o interesse pelas técnicas GUTD. A primeira delas é que, baseada no trabalho de Larsen (1980) cujo estudo leva a conclusão de que apenas $59 \%$ da potência máxima na barra de tração é utilizada, citam que o procedimento GUTD pode ser adotado para se alcançar maior eficiência nas operações. A segunda observação para justificar a adoção deste procedimento reside no fato de os motores atuais apresentarem um elevado torque mesmo a baixas rotações, o que permite elevadas cargas a baixas rotações, ou seja, boa reserva de torque. A terceira observação adicional é em relação ao desenvolvimento de bombas injetoras governadas eletronicamente, que facilitará a mensuração da carga no motor, viabilizando o controle da transmissão e outras funções.

Dos ensaios conduzidos com 10 operadores diferentes, Schrock et.al. (1986) concluíram que houve uma expressiva economia, variando de $6 \%$ até $37 \%$, 
com um valor médio de $12,5 \%$, sempre quando comparado com uma operação tida como normal. Dos dez operadores consultados, apenas um relacionou a deficiência da técnica "gear up - throttle down" quanto a reserva de torque, problema este facilmente corrigido por uma programação que prevê uma reserva mínima de torque.

Schrock et.al. (1990), comparam a redução no consumo de combustível obtida devido à três formas diferentes de troca de marchas:

- troca manual;

- troca mecânica automática de marchas;

- troca através de relação contínua de transmissão (CVT- "continuously variable transmissions" - transmissão variável continuamente).

e fizeram uma classificação da carga imposta ao trator como sendo:

- variação de carga devido a diferentes tipos de trabalho;

- variação de carga que ocorre durante um mesmo tipo de trabalho.

Citam Schrock et.al. (1990) que o procedimento "gear up - throttle down" é adequado para otimizar o consumo de combustivel devido a variação da carga associado ao tipo de trabalho, porém não apresenta expressiva economia quando a variação da carga ocorre num mesmo tipo de trabalho. Neste caso, sugere que um controle da rotação do motor e da relação de transmissão seja feito por um sistema de maneira a ser ter uma realimentação dos parâmetros medidos. Nos seus ensaios, foram fixados 4 ciclos de cargas crescentes: A, B, C e D.

Os resultados obtidos por Schrock et.al. (1990) durante os ensaios com cargas diferenciadas para um mesmo tipo de trabalho foram os seguintes:

1- Troca de Marchas Manualmente. Os resultados indicam que a redução da rotação do motor devido ao uso de marchas mais longas, resulta em perceptíveis economias. Para cargas leves e moderadas (A, B e C), o motor pode ter 
sua rotação diminuída em até $30 \%$ quando comparado com operações tidas como normais, com uma economia de 20 a 30\%; para cargas maiores (D), o motor tolera uma redução de apenas $15 \%$ na rotação, com uma economia estimável em aproximadamente de $9 \%$.

2- Troca Mecânica Automática de Marchas com Sistema de Realimentação de Informação. Neste caso, utilizou-se cinco das dezesseis marchas disponíveis no trator (da $7^{\underline{a}}$ à $11^{\underline{a}}$ ), obtendo-se economias de 19 a $45 \%$ no consumo de combustivel (dependendo do ciclo da carga) quando comparado com o respectivo consumo, ao ser fixada arbitrariamente a $7^{\mathrm{a}}$ marcha. $\mathrm{O}$ que se observou no caso do ciclo de cargas leves e médias foi que a freqüência de troca de marchas foi muito baixa, e também que freqüentemente o motor estava trabalhando a baixas rotações ("gear up - throttle down").

3- Troca utilizando-se CVT. Este sistema promove uma pequena economia adicional de aproximadamente 5\% quando comparado com a troca mecânica automática, já que não há discretização das marchas, podendo melhor adaptar o motor às exigências de campo.

Um trabalho realizado por Kotzabassis et.al. (1994), junto à Universidade do Texas, no departamento de extensão rural ("Texas Agricultural Extension Service"), propõem a aplicação prática do procedimento GUTD. Para estes pesquisadores e extensionistas o hábito dos operadores deve ser mudado, já que antigamente os tratores, devido à construção do motor e da transmissão, deveriam operar com seus motores em máxima rotação, e hoje, devido à tecnologia empregada nos motores e elevado número de marchas das transmissões, o trator pode operar com o motor a cargas parciais, mantendo-se uma reserva de torque mínimo.

Reafirma Kotzabassis et.al. (1994) que, devido à redução da reserva de torque observada acima, o princípio GUTD pode ser aplicado apenas quando o trator 
opera com cargas moderadas a leves (menores que $75 \%$ da potência máxima). Isto não é um problema grave, já que os motores modernos apresentam uma elevada reserva de torque, e também pelo fato que na média $59 \%$ da potência máxima do trator é utilizada. (Schrock, 1986).

O algoritmo desenvolvido para a aplicação do GUTD é o seguinte:

** calcular a rotação do motor que corresponda $70 \%$ da rotação nominal (aquela rotação desenvolvida à máxima potência, dado pelo fabricante).

1- Selecionar a rotação e a marcha como se usualmente se faria a operação, observando a velocidade do trator;

2- Caso a rotação do motor diminua mais de $170 \mathrm{rpm}$ (até 200 , conforme o motor) quando se compara a rotação de serviço com a rotação com o motor trabalhando livre, deve-se trabalhar com a combinação de marcha e rotação feita no passo 1;

3- Senão, caso a rotação do motor for reduzida menos que $170 \mathrm{rpm}$ (ou 200), pode-se aplicar o GUTD. Para isto, basta selecionar a próxima marcha mais alta e reduzir a aceleração de tal forma que se obtenha a velocidade de deslocamento anterior;

4- Se a nova rotação for maior que $70 \%$ da rotação nominal, repita o passo 2 ;

5- Se a nova rotação for menor que $70 \%$ da nominal, então selecione a marcha e aceleração anteriores, e permaneça com esta combinação.

Graficamente, em blocos: 


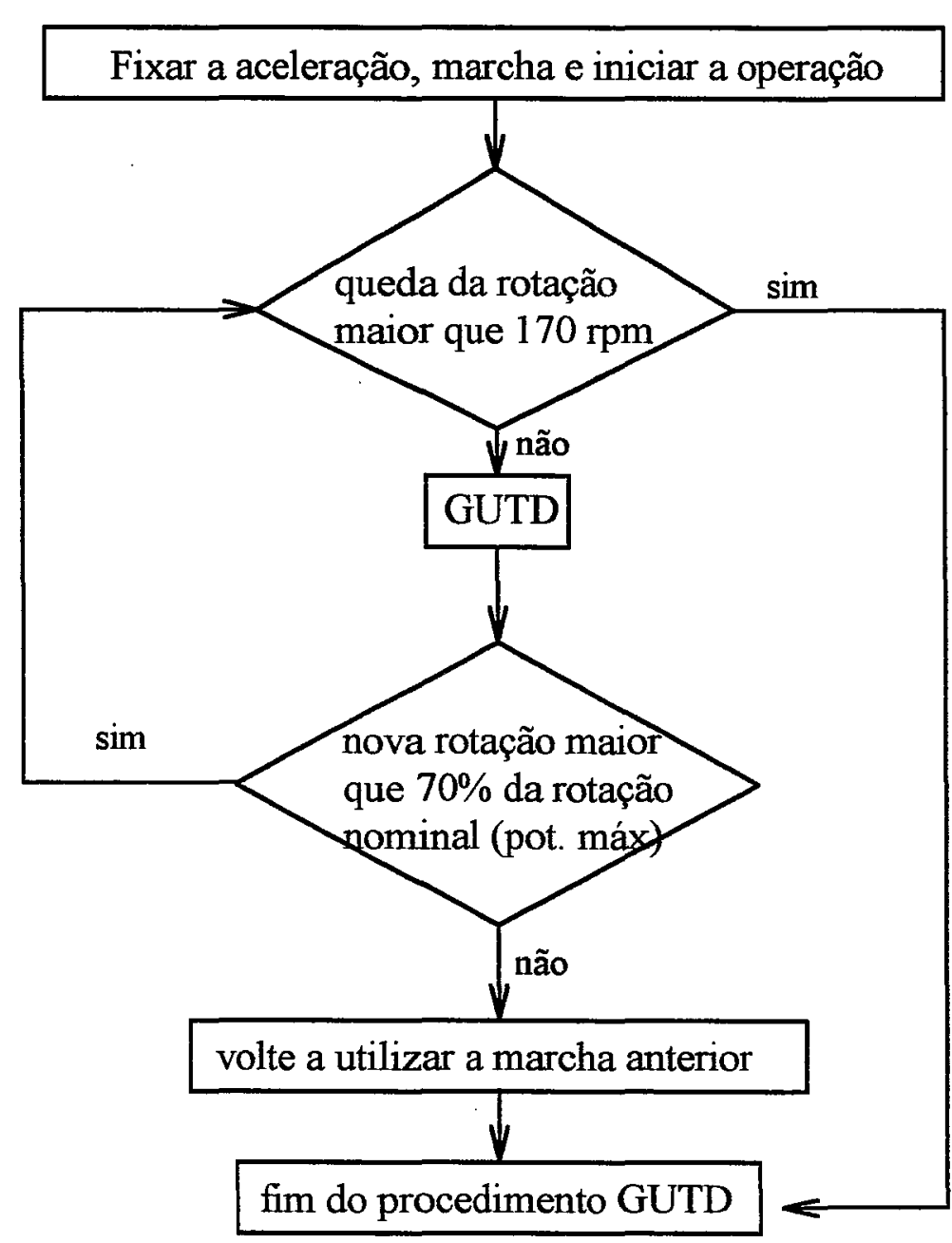

Figura 14: Diagrama de blocos do funcionamento do GUTD. (fonte: Kotzabassis et.al.1994)

\section{9- Análise do Desempenho do Trator em Ensaio de Campo}

Lima et.al. (1993) estudaram o rendimento global de um trator agrícola operando em solo agrícola plano e horizontal, sob diferentes marchas, em regime estável de trabalho e sem utilizar a tomada de potência. 
Apontam que o consumo específico de combustível na barra de tração é um indicador da eficiência de conversão da energia química do combustível em energia mecânica na forma de potência de tração. $O$ seu valor é determinado por:

$$
\mathrm{CECG}=\frac{1000 \cdot \mathrm{CH}}{\mathrm{Pbdt}}
$$

onde: $\mathrm{CECG}=$ consumo especifico de combustível na barra de tração $(\mathrm{g} / \mathrm{kW} . \mathrm{h})$

$\mathrm{CH}=$ consumo horário de combustível $(\mathrm{kg} / \mathrm{h})$

$\mathrm{Pbdt}=$ potência desenvolvida na barra de tração $(\mathrm{kW})$

Portanto, o rendimento global do trator $\left(\eta_{\mathrm{t}}\right)$ é definido por:

$$
\eta_{\mathrm{t}}=\frac{3600}{\mathrm{H} \cdot \mathrm{CECG}}
$$

onde: $\mathrm{H}=$ poder calorífico inferior do combustível $(\mathrm{MJ} / \mathrm{kg})$

Na modelagem, utilizaram a mesma correlação proposta por Souza et.al. (1991), equações 18 e 19, para a determinação do rendimento global do trator em pista de concreto, para o trator em condição de trabalho de tração na barra em solo agrícola

Para se avaliar o torque desenvolvido pelo motor nas condições de trabalho, utilizaram-se do método descrito por Souza e Milanez (1988), que discorrem sobre a relação do torque com a rotação do motor e o débito da bomba, que é a massa injetada de combustível por cilindro e por ciclo. A relação é:

$$
\mathrm{T}=1_{\mathrm{o}}+1_{1} \cdot \mathrm{D}+\mathrm{l}_{2} \cdot \mathrm{D}^{2}+\mathrm{l}_{3} \cdot \mathrm{N}+1_{4} \cdot \mathrm{N}^{2}
$$

onde: $\mathrm{T}=$ torque do motor $(\mathrm{N} . \mathrm{m})$; 
$\mathrm{D}=$ débito de combustível por cilindro e por ciclo (mg);

$\mathrm{N}=$ rotação do motor (rpm);

$1_{0} \ldots 1_{4}=$ coeficientes determinados em ensaios de desempenho.

Lima et.al. (1993), após o ensaio do motor em bancada, realizaram o ensaio do trator em campo utilizando quatro rotações diferentes do motor, quatro marchas diferentes e cargas crescentes na barra de tração.

Os resultados a que Lima et.al. (1993) chegaram, mostram que a equação para o cálculo do rendimento global do trator em pista de concreto proposta por Souza et.al. (1991) também pode ser utilizada em ensaios de desempenho em campo, mantendo-se a mesma precisão. Concluíram também que para se otimizar o consumo específico de combustível de um trator baseando-se somente na curva de desempenho do motor, é necessária a adoção de uma região de consumo específico mínimo, porém que o consumo específico mínimo de combustível para cada marcha ocorreu em diferentes pontos de trabalho, isto é, a diferentes torques e rotações do motor.

\subsection{0- Modelos Empíricos da Razão Dinâmica de Tração}

Wismer \& Luth (1972) desenvolveram uma expressão especifica para determinar a razão dinâmica de tração $(\mathrm{F} / \mathrm{W})$, como descrita abaixo:

$$
\mathrm{RDT}=\mathrm{F} / \mathrm{W}=0,75 .\left(1-\mathrm{e}^{-0,3 . \mathrm{CN} \cdot \mathrm{s}}\right)-(1,2 / \mathrm{CN}+0,04)
$$

onde: RDT. razão dinâmica de tração;

$\mathrm{CN} \ldots$ índice de mobilidade $(\mathrm{CN}=\mathrm{IC} . \mathrm{b} . \mathrm{d} / \mathrm{W})$;

s... patinamento; 
b... largura da secção do pneu sem carga;

d... diâmetro do pneu sem carga;

IC..indice de cone médio na camada de $0-15 \mathrm{~cm}$;

W..carga dinâmica sobre o rodado de tração;

F...força de tração.

A expressão que resulta na eficiência tratória é:

E.T. $=$ RDT. $(1-\mathrm{s}) /\left(0,75 \cdot\left(1-\mathrm{e}^{-0,3 . \mathrm{CN} \cdot \mathrm{s}}\right)\right)$

onde: E.T.. eficiência tratória.

Brixius (1987), revisando o modelo proposto por Wismer \& Luth (1972), concluiu que a deflexão do pneu e suas dimensões deveriam ser considerados, e propôs a seguinte expressão:

$\mathrm{RDT}=0,88 \cdot\left(1-\mathrm{e}^{-0,1 \cdot \mathrm{Bn}}\right) \cdot\left(1-\mathrm{e}^{-7,5 . \mathrm{s}}\right)-\left(1,0 / \mathrm{Bn}+0,5 \cdot \mathrm{s} / \mathrm{Bn}^{0,5}\right)$

onde: $\mathrm{Bn} . .$. índice de mobilidade;

$$
\mathrm{Bn}=\mathrm{CN} .[(1+5 . \delta / \mathrm{h}) /(1+3 . \mathrm{b} / \mathrm{d})]
$$

onde: $\delta \ldots$ deflexão percentual do pneu (geralmente considerado $20 \%$ );

h... secção de altura do pneu;

d... largura do pneu. 


\section{3 - MATERIAL E MÉTODOS}

Os ensaios realizados durante a pesquisa estiveram voltados basicamente a avaliar o consumo de combustível de um trator agrícola, relacionando-o ao desempenho na barra de tração. Para que se fizesse o ensaio, da mesma forma que é feito em ensaios normalizados em pista de concreto, formou-se um comboio, composto pelo trator, que traciona um conjunto, e sobre o qual tem-se interesse, e um carro dinamométrico, responsável pela carga imposta ao trator. Pelo fato deste ensaio ter sido realizado em solo agrícola, o carro dinamométrico foi substituído por um trator, potente o suficiente para impor a resistência necessária.

\section{1- Trator ensaiado}

O trator ensaiado foi um Valmet $985 S 4 \times 4$ com motor diesel turbo, tração dianteira auxiliar ligada, equipado com rodado dianteiro $14.9-24$ diagonal, 8 lonas, e rodado traseiro 18.4 - 34 diagonal, 10 lonas, calibrados com 18 e 24 PSI, respectivamente. $\mathrm{O}$ trator encontrava-se em estado de novo, com 85 horas de uso.

As principais características técnicas fornecidas pelo fabricante do trator ensaiado são:

\subsection{1- Motor}

Marca VALMET

Modelo 420 DS

Tipo injeção direta; aspiração forçada

Número de cilindros. 4

Cilindrada $4400 \mathrm{~cm}^{3}$ 
Relação de compressão $16,5: 1$

Potência Máxima - kW (cv)/rpm $77,2(105) / 2300$ (NBR 5484)

Torque Máximo - Nm (mkgf)/rpm $390(39,8) / 1400$ (NBR 5484)

Rotação máxima livre $2530 \mathrm{rpm}$

\subsection{2- Transmissão}

O trator Valmet $985 S 4 \times 4$ turbo estava equipado com uma caixa de câmbio parcialmente sincronizada, com 8 marchas à frente e 4 à ré, e com o dispositivo denominado multitorque, com o qual através de um simples toque no botão, envia-se um comando elétrico para o acoplamento hidráulico e assim seleciona-se uma relação mais alta ou mais baixa, conforme o seu posicionamento anterior, sem parar o trator, ainda que o mesmo esteja sob carga. Pode-se dizer que este trator dispunha de 16 marchas à frente, com as seguintes relações de transmissão:

Tabela 2: Relações de transmissão do trator ensaiado.

\begin{tabular}{|c|c||c|c|}
\hline marcha & relação & marcha & relação \\
\hline L1R & $1: 251,23$ & H1R & $1: 74,53$ \\
\hline L1L & $1: 207,11$ & H1L & $1: 61,44$ \\
\hline L2R & $1: 179,72$ & H2R & $1: 53,35$ \\
\hline L2L & $1: 148,16$ & H2L & $1: 43,98$ \\
\hline L3R & $1: 126,75$ & H3R & $1: 37,46$ \\
\hline L3L & $1: 104,49$ & H3L & $1: 30,88$ \\
\hline L4R & $1: 101,02$ & H4R & $1: 29,89$ \\
\hline L4L & $1: 83,28$ & H4L & $1: 24,64$ \\
\hline
\end{tabular}




\subsection{3- Características Dimensionais e Ponderais}

Condição de lastragem metálico e líquido

Peso dianteiro $21896 \mathrm{~N}$

Peso traseiro $37945 \mathrm{~N}$

PesoTotal $59841 \mathrm{~N}$

Altura da linha de tração. $470 \mathrm{~mm}$

Distância entre eixos. $2500 \mathrm{~mm}$

Distância do Centro de Gravidade ao eixo traseiro. $1090 \mathrm{~mm}$

Bitola Dianteira $1710 \mathrm{~mm}$

Bitola Traseira. $1740 \mathrm{~mm}$

\section{2- Trator Lastro}

$\mathrm{Na}$ realização dos ensaios de campo, o carro dinamométrico foi substituído por um trator, o qual impôs a carga necessária para frenar o trator ensaiado. Para tanto, o trator escolhido foi um trator Massey Ferguson 630, com tração - $4 \times 4$, totalmente lastrado.

\section{3- Medicão do consumo de combustível}

Para a medição do consumo de combustível nos ensaios de campo foi utilizada a técnica volumétrica, medindo-se o volume de combustível consumido pela leitura da bureta, e o tempo transcorrido através de um cronômetro digital sincronizado com as válvulas que permitiam o consumo do combustível armazenado nas buretas. As figuras 15 e 16 mostram em detalhe o funcionamento do equipamento. 


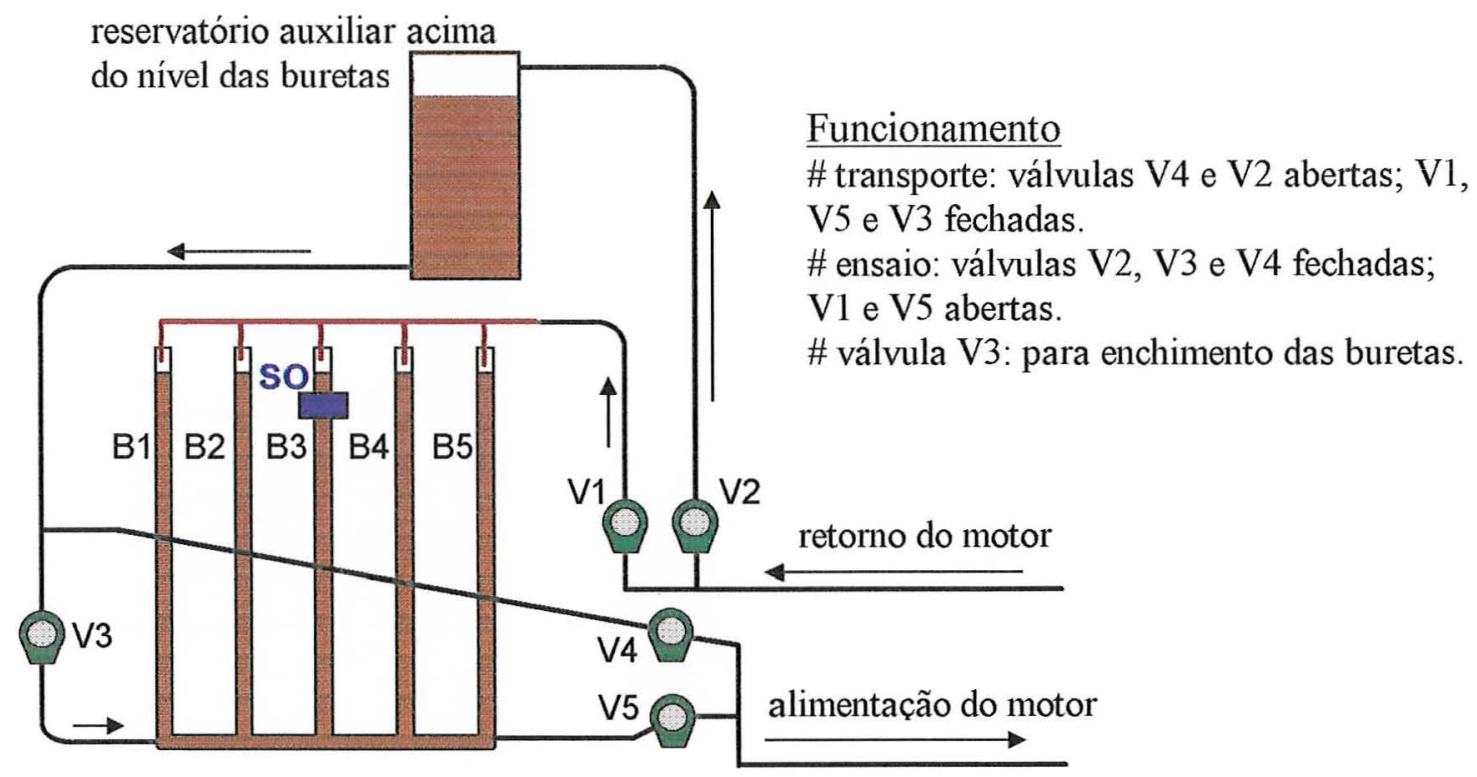

onde: $B_{i}=$ buretas interligadas em suas bases;

$\mathrm{V}_{\mathrm{j}}=$ válvulas solenóides de passagem do combustivel;

$\mathrm{SO}=$ sensor óptico colocado na marcação zero da bureta central.

Figura 15: Vista esquemática do medidor de combustível

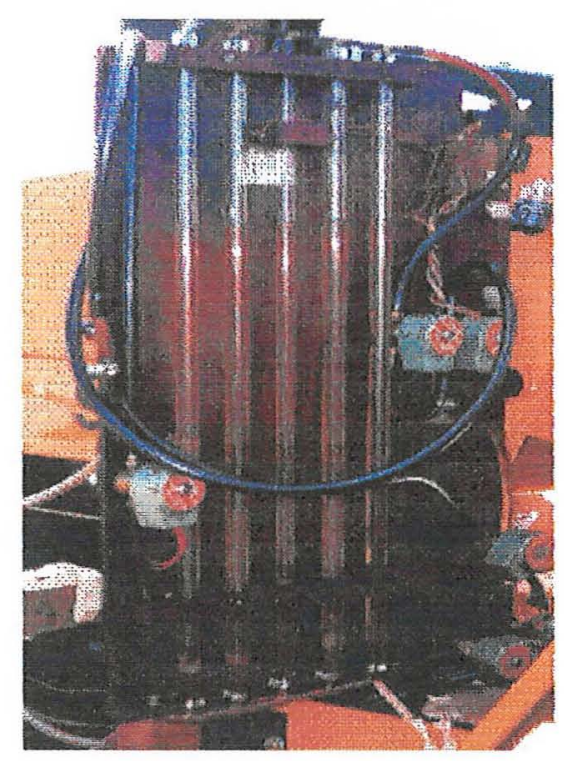

Figura 16: Vista do medidor de combustível 
O funcionamento deste equipamento se dá de forma que, quando acionado, o conjunto de válvulas solenóides é energizado de maneira que o motor consuma apenas o combustível contido nas buretas e o diesel do retorno volte às buretas. A leitura do consumo se dá pela bureta central (B3), a qual é graduada. $\mathrm{O}$ cronômetro digital, que indicará o tempo durante o qual se consumiu o diesel das buretas, é acionado quando o nível de combustível passar pelo sensor óptico. A calibragem feita com o equipamento revelou que a cada 10 traços lidos corresponde a um volume de $6,89 \mathrm{ml}$.

O início e o término do processo de medição do consumo de combustível das buretas se dá pelo acionamento de um botão "início" e um botão "fim", respectivamente, os quais se encontram no painel de controle, conforme visto na figura 17 .

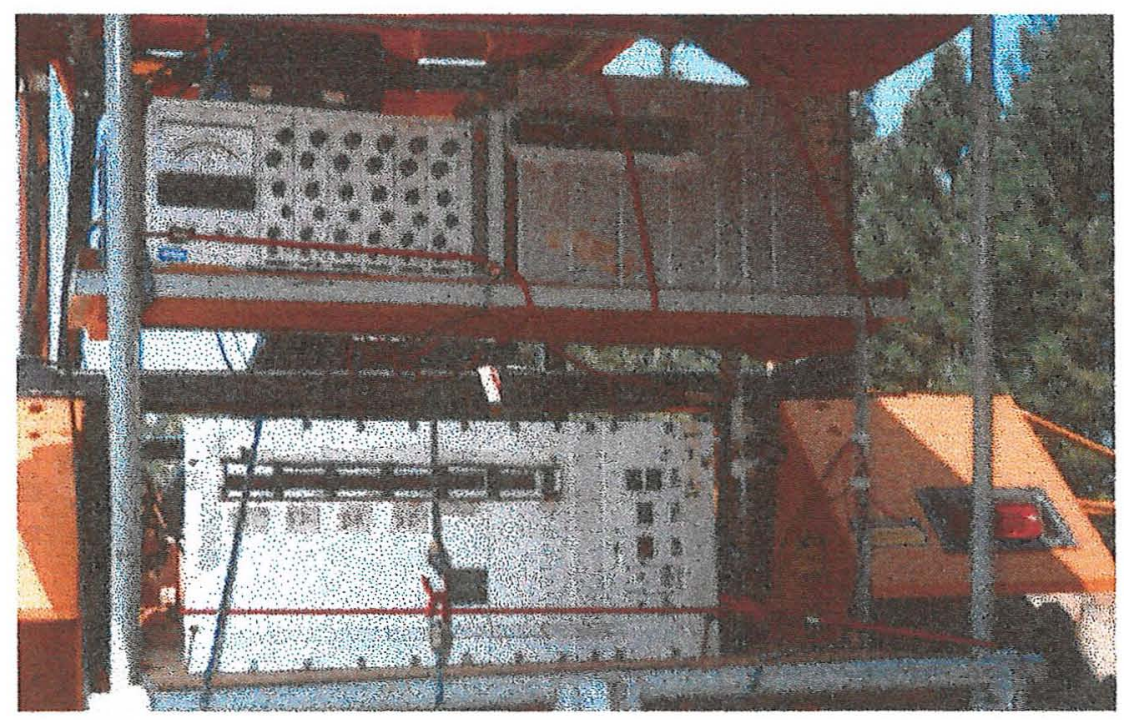

Figura 17: Vista do painel de controle. 


\section{4- Combustível}

O combustivel (óleo diesel) utilizado durante os ensaios tem poder calorífico inferior igual a $42,6 \mathrm{MJ} / \mathrm{kg}$. A sua densidade foi determinada através de ensaio laboratorial, o qual revelou um comportamento linear da densidade em relação à temperatura. A interpolação linear obtida foi:

Dens. Comb. $\left(\right.$ gramas $\left./ \mathrm{dm}^{3}\right)=-0,70$. Temperatura $\left({ }^{\circ} \mathrm{C}\right)+858,38 \quad\left(\mathrm{R}^{2}=0,98\right)$

\section{5- Medicão das Temperaturas e Umidade Relativa}

Para a medição da temperatura do óleo diesel fez-se uso de um sensor de temperatura que opera baseado no princípio da variação da resistividade elétrica de um termopar, imerso no reservatório auxiliar de combustível.

O termopar utilizado foi do tipo J (ferro-constantan), o qual foi referenciado a zero graus Celsius através de uma extensão para captação da temperatura de referência no gelo em recipiente adiabático.

A temperatura do ar atmosférico e a umidade relativa foram fornecidas por uma base meteorológica montada a aproximadamente 500 metros de distância do local dos ensaios. Estes dados foram fornecidos de meia em meia hora, conforme a tabela 3, a qual relaciona a temperatura e a umidade do ar nos dias do ensaio $(16,18 \mathrm{e}$ 19 de Setembro), e também em intervalos de 30 em 30 minutos. 
Tabela 3: Temperatura e umidade do ar no local do ensaio.

\begin{tabular}{|c|c|c|c|c|c|c|}
\hline \multirow{2}{*}{$\begin{array}{c}\text { horário da } \\
\text { leitura }\end{array}$} & \multicolumn{2}{|c|}{ dia 16 } & \multicolumn{2}{c|}{ dia 18 } & \multicolumn{2}{c|}{ dia 19 } \\
\hline & tp. $\left({ }^{\circ} \mathrm{C}\right)$ & U.R. (\%) & tp. $\left({ }^{\circ} \mathrm{C}\right)$ & U.R. (\%) & tp. $\left({ }^{\circ} \mathrm{C}\right)$ & U.R. (\%) \\
\hline $8: 00$ & & & 14,83 & 80,6 & 16,03 & 85,0 \\
\hline $8: 30$ & & & 15,80 & 77,5 & 17,24 & 80,9 \\
\hline $9: 00$ & & & 16,84 & 73,4 & 18,10 & 76,5 \\
\hline $9: 30$ & & & 17,94 & 69,5 & 19,00 & 73,5 \\
\hline $10: 00$ & & & 18,43 & 68,2 & 20,33 & 69,3 \\
\hline $10: 30$ & & & 19,14 & 65,7 & 21,57 & 64,8 \\
\hline $11: 00$ & & & 19,87 & 63,4 & 22,58 & 61,9 \\
\hline $11: 30$ & & & 20,84 & 61,1 & 23,30 & 60,2 \\
\hline $12: 00$ & & & 21,34 & 58,9 & 24,08 & 57,9 \\
\hline $12: 30$ & & & 22,11 & 57,1 & 24,69 & 54,2 \\
\hline $13: 00$ & & & 22,61 & 55,8 & 25,40 & 50,5 \\
\hline $13: 30$ & & & 23,00 & 54,8 & & \\
\hline $14: 00$ & & & 23,34 & 53,9 & & \\
\hline $14: 30$ & & & 23,66 & 52,7 & & \\
\hline $15: 00$ & & & 23,66 & 52,3 & & \\
\hline $15: 30$ & 28,74 & 39,3 & 23,42 & 52,6 & & \\
\hline $16: 00$ & 28,56 & 38,1 & 23,45 & 52,6 & & \\
\hline $16: 30$ & 28,31 & 37,1 & 23,07 & 53,3 & & \\
\hline $17: 00$ & 28,00 & 36,2 & 22,38 & 55,4 & & \\
\hline
\end{tabular}

3.6- Medicão da Pressão Atmosférica

A medição da pressão barométrica foi determinada no posto do Departamento de Física e Meteorologia - ESALQ-USP. A tabela 4 mostra a pressão barométrica nos dias do ensaio:

Tabela 4: Pressão barométrica durante os dias de ensaio.

\begin{tabular}{|l|c|c|c|c|}
\hline \multicolumn{1}{|c|}{ dia } & 16 & 17 & 18 & 19 \\
\hline pressão $(\mathrm{mmHg}):$ manhã & 716,7 & 717,6 & 721,0 & 722,0 \\
\hline pressão $(\mathrm{mmHg})$ : tarde & 716,5 & 719,6 & 721,0 & 719,1 \\
\hline
\end{tabular}


3.7- Caracterização da Área e do Solo

Os ensaios foram realizados na Fazenda Experimental Areião, da ESALQ-USP, situada no município de Piracicaba - S.P.

A área ocupada pelos ensaios somaram aproximadamente 5,0 ha, sendo que foram conduzidos dois meses após a colheita de feijão. $\mathrm{O}$ campo foi roçado quinze dias antes do início dos ensaios.

A cobertura vegetal, determinada pelo método de se esticar um cabo sobre a superficie segundo Laflen (1981), na média revelou ser um valor de aproximadamente $33 \%$. A figura 18 ilustra a distribuição da vegetação pelo solo.

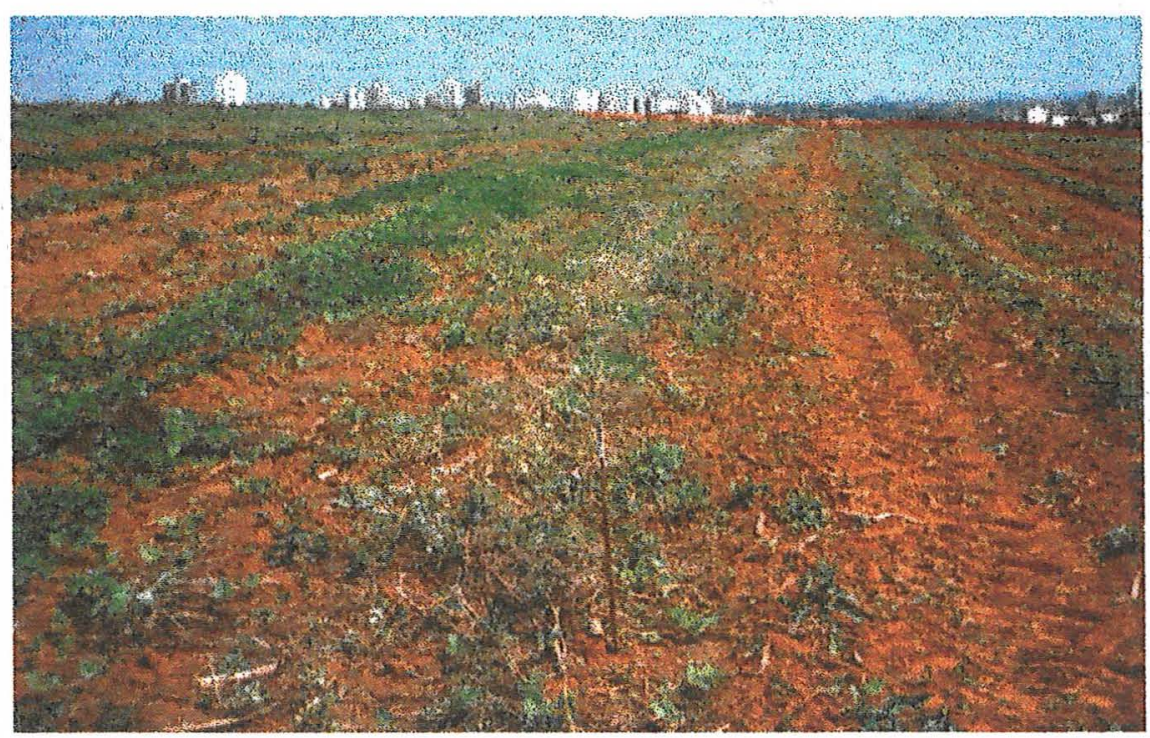

Figura 18: Vista do campo de ensaios.

A classe textural do solo foi analisada segundo o Triângulo de Classificação, citado por Kiehl (1979):

Classe Textural: Argila.

Frações Granulométricas: $\quad$ Argila: 40,0\%

Silte: $25,2 \%$

Areia: $34,8 \%$ 
Para a determinação da densidade do solo, fez-se uso do método de coleta utilizando o cilindro volumétrico. Os cilindros utilizados apresentavam como dimensões médias $47,2 \mathrm{~mm}$ de diâmetro e $46,8 \mathrm{~mm}$ de comprimento. Com a utilização deste equipamento foi possível coletar o solo nos seguintes intervalos de profundidades: $0-5$, de 5-10 e de $10-15 \mathrm{~cm}$. Os valores de densidade e umidade do solo foram obtidos pela média de quinze (15) determinações casualizadas na área de ensaio, para cada intervalo de profundidade, e estão apresentados na tabela 5.

Tabela 5: Resultados médios de umidade e densidade do solo.

\begin{tabular}{|l|c|c|c|}
\hline profundidade $(\mathrm{cm})$ & $0-5$ & $5-10$ & $10-15$ \\
\hline umidade média $(\%)$ & 18,2 & 19,5 & 20,1 \\
\hline densidade média $(\mathrm{g} / \mathrm{ml})$ & 1,74 & 1,76 & 1,76 \\
\hline
\end{tabular}

$\mathrm{Na}$ determinação da resistência à penetração, utilizou-se um penetrógrafo de mola da marca Soiltest, o qual foi equipado com o cone de área de base igual à $129,28 \mathrm{~mm}^{2}$. A haste foi introduzida no solo através da força do operador, com velocidade constante, conforme a norma ASAE S313.1, sendo o valor da força e sua respectiva profundidade registradas em um cartão. $\mathrm{O}$ número de determinações feitas foi função do número de ensaios realizados, uma vez que se determinou a resistência à penetração do solo antes e depois da passagem do rodado do trator ensaiado. Na leitura dos cartões, registrou-se os dados a três profundidades: 5,10 e 15 $\mathrm{cm}$, sendo que o índice de cone médio está indicado na tabela 6 .

Tabela 6: Índice de Cone (I.C.) médio da área do ensaio.

\begin{tabular}{|l|c|c|c|}
\hline profundidade $(\mathrm{cm})$ & 5,0 & 10,0 & 15,0 \\
\hline I.C. antes da passagem $\left(\mathrm{kgf} / \mathrm{cm}^{2}\right)$ & 15,10 & 18,94 & 21,42 \\
\hline I.C. após a passagem $\left(\mathrm{kgf} / \mathrm{cm}^{2}\right)$ & 26,75 & 24,41 & 22,88 \\
\hline
\end{tabular}




\section{8- Medicão da Rotacão do Motor}

A medição da rotação do motor durante os ensaios foi feita diretamente através do tacômetro do trator. Porém, pelo fato de este tacômetro apresentar um erro sistemático de leitura, fez-se previamente uma calibração deste por meio de um tacômetro dotado de foto-sensor, direcionado diretamente ao volante do motor.

\section{9- Medição da Força}

Para a determinação da força de tração durante o ensaio de campo utilizou-se uma célula de carga à base de "strain-gauge" da marca Kyowa, tipo LU5TE com capacidade máxima de $49050 \mathrm{~N}$ (5000kgf), sendo que o seu sinal (pulsos) foi integrado em todo o tempo do ensaio, obtendo-se, por isso, valores resultantes médios do esforço, sendo que a leitura foi feita no painel de controle após o sinal passar por um conversor analógico/digital. $O$ início do processo se dava com a passagem de um sensor (foto-sensor) para deteç̧ão das estacas, o que permitia dar um sinal para o início e para o fim do ensaio.

\subsection{0-Medicão da Velocidade}

Os ensaios foram realizados de forma que um percurso de 40 metros em linha reta fossem percorridos para cada combinação de marcha, aceleração e carga. Para isto, toda a área foi estaqueada de tal forma que em cada início e fím de um ensaio o conjunto passasse por uma estaca.

O trator ensaiado estava equipado com um sensor de passagem (fotosensor) para deteç̧ão destas estacas, o que permitia dar um sinal para o início e para o fim do ensaio. Este sinal disparava o contador de tempo. 
Dessa forma, calculou-se a velocidade média de deslocamento de todo o comboio pela fórmula:

$$
\mathrm{V}=3,6 * 0,040 / \mathrm{t}
$$

onde: $\mathrm{V} \ldots$ velocidade média de deslocamento $(\mathrm{km} / \mathrm{h})$

t... tempo para percorrer os 40 metros (segundo)

\subsection{1- Medicão do Patinamento}

Para se determinar o patinamento das rodas motrizes, utilizou-se quatro geradores de pulsos, cada qual ligado a um roda, os quais enviavam o sinal para o seus respectivos contadores no painel de controle. Estes geradores de pulsos eram acionados pelo sensor de passagem quando este passava pela estaca; a cada giro completo da roda, gerava-se 60 pulsos, registrados pelogcontadores.

Para a calibração do sistema, trafegou-se com o trator sem carga no próprio campo onde se realizou o ensaio. No cálculo do patinamento, calculou-se a diferença dos pulsos gerados com e sem carga, dividindo este resultado pelo número de pulsos gerados com carga.

As figuras 19 e 20 mostram como o equipamento foi montado no trator e detalhes de funcionamento.

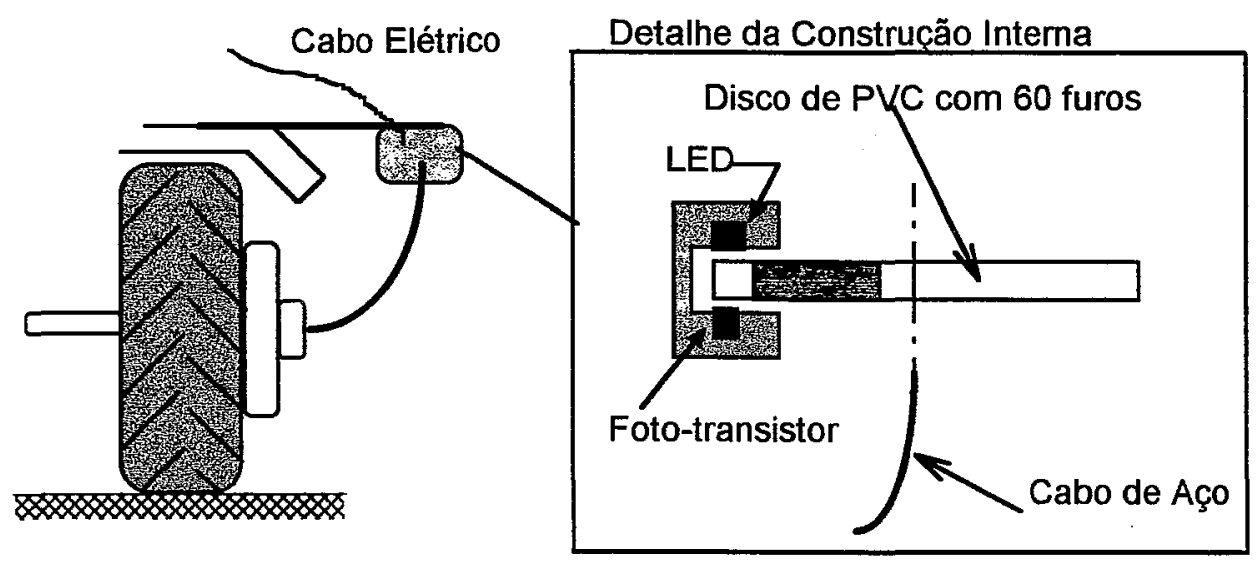

Figura 19: Esquematização dos geradores de sinal para determinação do patinamento das rodas motrizes. 


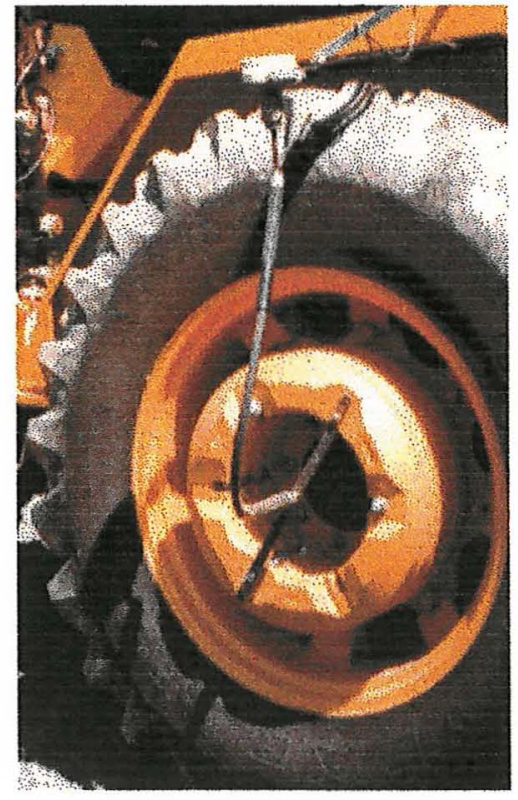

Figura 20: Montagem do gerador de sinal de patinamento.

\subsection{2- Procedimento Experimental}

\subsection{1- Campo e Condicões de Tração}

O campo onde se realizou o ensaio foi previamente escolhido de tal maneira que tivesse características semelhantes às de um campo pós-colheita de uma cultura. Procurou com isto dar ao trator uma condição de tração próxima a que se encontra na realidade, ou seja, a que o produtor geralmente encontra em sua propriedade.

No ensaio de campo, o trator ensaiado foi carregado pela barra de tração por um trator lastrọ, de tal maneira que esforç̧os crescentes puderam ser impostos de forma que explorasse toda uma gama de potência velociadade de deslocamento, deslizamento das rodas e principalmente que um grande intervalo de consumo específico fosse atingido. 
O princípio utilizado durante o ensaio em campo foi o de manter a posição fixa da alavanca de acionamento da bomba injetora do trator ensaiado. A cada posicionamento da alavanca de aceleração, corresponde uma única rotação máxima livre do motor, que são: 2300, 2000, 1500 e 1200 rpm.

Os ensaios foram realizados em três marchas diferentes, de tal forma que explorasse o intervalo de velocidades que mais se aplica às operações agrícolas onde se exige força e potência. As marchas utilizadas, segundo a denominação transcrita no próprio trator, foram: $\mathrm{L} 2 \mathrm{R}, \mathrm{L} 2 \mathrm{~L}$ e $\mathrm{L} 3 \mathrm{~L}$, cujas relações finais são $1: 179,72 ; 1: 148,16$ e 1:104,49, respectivamente. Nessas marchas, com o motor trabalhando a $2300 \mathrm{rpm}$, as velocidades máximas alcançadas foram $4,69(1,303) ; 5,84$ $(1,622)$ e $8,05 \mathrm{~km} / \mathrm{h}(2,236 \mathrm{~m} / \mathrm{s})$, respectivamente, determinadas em um ensaio preliminar.

As cargas impostas pelo trator lastro foram definidas pela diferença percentual na velocidade do trator ensaiado e do trator lastro, ambos sem carga.

Assim, para o trator ensaiado (Valmet) trabalhando a $2300 \mathrm{rpm}$, a velocidades do trator lastro (Massey) foram definidas, para o ensaio, como sendo 10; 28 e $45 \%$ menores que a velocidade do Valmet para as marchas utilizadas, ou seja, 10; 28 e $45 \%$ menores que 4,$69 ; 5,84$ e $8,05 \mathrm{~km} / \mathrm{h}$. Portanto, para cada relação de transmissão e rotação do trator ensaiado, e também para cada carga existe uma velocidade que o trator lastro deve se deslocar para que imponha a correta força de tração, ou seja, uma rotação e marcha adequadas.

As porcentagens de redução da velocidade foram função da rotação do motor do trator ensaiado. Assim, para $2300 \mathrm{rpm}$ no motor, as diferenças teóricas foram de $10 \%, 28 \%$ e $45 \%$; para $2000 \mathrm{rpm}$ de $10 \%, 28 \%$ e $45 \%$; para $1500 \mathrm{rpm}$ de $10 \%, 22 \%$ e $35 \%$ e finalmente para $1200 \mathrm{rpm}$ de $10 \%, 20 \%$ e $30 \%$, obtendo-se com isto operacionalidade do sistema. A tabela 7 mostra a gama de combinações utilizadas, e as respectivas marchas e rotações utilizadas no trator lastro para se obter a resistência necessária. 
Tabela 7: Marchas e rotações utilizadas no trator lastro para impor a força necessária no trator ensaiado.

\begin{tabular}{|c|c|c|c|c|c|c|c|}
\hline & redução & \multicolumn{2}{|c|}{ Valmet L2R } & \multicolumn{2}{|c|}{ Valmet L2L } & \multicolumn{2}{|c|}{ Valmet L3L } \\
\hline condições no & MF 630 & marcha & $\begin{array}{c}\text { rotação } \\
\text { livre }\end{array}$ & marcha & $\begin{array}{c}\text { rotação } \\
\text { livre }\end{array}$ & marcha & $\begin{array}{l}\text { rotação } \\
\text { livre }\end{array}$ \\
\hline \multirow{3}{*}{$\begin{array}{l}\text { rotação máxima livre } \\
\text { do motor Valmet: } \\
2300 \mathrm{rpm}\end{array}$} & $10 \%$ & 4 & 1850 & 5 & 1789 & 6 & 1987 \\
\hline & $28 \%$ & 3 & 1846 & 4 & 1842 & 5 & 1972 \\
\hline & $45 \%$ & 2 & 1857 & 3 & 1740 & 4 & 1942 \\
\hline \multirow{3}{*}{$\begin{array}{c}\text { rotação máxima livre } \\
\text { do motor Valmet: } \\
2000 \mathrm{rpm}\end{array}$} & $10 \%$ & 3 & 2005 & 4 & 2000 & 5 & 2142 \\
\hline & $28 \%$ & 2 & 2116 & 3 & 2000 & 4 & 2200 \\
\hline & $45 \%$ & 1 & 2075 & 2 & 2008 & 3 & 2100 \\
\hline \multirow{3}{*}{$\begin{array}{l}\text { rotação máxima livre } \\
\text { do motorValmet: } \\
1500 \mathrm{rpm}\end{array}$} & $10 \%$ & 2 & 1980 & 3 & 1875 & 4 & 2074 \\
\hline & $22 \%$ & 2 & 1700 & 2 & 2138 & 4 & 1790 \\
\hline & $35 \%$ & 1 & 1846 & 2 & 1780 & 3 & 1860 \\
\hline \multirow{3}{*}{$\begin{array}{l}\text { rotação máxima livre } \\
\text { do motorValmet: } \\
1200 \mathrm{rpm}\end{array}$} & $10 \%$ & 1 & 2040 & 2 & 1972 & 3 & 2065 \\
\hline & $20 \%$ & 1 & 1818 & 2 & 1750 & 3 & 1836 \\
\hline & $30 \%$ & 1 & 1580 & 1 & 1975 & 3 & 1606 \\
\hline
\end{tabular}

Como é possivel verificar pela tabela 7, existem 36 combinações para se determinar a variação do consumo específico. Cada ensaio foi repetido quatro vezes, no que resulta em 144 determinações em campo. Estas 144 determinações foram distribuídas ao acaso para que se evitasse a interferência de algum fator de campo desconhecido.

\subsection{2 - Procedimento Geral do Ensaio}

Como os ensaios foram totalmente casualizados, foram feitas planilhas para que os operadores dos tratores trabalhassem em harmonia e sincronismo. A cada ensaio (determinação), o tratorista do trator ensaiado tinha uma rotação e uma marcha a seguir, enquanto isto o tratorista do trator lastro também deveria selecionar a marcha e rotação especificadas, de tal maneira que a casualização adotada tornava possível a previsão do comportamento do esforço e velocidade resultantes.

Ressalta-se que as determinações, realizadas em ensaios de 40 metros cada, conforme ilustrado na figura 21 , foram executadas com os tratores 
em regime permanente. Esta condição de regime foi plenamente atingida pois, para cada determinação, foi dado um espaço de aproximadamente 10 metros, suficiente para que o conjunto o-alcançasse.

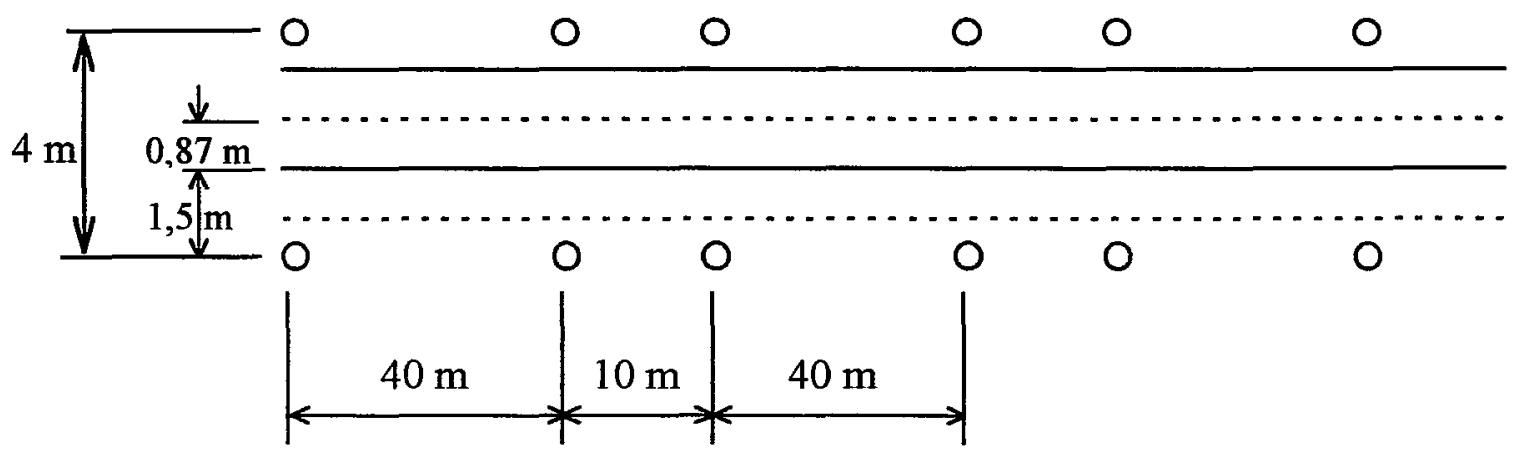

onde: O....representação da estaca.

_ rastro deixado pelo rodado do trator ao se deslocar para a direita. rastro deixado pelo rodado do trator ao se deslocar para a esquerda.

Figura 21: Posicionamento das estacas.

Como é possível verificar na figura 21 , o espaçamento lateral das estacas adotado foi de 4,0 metros, de maneira tal que o tráfego dos tratores não se fizesse sobre a passada anterior dos pneus, evitando-se assim a inclusão de mais um fator não considerado.

A figura 22 mostra o comboio formado pelos dois tratores durante o ensaio. 


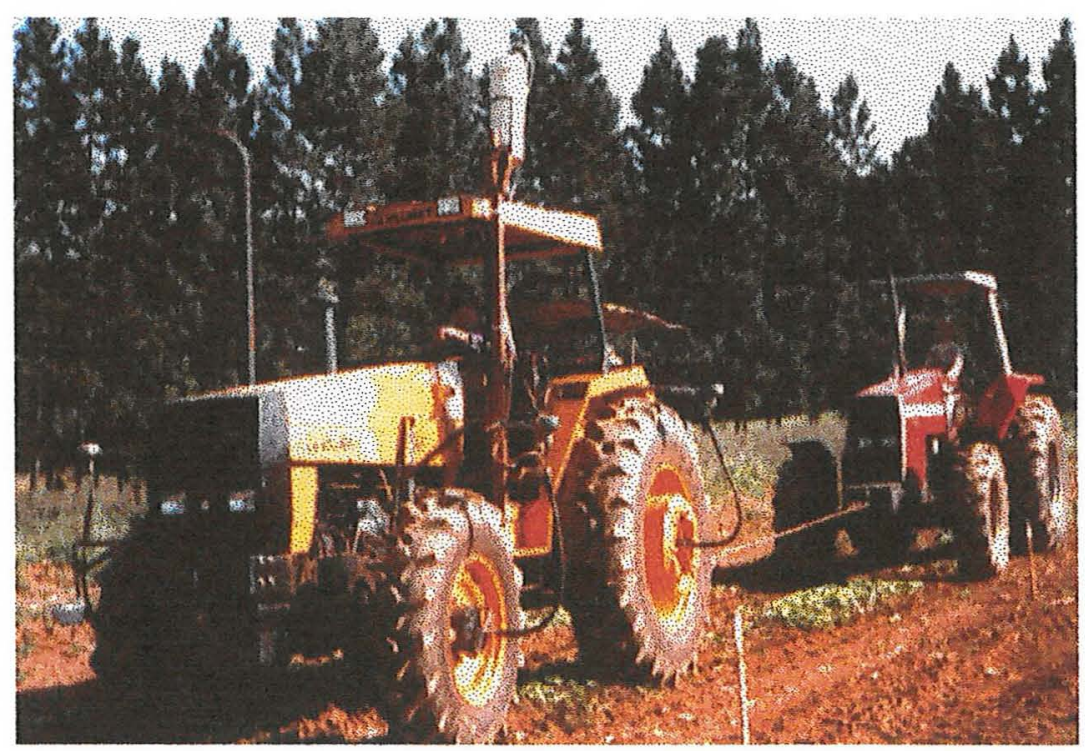

Figura 22: Vista lateral do comboio.

\subsection{3- Avaliação do Rendimento Global do Trator em Campo}

Para a avaliação do comportamento do rendimento (ou eficiência) global do trator foi utilizada a equação 19 , sendo que também foi considerada a simplificação desta equação 19, fixando as restrições nas constantes 5 e 6 iguais à zero, reduzindo o segundo membro a uma elipse, haja visto que o determinante calculado é positivo.

As considerações e os gráficos serão feitos para o modelo simplificado, já que Almeida (1990) mostrou que não há significativa redução da precisão de utilizar o modelo simplificado ao invés do modelo completo.

$\mathrm{O}$ interesse de se utilizar o modelo simplificado (parabolóide-elíptico) se justifica por ser parametrizável, e portanto facilitar na elaboração das curvas de isoconsumo.

Para a construção das curvas de iso-consumo, fez-se uso do software Excel, no qual se montou planilhas para resolução da seguinte equação do segundo 
grau em $\mathrm{F}$, derivada da equação parabolóide-eliptico do rendimento (eq. 19 simplificada):

$$
f_{4} \cdot \mathbf{F}^{2}+\left(f_{2}+f_{8} \cdot V\right) \cdot \mathbf{F}+\left(f_{1}+f_{3} \cdot V+f_{7} \cdot V^{2}-\eta_{t}\right)=0
$$

Portanto, fixando-se uma eficiência $\eta_{\mathrm{t}}$, pode-se montar uma planilha a qual dá como resultado as duas raízes da força para cada velocidade (V), utilizando-se o método de resolução de Báskara.

\subsection{4- Reducão dos Resultados}

O desempenho do motor é sensivelmente influenciado pelas condições atmosféricas, tais como pressão, temperatura, e umidade do ar.

Pelo fato do ensaio ter sido realizado em três dias, e nestes três dias as condições ambientais não terem sido constantes, fez-se a devida alteração através do cálculo do fator de correção, estabelecido pela norma NBR 5484.

Esta correção veio a contribuir para a melhora do ajuste do modelo proposto, e por isso trabalha-se somente com os resultados corrigidos.

\subsection{5- Análise Estatística}

O grau de ajuste dos dados obtidos durante o ensaio de campo às correlações propostas foi avaliado através do coeficiente de determinação múltipla $\mathrm{R}^{2}$ e também pelo teste $F$.

Para tanto, utilizou-se o software estatístico SAS, o qual também forneceu as constantes das correlações propostas. 


\subsection{6- Verificação do Procedimento GUTD}

O procedimento GUTD ("gear up and throttle down" - marcha acima e aceleração reduzida) citado por diversos pesquisadores, foi verificado através do uso das equações de iso-consumo (ou de parâmetros múltiplos) determinadas anteriormente.

Para tanto, foram construídos dois gráficos que representaram o ganho percentual na eficiência pela simples troca de marcha e reposicionamento da alavanca de aceleração da bomba injetora.

Para a troca de marcha do trator Valmet $985 S$ de L2R para L2L, foi construído um gráfico no software Excel, onde estão representadas as curvas de isoganho de eficiência, a curva envoltória da força máxima e as curvas de iso-potência obtidas da marcha L2R. Para a construção da curva envoltória da força máxima, adotou-se a menor das forças dos dados de força máxima das duas marchas envolvidas, para todo intervalo de velocidade, já que este gráfico mostra o campo de possibilidade de aplicação das duas marchas.

A outra possível troca de marcha, e em relação a qual se fez a análise, é de L2L para L3L. O gráfico foi feito da mesma forma que o anterior.

3.17- Análise da Razão Dinâmica de Tracão obtida pelos dados experimentais e pelos $\underline{\text { modelos propostos }}$

Com os dados experimentais e com os de índice de cone da área utilizada durante os ensaios, é possível analisar o comportamento da razão dinâmica de tração do trator, comparando-o com o previsto por modelos propostos por Wismer \& Luth (1972) e Brixius (1987) através da construção de gráficos e pelo cálculo do 
RMS (raiz do quadrado médio), que é uma estimativa do erro global cometido pelo modelo.

Cada modelo proposto foi então comparado com os dados experimentais, utilizando-se da seguinte expressão para o cálculo do RMS:

$$
\mathrm{RMS}=\sqrt{\frac{\sum(\text { Dados Experimentais }- \text { Dados Modelo })^{2}}{\text { Número de Dados }}}
$$




\section{4- RESULTADOS E DISCUSSÃo}

\section{1- Dados Referentes às condicões do Solo}

Os dados referentes às condições do solo estão relacionados nas tabelas $\mathrm{A} 1, \mathrm{~A} 2$ e A3, respectivas à densidade do solo, umidade e resistência à penetração, no anexo $\mathrm{A}$.

Quanto à densidade do solo, esta se manteve estável em todo o campo onde se realizou o ensaio com um valor médio de $1,75 \mathrm{~g} / \mathrm{ml}$ e com um desvio padrão de $0,0664 \mathrm{~g} / \mathrm{ml}$, evidenciando a homogeneidade do solo em questão.

A umidade média do solo em questão encontrava-se num valor aproximado de $19,00 \%$.

Observa-se, dos dados da tabela $\mathrm{A} 3$, que o grau de compactação medido em termos de índice de cone, na média, aumentou significativamente devido à passagem do rodado do trator. Este aumento no índice de cone foi maior para a camada superficial (de 0 a $5 \mathrm{~cm}$ ), e menor para a camada de 10 a $15 \mathrm{~cm}$ de profundidade devido à distribuição de tensões no solo, conforme afirmado por Balastreire (1987).

\section{2- Dados dos Ensaios de Campo}

Nas tabelas B1, B2 e B3, do Anexo B, relacionam-se os dados do ensaio de campo com o Trator Valmet $985 S$. Na tabela B1 estão os dados de calibração da célula de carga, e na tabela B2, os dados referentes à calibração para o 
cálculo do patinamento. $\mathrm{Na}$ tabela $\mathrm{B} 3$, estão relacionados os dados de ensaio propriamente dito.

4.3- Cálculos da Força, Velocidade de Deslocamento, Potência Corrigida, Patinamento e Eficiência Global do Trator $\left(\eta_{t}\right)$.

Com os dados de ensaio, calcularam-se a força, velocidade, potência corrigida, patinamento e eficiência global do trator $\left(\eta_{t}\right)$, relatados na tabela $\mathrm{C} 1$, Anexo $\mathrm{C}$.

$\mathrm{Na}$ tabela C1 (pág. 102), verifica-se que o procedimento adotado de ensaio foi adequado às espectativas do trabalho, já que foi possível impor ao trator ensaiado cargas e patinamentos bem diversos, em um amplo intervalo de velocidades, obtendo-se com isso potências variando de quase zero até a máxima potência possivel de obter em campo (segundo a expressão de Bowers (1978), citado por Khalilian et.al. (1984)), e finalmente uma grande variação na eficiência global do trator, medido em relação à potência na barra de tração. 
4.4- Eficiência Global Reduzida do trator em função das variáveis Forca de Tração (F) e Velocidade de Deslocamento (V).

\subsection{1- Para a Marcha L2R}

A tabela 8 mostra os estimadores dos coeficientes da equação de regressão da eficiência global em relação à velocidade e força. (eq. 19)

Tabela 8: Estimadores dos coeficientes para a marcha L2R

\begin{tabular}{|c|c|c|}
\hline & Parabolóide-elíptica & Completa \\
\hline$f_{1}$ & $-3,77278^{\mathrm{NS}}$ & $-9,24971^{\mathrm{NS}}$ \\
\hline $\mathrm{f}_{2}$ & $0,013238^{*}$ & $0,018959^{* * * *}$ \\
\hline $\mathrm{f}_{3}$ & $8,494547^{* * *}$ & $9,2725^{* * *}$ \\
\hline $\mathrm{f}_{4}$ & $-2.859 \mathrm{E}-6^{*}$ & $-4,239 \mathrm{E}-6^{\mathrm{NS}}$ \\
\hline $\mathrm{f}_{5}$ & -- & $-2,9 \mathrm{E}-10^{\mathrm{NS}}$ \\
\hline $\mathrm{f}_{6}$ & -- & $1,05 \mathrm{E}-13^{\mathrm{NS}}$ \\
\hline $\mathrm{f}_{7}$ & $-1,62982^{* * * *}$ & $-1,64917^{* * * *}$ \\
\hline $\mathrm{f}_{8}$ & $-1.99 \mathrm{E}-4^{\mathrm{NS}}$ & $4,58 \mathrm{E}-4^{\mathrm{NS}}$ \\
\hline $\mathrm{R}^{2}$ & $0,8783^{2}$ & $0,8897^{2}$ \\
\hline
\end{tabular}

onde:

* = significativo, pelo teste $\mathrm{F}, \mathrm{a} 0,1 \%$ de probabilidade.

** = significativo, pelo teste $\mathrm{F}$, a $1,0 \%$ de probabilidade.

*** = significativo, pelo teste $\mathrm{F}$, a $5,0 \%$ de probabilidade.

$* * * *$ = significativo, pelo teste $\mathrm{F}$, a $10 \%$ de probabilidade.

N.S. = não significativo, pelo teste $\mathrm{F}, \mathrm{a} 10 \%$ de probabilidade. 


\subsection{2- Para a Marcha L2L}

A tabela 9 mostra os estimadores dos coeficientes da equação de regressão da eficiência global em relação à velocidade e força. (eq. 19)

Tabela 9: Estimadores dos coeficientes para a marcha L2L

\begin{tabular}{|c|c|c|}
\hline & Parabolóide-elíptica & Completa \\
\hline $\mathrm{f}_{1}$ & $-6,401281^{\text {NS }}$ & $-5,607138^{\mathrm{NS}}$ \\
\hline $\mathrm{f}_{2}$ & $0,015954^{*}$ & $0,012150^{\mathrm{NS}}$ \\
\hline $\mathrm{f}_{3}$ & $8,392981^{* * *}$ & $8,167600^{* * *}$ \\
\hline $\mathrm{f}_{4}$ & $-0,000003557^{*}$ & $0,000002358^{\mathrm{NS}}$ \\
\hline $\mathrm{f}_{5}$ & -- & $-2,831608 \mathrm{E}-9^{\mathrm{NS}}$ \\
\hline $\mathrm{f}_{6}$ & -- & $4,197906 \mathrm{E}-13^{\mathrm{NS}}$ \\
\hline $\mathrm{f}_{7}$ & $-1,228270^{* * *}$ & $-1,188038^{* * *}$ \\
\hline $\mathrm{f}_{8}$ & $-0,000235^{\mathrm{NS}}$ & $-0,000286^{\mathrm{NS}}$ \\
\hline $\mathrm{R}^{2}$ & 0,8831 & $0,8882^{2}$ \\
\hline
\end{tabular}

onde:

* = significativo, pelo teste $\mathrm{F}, \mathrm{a} 0,1 \%$ de probabilidade.

** = significativo, pelo teste $\mathrm{F}$, a $1,0 \%$ de probabilidade.

*** = significativo, pelo teste $\mathrm{F}$, a $5,0 \%$ de probabilidade.

$* * * *$ = significativo, pelo teste $\mathrm{F}$, a $10 \%$ de probabilidade.

N.S. = não significativo, pelo teste $\mathrm{F}$, a $10 \%$ de probabilidade. 


\subsection{3- Para a Marcha L3L}

A tabela 10 mostra os estimadores dos coeficientes da equação de regressão da eficiência global em relação à velocidade e força. (eq. 19)

Tabela 10: Estimadores dos coeficientes para a marcha L3L

\begin{tabular}{|c|c|c|}
\hline & Parabolóide-elíptica & Completa \\
\hline $\mathrm{f}_{1}$ & $0,496158^{\mathrm{NS}}$ & $0,71014^{\mathrm{NS}}$ \\
\hline $\mathrm{f}_{2}$ & $0,012148^{*}$ & $0,027151^{* * *}$ \\
\hline $\mathrm{f}_{3}$ & $4,47102^{\mathrm{NS}}$ & $2,024510^{\mathrm{NS}}$ \\
\hline $\mathrm{f}_{4}$ & $-0,000002869^{*}$ & $-0,000013977^{\mathrm{NS}}$ \\
\hline $\mathrm{f}_{5}$ & -- & $2,328305 \mathrm{E}-9^{\mathrm{NS}}$ \\
\hline $\mathrm{f}_{6}$ & -- & $-4,50513 \mathrm{E}-14^{\mathrm{NS}}$ \\
\hline $\mathrm{f}_{7}$ & $-0,464308^{* * *}$ & $-0,245241^{\mathrm{NS}}$ \\
\hline $\mathrm{f}_{8}$ & $0,000008212^{\mathrm{NS}}$ & $0,000230^{\mathrm{NS}}$ \\
\hline $\mathrm{R}^{2}$ & $0,7912^{2}$ & 0,8451 \\
\hline
\end{tabular}

onde:

$$
\begin{aligned}
& * \quad=\text { significativo, pelo teste } \mathrm{F}, \text { a } 0,1 \% \text { de probabilidade. } \\
& * * \quad=\text { significativo, pelo teste } \mathrm{F}, \text { a } 1,0 \% \text { de probabilidade. } \\
& * * * \quad=\text { significativo, pelo teste } \mathrm{F}, \text { a } 5,0 \% \text { de probabilidade. } \\
& * * * * \quad=\text { significativo, pelo teste } \mathrm{F}, \text { a } 10 \% \text { de probabilidade. } \\
& \text { N.S. } \quad=\text { não significativo, pelo teste } \mathrm{F}, \text { a } 10 \% \text { de probabilidade. }
\end{aligned}
$$

Conclui-se então que:

a) os tipos de correlação parabolóide-eliptica e completa foram significativas, pelo teste $\mathrm{F}$, à $0,1 \%$ de probabilidade, para todas as três marchas adotadas no trator ensaiado, apesar dos seus coeficientes estimados não apresentarem necessariamente esta significância, o que comprova que o modelo adotado é adequado ao tipo de 
comportamento apresentado pelo trator em solo agrícola com as características mencionadas;

b) os coeficientes do modelo parabolóide-eliptico apresentam-se, na maioria das vezes, com uma maior significância que os coeficientes do modelo completo, contudo o coeficiente de determinação múltipla $\left(\mathrm{R}^{2}\right)$ do modelo completo é, em todos os casos, maior que do modelo simplificado (parabolóide-eliptico);

c) a precisão da correlação é considerada boa, desde que o coeficiente de correlação $\left(R^{2}\right)$ encontra-se entre 0,791 e 0,888 . Comparando com os estudos já realizados por Almeida (1990) e Lima (1993), estes valores são menores que os obtidos;

d) o estimador $f_{7}$ da equação 19 foi significativo na maioria da vezes (se não para o modelo completo, no modelo simplificado parabolóide-eliptico se mostrava significativo ao nível de $10 \%$ para a marcha $\mathrm{L} 2 \mathrm{R}$ e a $5 \%$ para as marchas $\mathrm{L} 2 \mathrm{~L}$ e $\mathrm{L} 3 \mathrm{~L}$ ). Isto significa que o ângulo de rotação da elipse sobre o plano cartesiano é significativo.

4.5- Estimadores dos coeficientes das equacões envoltórias de forca em funcão da velocidade, para as diversas marchas utilizadas.

As equações utilizadas para descrever a força máxima em função da velocidade de deslocamento do trator são as equações 20 (para o motor trabalhando na região do regulador) e 21 (para o motor trabalhando fora do regulador). 
Os coeficientes encontrados para cada marcha utilizada estão apresentados na tabela 11 .

Tabela 11: Coeficientes das equações envoltórias de força em função da velocidade, para as diversas marchas utilizadas.

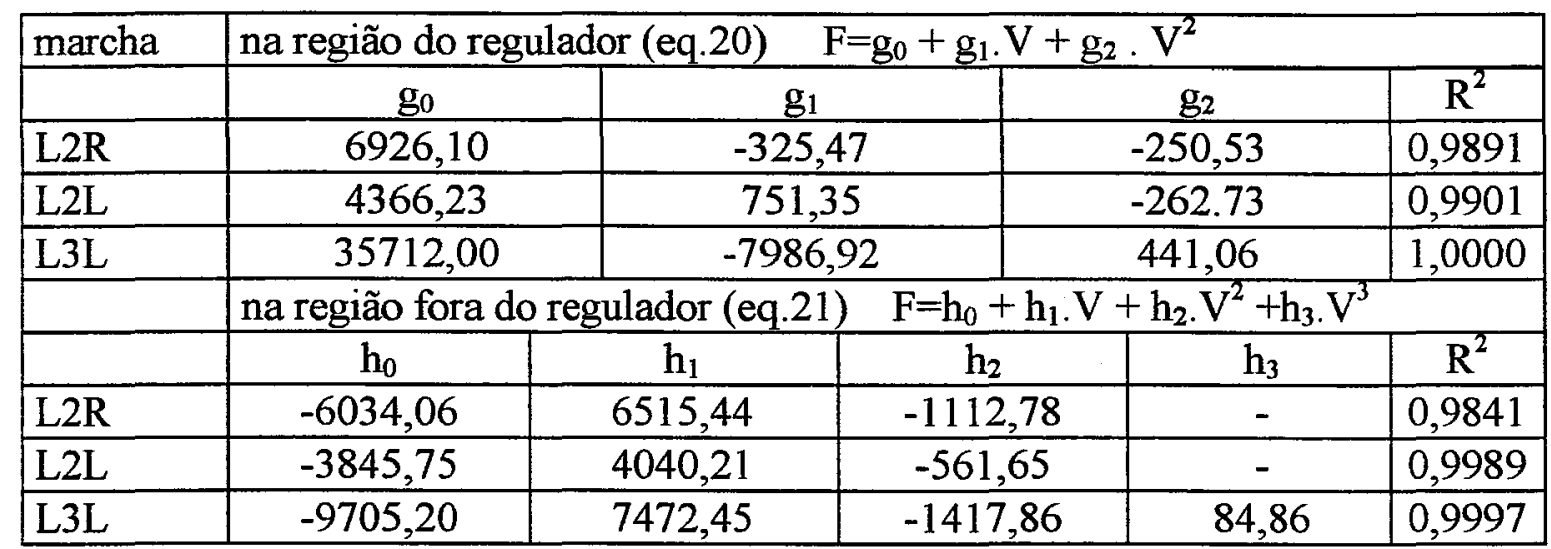

\section{6- Curvas de Iso-Consumo ou de Parâmetros Múltiplos.}

Com os valores dos estimadores dos coeficientes da equação 19 , construíram-se as seguintes curvas de iso-consumo, para cada marcha adotada durante o ensaio, fazendo-se uso dos modelo simplificado (parabolóide-eliptico), envolvendo as variáveis força de tração e velocidade de deslocamento.

Em todas as figuras, apresentam-se a linha de máxima força disponível para cada velocidade desenvolvida, as curvas de iso-potência (em termos de porcentagem da potência máxima atingida) e as curvas de iso-consumo ou isoeficiência.

Nestas figuras observa-se sempre uma região ótima de trabalho, definida como a região de mínimo consumo específico de combustível. 


\subsection{1- Curva de Iso-Consumo do Trator para a marcha L2R.}

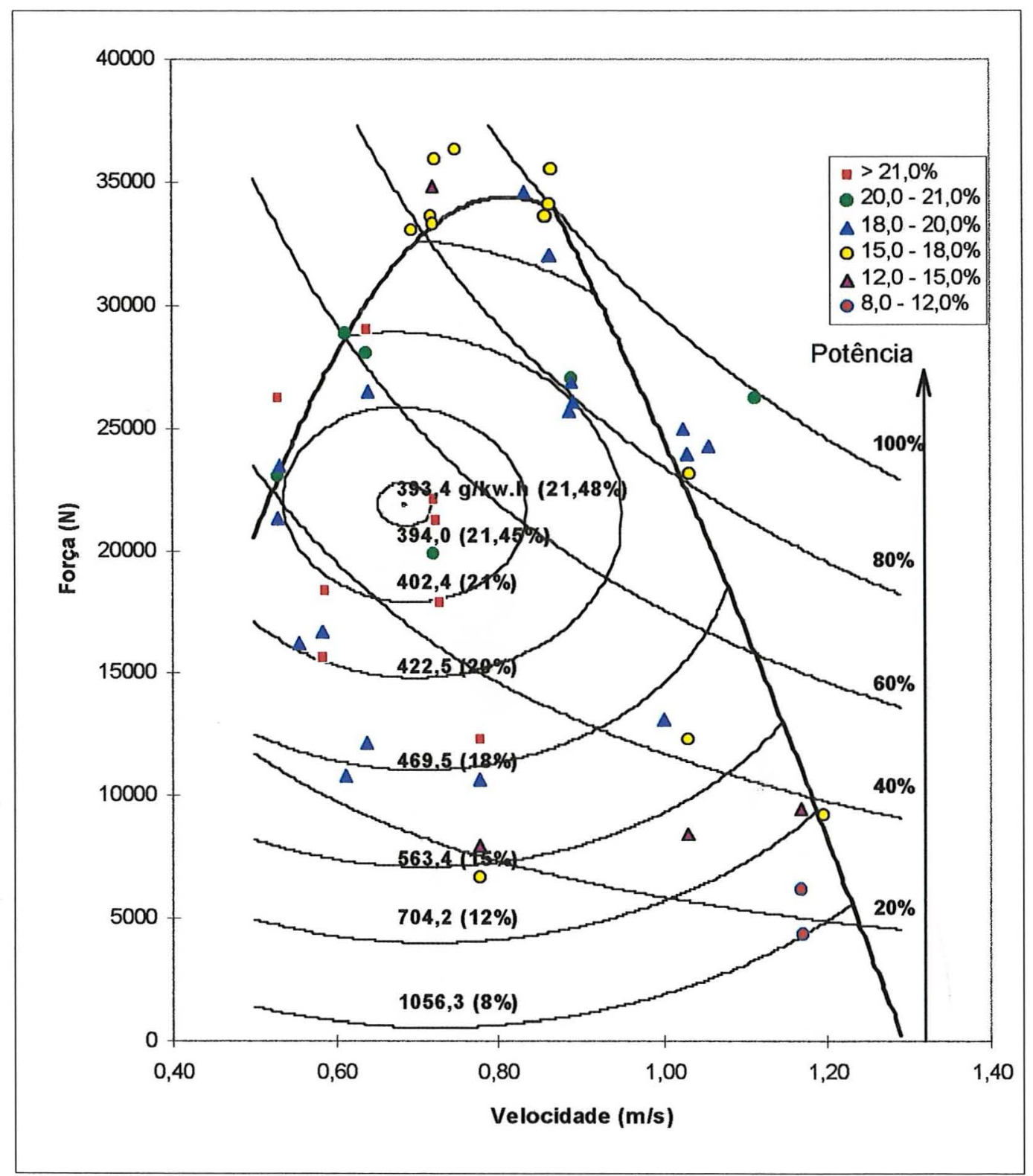

Figura 23: Curva de iso-consumo específico do trator operando em solo agrícola, em função da força na barra de tração e velocidade de deslocamento, para a marcha $L 2 R$, e os pontos experimentais obtidos dos ensaios. 


\subsection{2- Curva de Iso-Consumo do Trator para a marcha L2L}

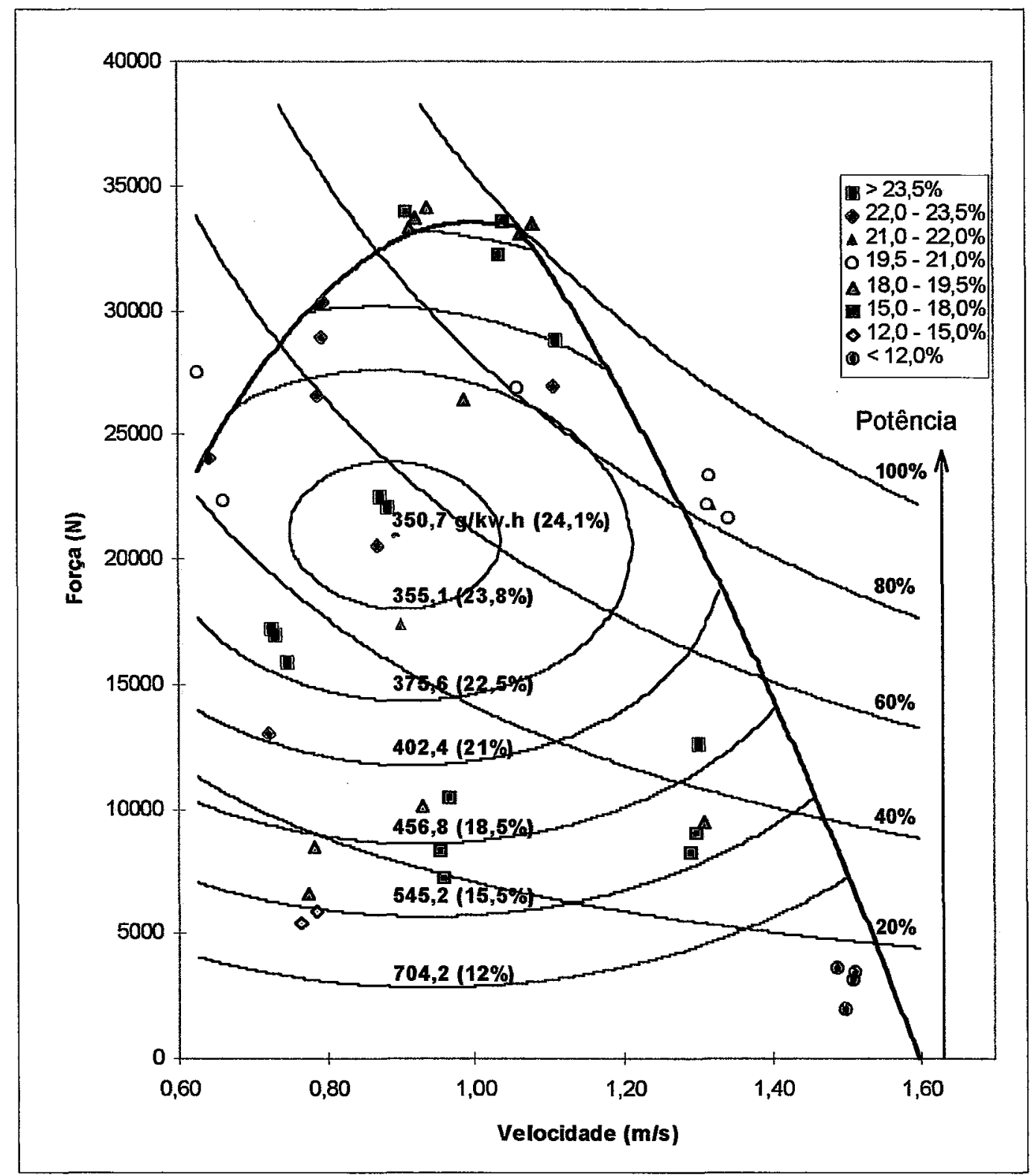

Figura 24: Curva de iso-consumo específico do trator operando em solo agrícola, em função da força na barra de tração e velocidade de deslocamento, para a marcha $L 2 L$, e os pontos experimentais obtidos dos ensaios. 
4.6.3- Curva de Iso-Consumo do Trator para a marcha L3L

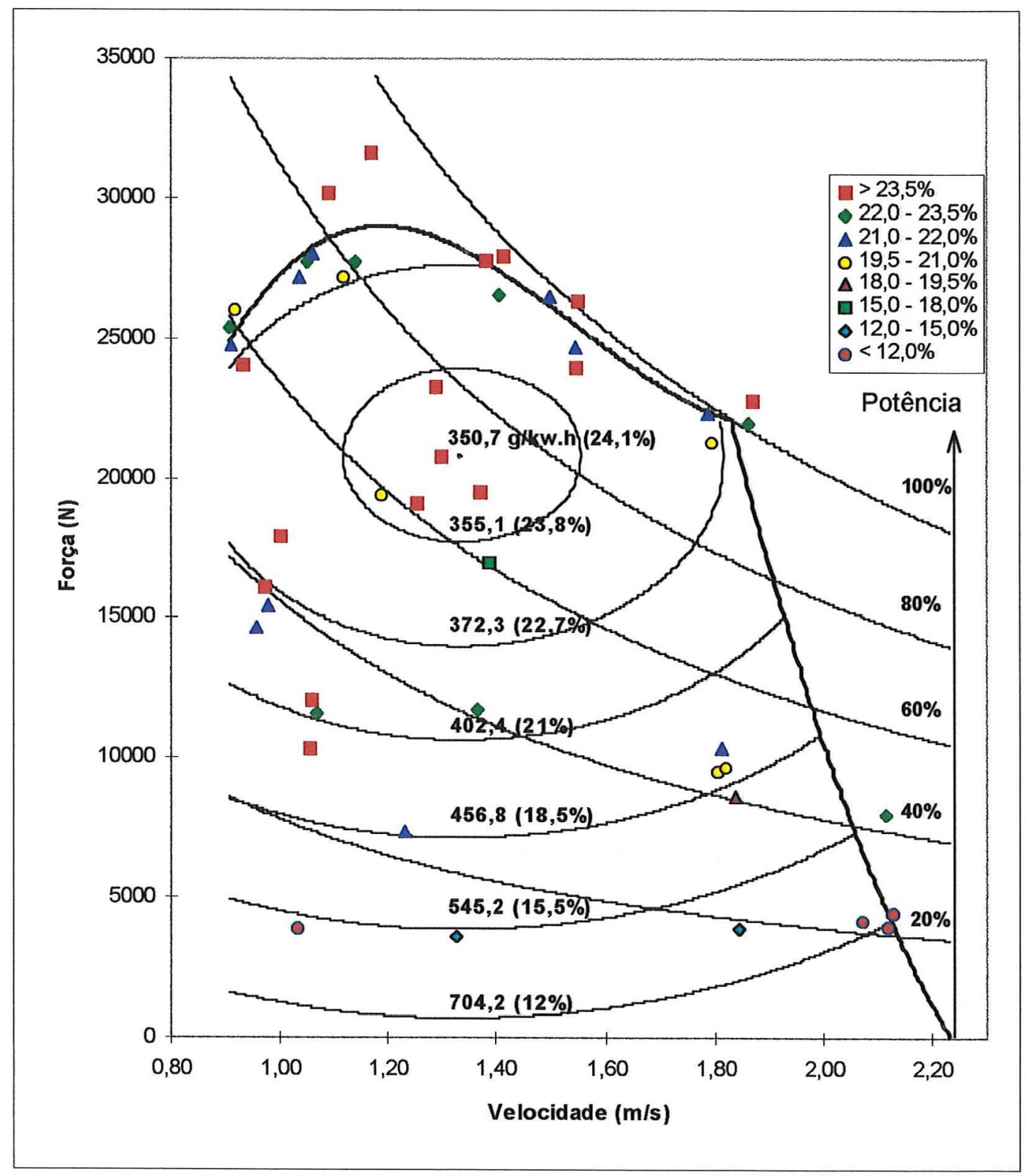

Figura 25: Curva de iso-consumo específico do trator operando em solo agrícola, em função da força na barra de tração e velocidade de deslocamento, para a marcha L3L, e os pontos experimentais obtidos dos ensaios. 
Observa-se, das figuras 23, 24 e 25, que a eficiência global do trator em operação sobre solo agrícola varia em função da combinação da velocidade de deslocamento e força de tração, e que para cada marcha adotada, existe uma combinação destes dois fatores que resulta na maximização desta eficiência.

Para a marcha L2R, a eficiência máxima obtida é de $21,48 \%$, e ocorre na combinação de $21895,9 \mathrm{~N}$ e $0,68 \mathrm{~m} / \mathrm{s}$; para a marcha $\mathrm{L} 2 \mathrm{~L}$, a eficiência máxima é de $24,1 \%$, na combinação de $20993,4 \mathrm{~N}$ e $0,89 \mathrm{~m} / \mathrm{s}$; para a marcha $\mathrm{L} 3 \mathrm{~L}, 24,1 \%$ à $20895,3 \mathrm{~N}$ e $1,34 \mathrm{~m} / \mathrm{s}$.

Observa-se que os pontos experimentais obtidos durante os ensaios, os quais foram utilizados para a determinação das curvas de iso-consumo, plotados juntamente com as curvas segundo as respectivas marchas utilizadas, encontram-se bem distribuídos em todo campo de utilização do trator (força e velocidade), sendo por isso realizada a intenção apresentada na metodologia em atingir todos os pontos operacionais do trator, e mais ainda, em alcançar uma variada gama de consumo específico (e portanto rendimento), conforme visto nestas figuras 23, 24 e 25 . Observa-se, também, que os pontos experimentais estão distribuídos, segundo o rendimento que cada um apresentou, conforme as curvas de iso-consumo obtidas.

Conclui-se destes dados que a eficiência máxima ocorre sempre a um nível determinado de força tratória, devido às condições de tração apresentadas pelo solo, e onde justamente ocorre o patinamento ao redor de 10 a $15 \%$.

\section{7-Curvas de Ganho de Eficiência Global do Trator na Troca de Marchas} (procedimento GUTD "Gear-Up and Throttle Down"- marcha acima e rotacão reduzida).

As curvas apresentadas nas figuras 27 e 29 são caracterizadas pelo ganho percentual na eficiência global do trator (e conseqüente redução do consumo especifico) ao se realizar a troca de marchas e redução de rotação do motor. Foram construídas tomando-se como base a equação 19 simplificada e os coeficientes 
determinados pela análise estatística. Nesta figuras 27 e 29 também estão representadas as curvas de iso-potência, sendo a porcentagem da potência máxima desenvolvida pela marcha mais reduzida do par estudado em cada caso.

\subsection{1- Troca da Marcha L2R para L2L}

A troca de marcha da $\mathrm{L} 2 \mathrm{R}$ para a $\mathrm{L} 2 \mathrm{~L}$ só pode ser executada na área de operação comum às duas marchas, como indicada na figura 26 .

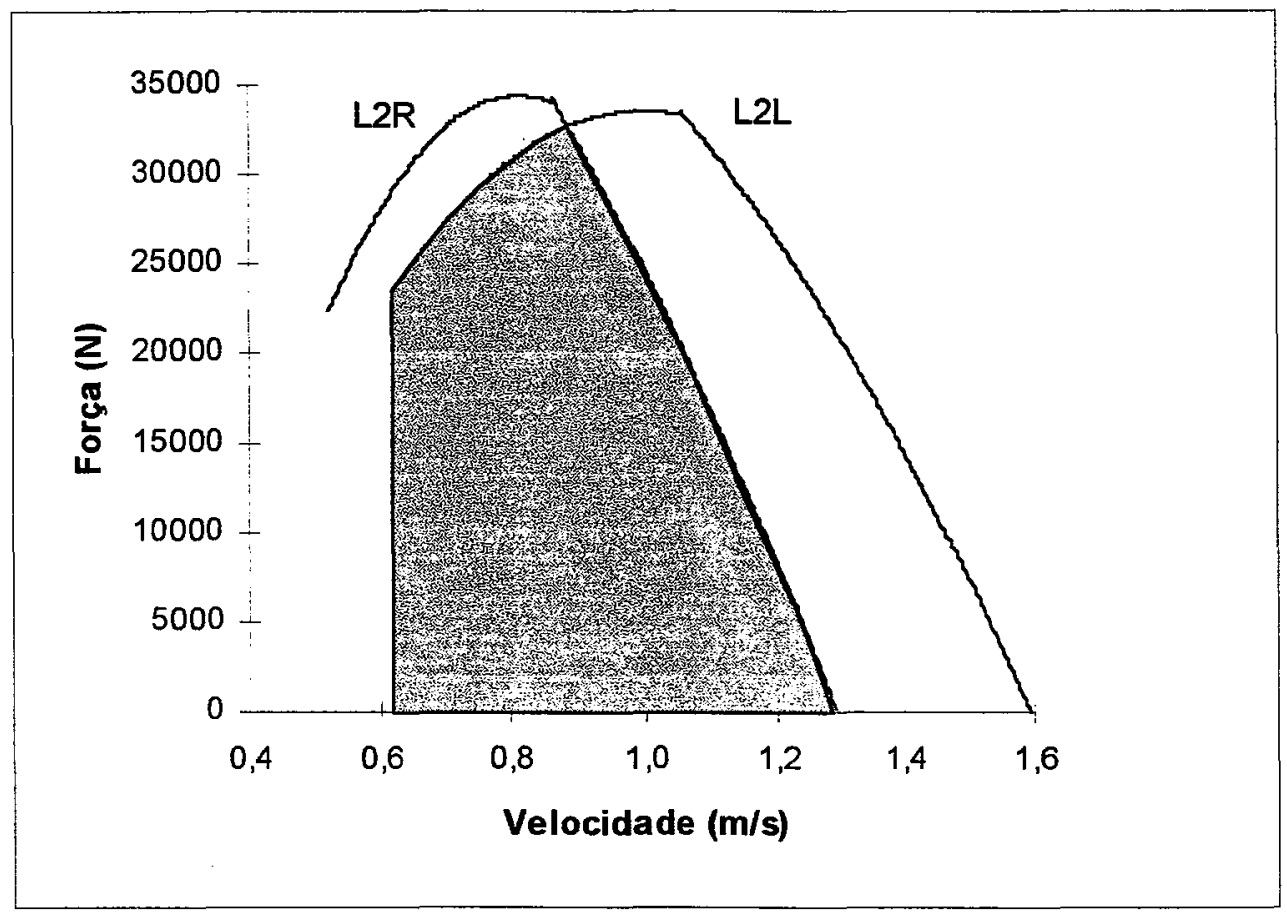

Figura 26: Indicação da área onde se pode realizar a troca de marchas de L2R para L2L - área hachuriada.

A figura 27 indica o ganho percentual na eficiência global ao se realizar a troca de marchas de $\mathrm{L} 2 \mathrm{R}$ para $\mathrm{L} 2 \mathrm{~L}$ e conseqüente redução da aceleração do motor para obter a mesma combinação de operação (força e velocidade). 


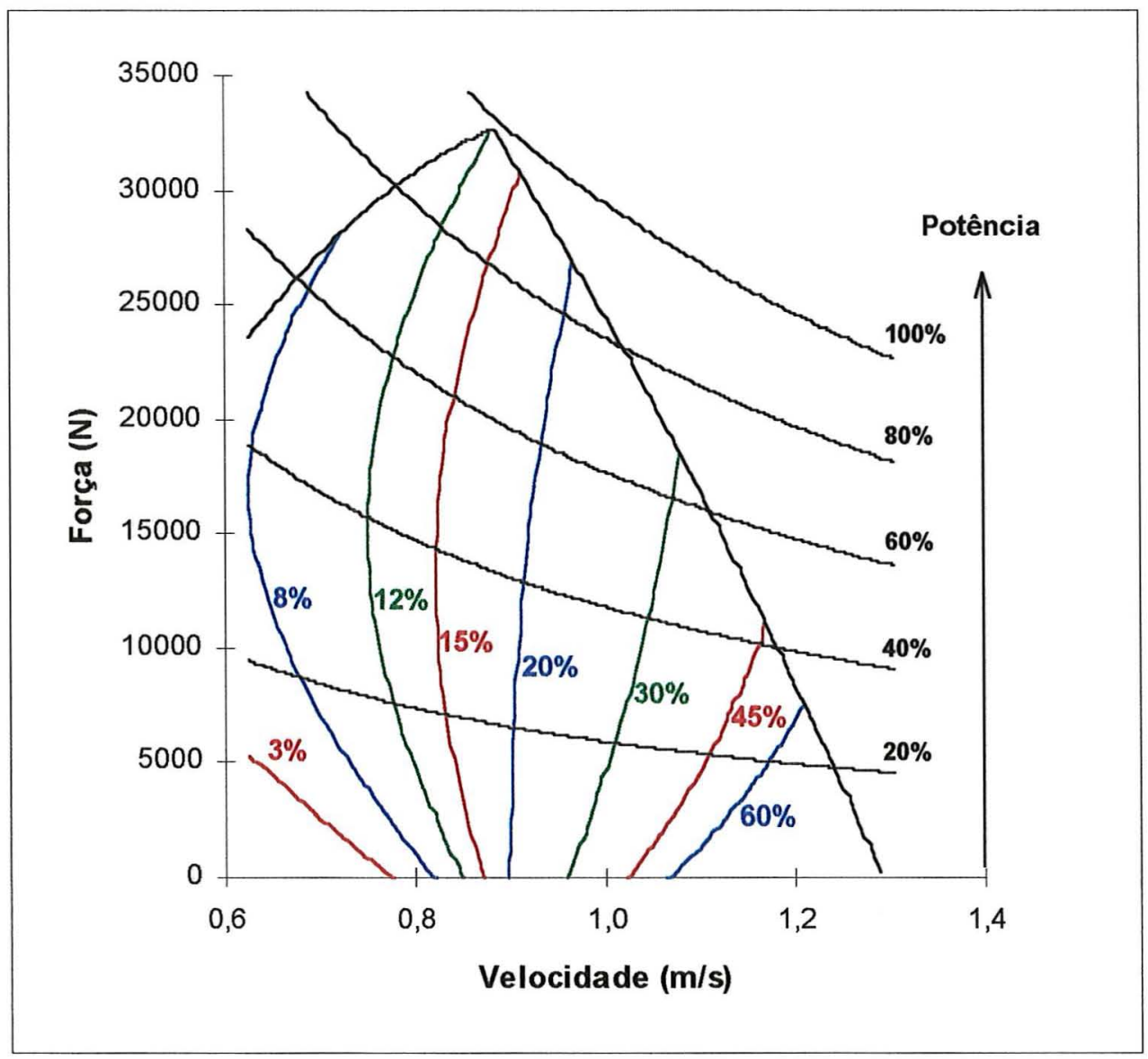

Figura 27: Curvas de iso-ganho de eficiência global do trator, na mudança da relação de transmissão de L2R para L2L. (as curvas de iso-potência são referentes ao trator operando na marcha L2R).

Como é possível observar, pode-se ter um ganho de 3 até $60 \%$ na eficiência global do trator pela simples troca de marchas, dependendo de sua região de trabalho (combinação de força na barra de tração e velocidade de deslocamento). Por exemplo, com o trator trabalhando a uma velocidade de $1,1 \mathrm{~m} / \mathrm{s}$ e fazendo uma força média de $15000 \mathrm{~N}$, na marcha L2R apresentará uma eficiência de $16,66 \%$, e na 
marcha $\mathrm{L} 2 \mathrm{~L}$, de $22,23 \%$, ou seja, um ganho de $33,43 \%$ na eficiência global do trator, como mostrado nesta figura 27.

\subsection{2- Troca da Marcha L2L para L3L}

A troca de marcha da $\mathrm{L} 2 \mathrm{~L}$ para a $\mathrm{L} 3 \mathrm{~L}$, de maneira idêntica a descrita no item 4.6.1, só pode ser executada na área de operação comum às duas marchas, como indicada na figura 28.

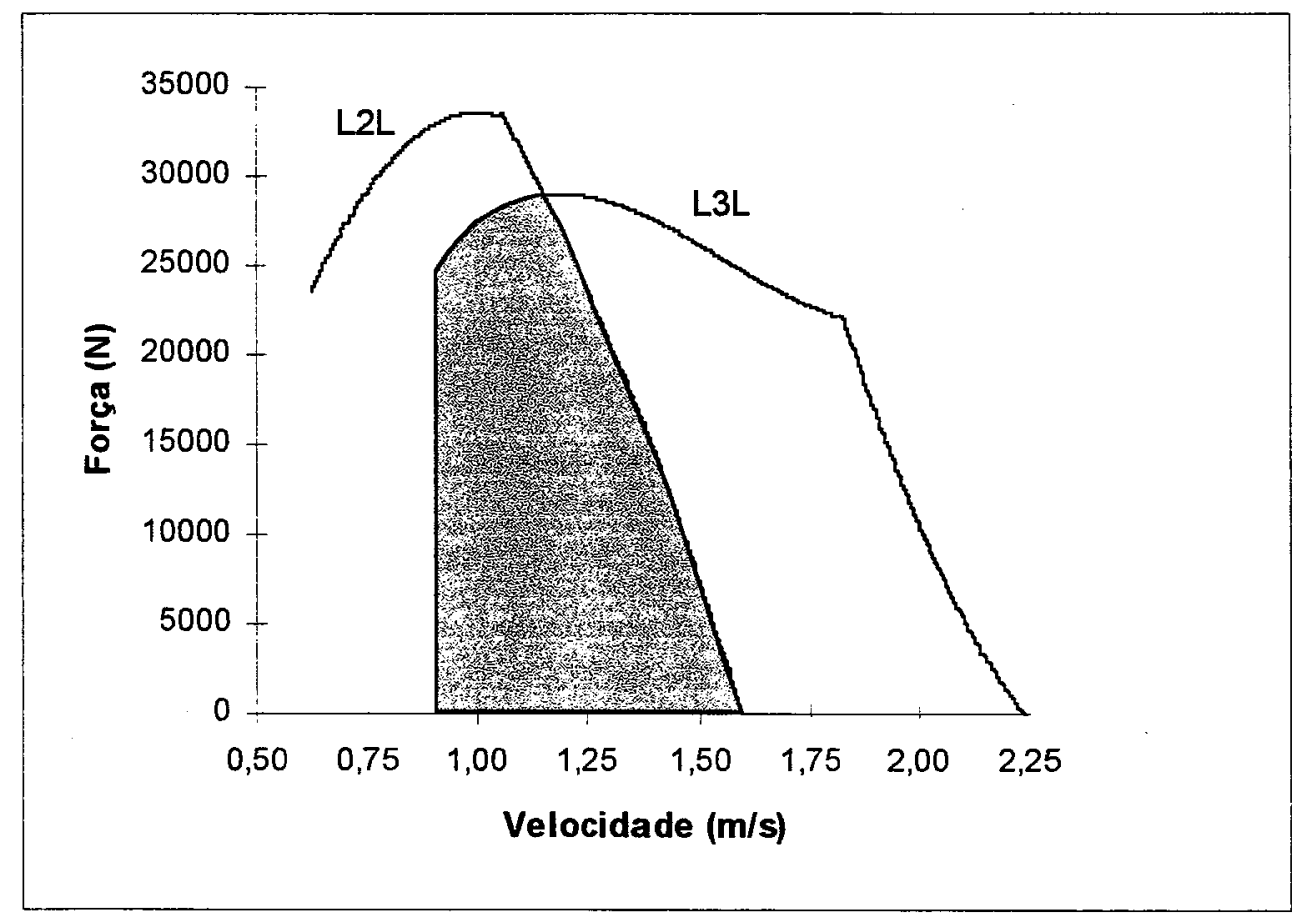

Figura 28: Indicação da área onde se pode realizar a troca de marchas de L2L para L3L - área hachuriada.

A figura 29 indica o ganho percentual de eficiência global ao se realizar a troca de marchas da L2L para a L3L, correspondente à área hachuriada da figura 28 . 


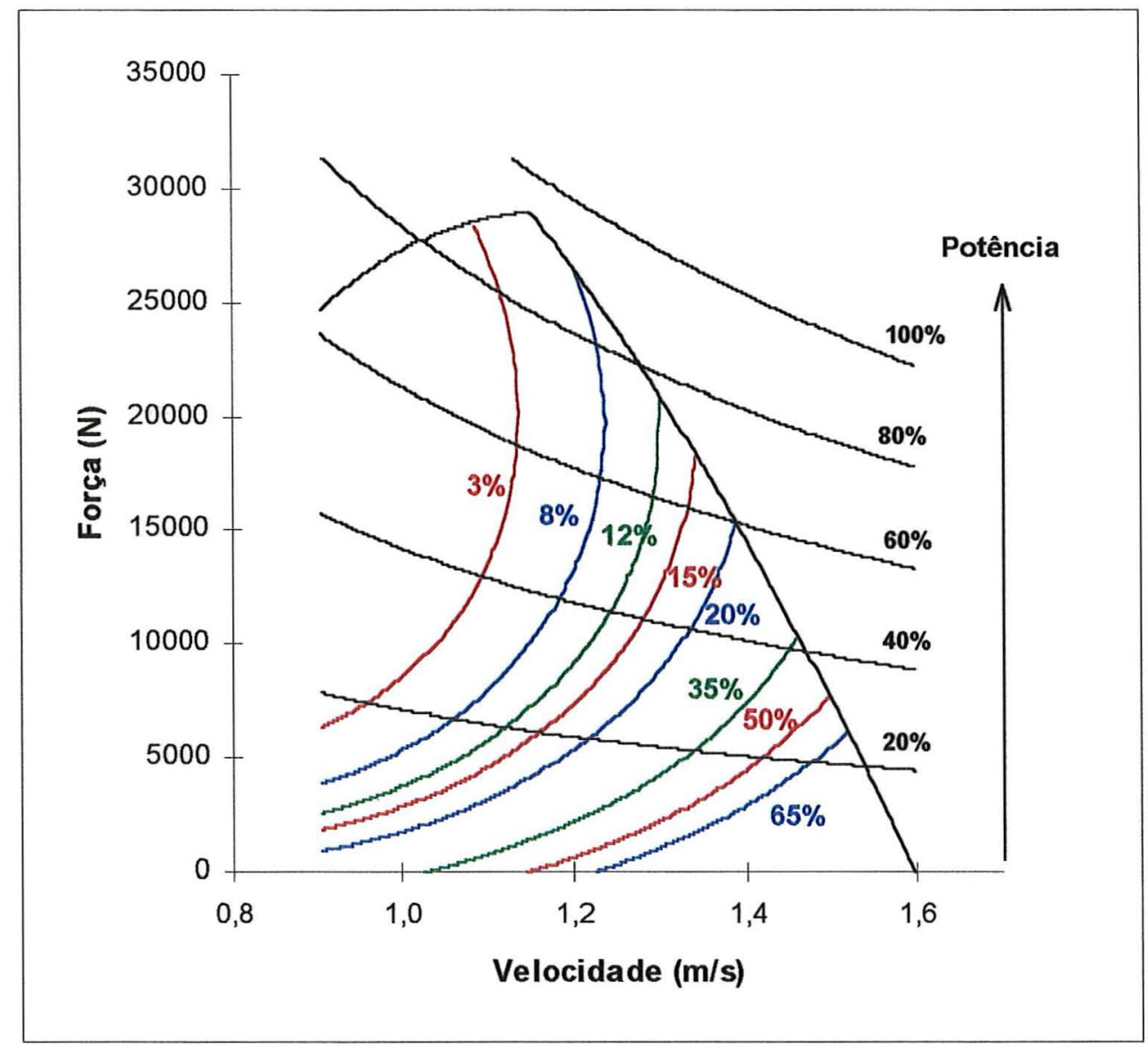

Figura 29: Curvas de iso-ganho de eficiência global do trator, na mudança da relação de transmissão de L2L para L3L. (as curvas de iso-potência são referentes ao trator operando na marcha L2L).

Da mesma forma que no caso anterior, é possível observar que se pode ter um ganho de 3 até $65 \%$ na eficiência global do trator pela simples troca de marchas de L2L para L3L (pode-se atingir maiores ganhos, porém em condições muito específicas de trabalho), dependendo de sua região de trabalho (combinação de força na barra de tração e velocidade de deslocamento). Por exemplo, com o trator trabalhando a uma velocidade de $1,2 \mathrm{~m} / \mathrm{s}$ e fazendo uma força média de $22000 \mathrm{~N}$, na marcha L2L apresentará uma eficiência de $22,55 \%$, e na marcha $\mathrm{L} 3 \mathrm{~L}$, de $24,04 \%$, ou 
seja, um ganho de $6,62 \%$ na eficiência global do trator, como mostrado nesta figura 29.

Das figuras 27 e 29, as quais mostram o ganho percentual na eficiência global do trator durante a troca de marchas $\mathrm{L} 2 \mathrm{R}$ para $\mathrm{L} 2 \mathrm{~L}$ e $\mathrm{L} 2 \mathrm{~L}$ para $\mathrm{L} 3 \mathrm{~L}$, respectivamente, observa-se que a percentagem de ganho não é apenas função da percentagem de potência utilizada do trator na barra de tração, como afirmado por Schrock et.al. (1986), mas também da combinação da velocidade de deslocamento e força de tração. Tomando-se como exemplo a figura 27 e uma demanda de potência de 60\% da máxima (potência normalmente utilizada, segundo Larsen (1980)), na troca de marcha L2R para L2L pode-se obter uma economia variando desde $8 \%$ até $35 \%$, função da combinação de força e velocidade.

Analisando-se as relações de transmissão e a troca de marchas, e ainda sendo que a relação de transmissão da marcha L2R é 1:179,72, da marcha L2L é $1: 148,16$ e da marcha $\mathrm{L} 3 \mathrm{~L}$ é $1: 104,49$, ao realizar-se a troca da marcha $\mathrm{L} 2 \mathrm{R}$ para $\mathrm{L} 2 \mathrm{~L}$ tem-se uma variação na relação de transmissão de $17,56 \%$, e ao realizar-se a troca da marcha L2L para L3L tem-se uma variação na relação de transmissão de $29,47 \%$. Estas porcentagens diferentes exercem significativa influência no ganho de eficiência global durante as trocas de marchas, e ficam melhor evidenciadas nas figuras 26 e 28 , já que a primeira mostra uma maior intersecção das áreas possiveis de trabalho das duas marchas envolvidas, e na segunda figura esta intersecção é menor.

Hermann et.al. (1982), afirmam que uma boa relação de transmissão ocorre quando a razão das velocidades máximas de duas marchas consecutivas está entre 1,1 e 1,2, como é o caso da troca $\mathrm{L} 2 \mathrm{R}$ para $\mathrm{L} 2 \mathrm{~L}$, mas não da $\mathrm{L} 2 \mathrm{~L}$ para a $\mathrm{L} 3 \mathrm{~L}$, sendo que neste trabalho, o trator ensaiado apresenta uma marcha intermediária entre L2L e L3L (L3R), mas que não foi utilizada para que esta análise também fosse possível de ser feita.

Portanto, fazendo-se uma melhor análise das figuras 27 e 29, observa-se que as suas curvas de iso-ganho de eficiência são visualmente diferentes. $\mathrm{Na}$ figura 27, observa-se que há um ganho percentual significativo na eficiência global mesmo 
quando utiliza-se uma grande porcentagem da potência máxima (por exemplo, a 80\% de potência máxima obtida na marcha $L 2 R$, pode-se obter um aumento na eficiência de até $24,24 \%$ na troca de marchas). Na figura 29 , este fato não ocorre; a elevadas porcentagens de potência, o ganho percentual não é tão elevado quanto na figura 27 (por exemplo, a $80 \%$ de potência máxima obtida na marcha $\mathrm{L} 2 \mathrm{~L}$, pode-se obter um aumento na eficiência de até 10,7\%, ganho menor que o anterior, ou mesmo trabalhando a $80 \%$ da potência máxima desenvolvida na marcha $L 2 R$, o que corresponde a $67 \%$ da marcha $\mathrm{L} 2 \mathrm{~L}$, o ganho não passa de $16,19 \%$ ). Contudo, a baixas exigências de potência e elevadas velocidades, o fato se inverte, com a troca de marcha de marcha de L2L para L3L sendo mais favorável que para o caso da troca L2R para L2L. Estes fatos ocorrem principalmente por dois motivos: a eficiência global máxima do trator ensaiado na marcha L2R é menor que nas outras duas marchas, e as relações de marcha L2R e L2L são mais próximas quando comparadas com a L2L e L3L, principalmente.

4.8-Comparacão dos modelos propostos da razão dinâmica de tração com os dados experimentais.

Foram utilizados dois modelos empíricos de simulação da razão dinâmica de tração para comparação com os dados experimentais. Os modelos adotados foram de Wismer \& Luth 1972) e de Brixius (1987).

$\mathrm{Na}$ figura 30 observa-se a disposição gráfica das curvas da razão dinâmica de tração plotadas em função do patinamento, através da aplicação dos métodos empíricos e do modelo adotado dos pontos experimentais, sendo este descrito pela expressão: $\mathrm{RDT}=0,04172 . \mathrm{s}^{(1,35173-0,35289 \cdot \log (s))}$, com um coeficiente de correlação múltipla $\left(\mathbf{R}^{2}\right)$ de 0,9622 . 


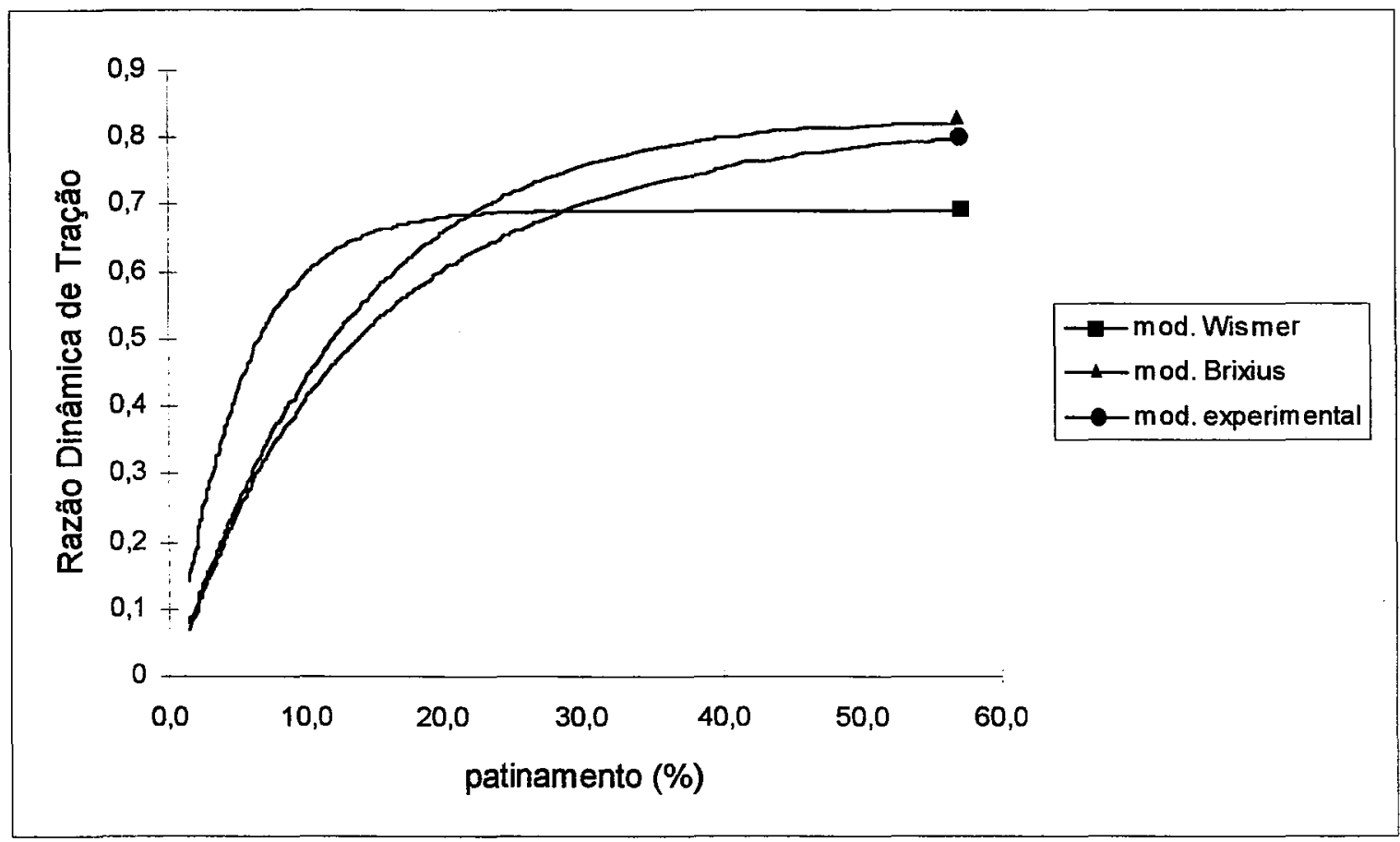

Figura 30: Comparação das curvas obtidas através da aplicação dos métodos empíricos com os pontos experimentais.

Pela análise do RMS (raiz do quadrado médio), observa-se que este assumiu valores de $13,18 \%$ e $3,76 \%$ comparando o modelo experimental com os modelos de Wismer \& Luth (1972) e de Brixius (1987), respectivamente.

Quanto à eficiência tratória, observa-se da figura 31 o seu aumento até $10 \%$ de patinamento, com uma posterior queda, vindo de acordo com que se observa na bibliografia. 


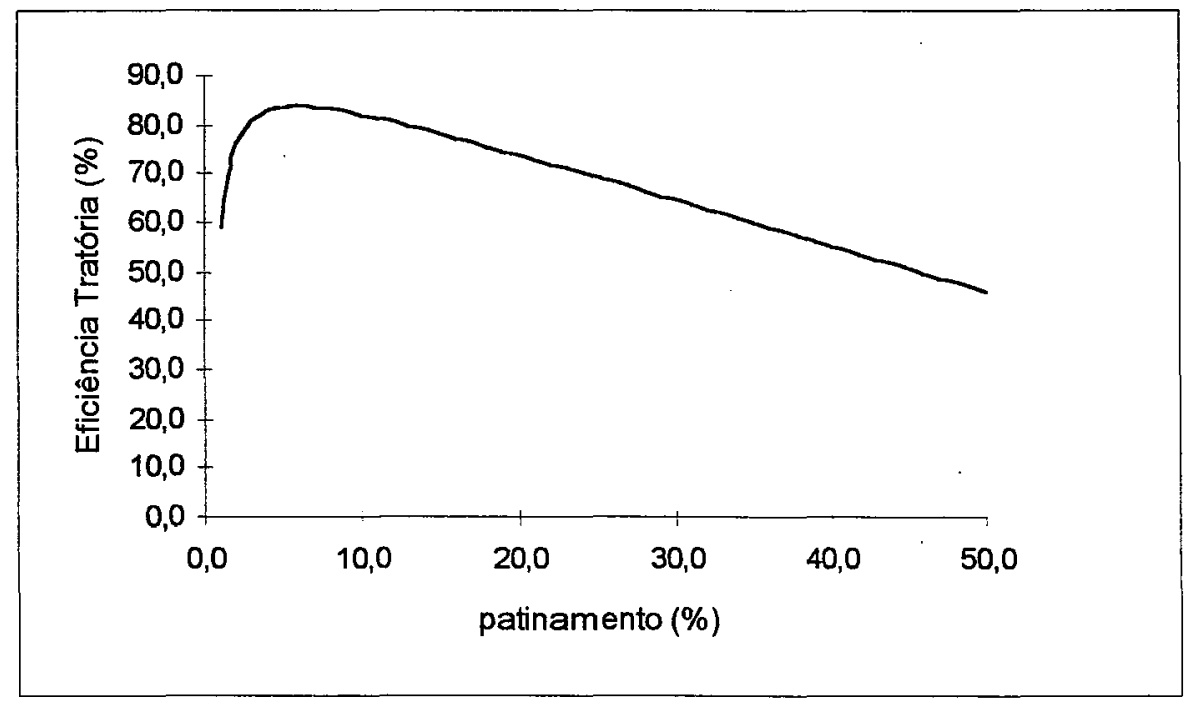

Figura 31: Eficiência tratória em função do patinamento das rodas do trator.

Este fato vem de encontro ao afirmado por Steinkampf (1981), que comprovou que o rendimento de tração é maximizado quando se atinge um patinamento de aproximadamente $10 \%$, sendo reduzido para patinamento menores ou maiores que este valor. 


\section{5- CONCLUSÕES}

1- A modelagem matemática adotada neste trabalho para a determinação da eficiência global do trator operando sobre solo agrícola (condições de campo) em função da velocidade de deslocamento e força de tração, mostrou ser adequada uma vez que foi significativa pelo teste $\mathrm{F}$ a $0,1 \%$ de significância;

2- A metodologia adotada durante os ensaios, número de repetições, condição de aplicação da carga no trator ensaiado e outras condições supra-citadas, foram adequadas para atender às exigências da modelagem matemática;

3- O modelo simplificado da equação $19\left\{\eta_{\mathrm{t}}=\mathrm{fç}(\mathrm{F}, \mathrm{V})\right\}$ (parabolóide-eliptico) mostrou ser adequado para a explicação da eficiência global do trator, e mais fácil de se trabalhar, tendo em vista de ser parametrizável ou ser transformado numa simples equação de segundo grau em $\mathrm{F}$, a qual torna simples a representação gráfica bidimensional, sem perda apreciável de precisão;

4- $\mathrm{O}$ coeficiente de correlação $\left(\mathrm{R}^{2}\right)$ foi significativamente menor que os encontrados por outros autores supra-citados, devido às condições variáveis não constatadas, como por exemplo, variação nas condições do solo;

5- Das curvas de iso-consumo em função da velocidade e força (figuras 23,24 e 25), observa-se que para otimizar o consumo de combustivel para o trator em trabalho sobre solo agrícola, deve-se trabalhar na região de mais baixo consumo específico, para qualquer marcha adotada, região esta localizada no interior das elipses que representam o menor consumo específico de combustível; 
6- O procedimento GUTD ("gear up and throttle down") é um ótimo conceito operacional visando a economia quando o critério é a redução no consumo de combustível, com resultados numéricos parecidos com os que os pesquisadores mencionados já obtiveram, e portanto deveria ser amplamente divulgado no meio rural;

7- Os tratores deveriam ter um número mínimo de marchas à frente muito bem escalonadas seguindo o critério de Hermann et.al. (1982), sendo que o maior número delas deveria estar concentrada na região de utilização de máxima potência, favorecendo a aplicação do procedimento GUTD;

8- Nas condições do estudo, o modelo de razão dinâmica de tração proposto por Brixius (1987) se aproximou mais do modelo experimental do que o modelo proposto por Wismer \& Luth (1972).

\section{RECOMENDAÇÕES PARATRABALHOS FUTUROS}

1- Construção de um indicador de marchas para adaptação em qualquer trator, sem a necessidade de serem feitos ensaios preliminares, e verificação de sua aplicabilidade e viabilidade durante o uso em campo;

2- Construção de um sistema eletro-hidráulico para a troca mecânica automática de marchas, visando a aplicação do procedimento GUTD, com posteriores ensaios padronizados e testes estatísticos. Utilização do trator equipado em operações de preparo de solo, observando-se o consumo e operacionalidade do conjunto;

3- Estudo e construção de um sistema eletro-hidráulico para a troca automática das marchas mecânicas e controle da rotação do motor, dada a velocidade de trabalho, com posteriores ensaios. 
ANEXO A: Características do Solo na Área Ensaiada.

Tabela A1 : Dados referentes à densidade do solo, com amostras recolhidas em 12 pontos aleatoriamente espalhados pela área de ensaio, nas três profundidades $(0-5 \mathrm{~cm}$; $5-10 \mathrm{~cm} ; 10-15 \mathrm{~cm})$.

\begin{tabular}{|c|c|c|c|}
\hline ponto de amostragem & \multicolumn{3}{|c|}{ densidade global em $\mathrm{g} / \mathrm{ml}$} \\
\hline & \multicolumn{3}{|c|}{ profundidades no solo } \\
\hline & $0-5 \mathrm{~cm}$ & $5-10 \mathrm{~cm}$ & $10-15 \mathrm{~cm}$ \\
\hline 1 & 1,69 & 1,76 & 1,79 \\
\hline 2 & 1,72 & 1,81 & 1,76 \\
\hline 3 & 1,65 & 1,79 & 1,80 \\
\hline 4 & 1,62 & 1,73 & 1,72 \\
\hline 5 & 1,82 & 1,80 & 1,76 \\
\hline 6 & 1,77 & 1,77 & 1,77 \\
\hline 7 & 1,71 & 1,84 & 1,62 \\
\hline 8 & 1,84 & 1,57 & 1,76 \\
\hline 9 & 1,79 & 1,69 & 1,68 \\
\hline 10 & 1,73 & 1,81 & 1,80 \\
\hline 11 & 1,67 & 1,75 & 1,83 \\
\hline 12 & 1,82 & 1,77 & 1,79 \\
\hline média & 1,74 & 1,76 & 1,76 \\
\hline
\end{tabular}


Tabela A2: Dados referentes à umidade do solo das amostras recolhidas em 12 pontos aleatórios da área do ensaio, nas profundidades $(0-5 \mathrm{~cm} ; 5-10 \mathrm{~cm} ; 10-15 \mathrm{~cm})$.

\begin{tabular}{|c|c|c|c|}
\hline ponto de amostragem & \multicolumn{3}{|c|}{ umidade (\%) } \\
\hline & \multicolumn{3}{|c|}{ profundidades no solo } \\
\hline & $0-5 \mathrm{~cm}$ & $5-10 \mathrm{~cm}$ & $10-15 \mathrm{~cm}$ \\
\hline 1 & 17,77 & 20,27 & 20,78 \\
\hline 2 & 18,61 & 19,41 & 20,52 \\
\hline 3 & 17,46 & 19,36 & 18,84 \\
\hline 4 & 19,42 & 20,41 & 20,97 \\
\hline 5 & 17,83 & 18,88 & 19,57 \\
\hline 6 & 18,91 & 19,26 & 20,42 \\
\hline 7 & 16,93 & 17,19 & 23,63 \\
\hline 8 & 16,26 & 21,37 & 19,86 \\
\hline 9 & 17,48 & 21,29 & 22,71 \\
\hline 10 & 19,19 & 18,62 & 18,65 \\
\hline 11 & 17,97 & 19,10 & 17,80 \\
\hline 12 & 16,19 & 18,71 & 18,33 \\
\hline média & 17,83 & 19,49 & 20,17 \\
\hline
\end{tabular}

Tabela A3: Dados referentes à resistência à penetração, em $\mathrm{kgf} / \mathrm{cm}^{2}$, na linha do rodado do trator, antes e após a sua passagem, nas profundidades $(0-5 \mathrm{~cm} ; 5-$ $10 \mathrm{~cm} ; 10-15 \mathrm{~cm})$.

\begin{tabular}{|c|c|c|c|c|c|c|c|}
\hline & & \multicolumn{3}{|c|}{ antes da passagem } & \multicolumn{3}{|c|}{ após a passagem } \\
\hline amostra & ensaio & $5 \mathrm{~cm}$ & $10 \mathrm{~cm}$ & $15 \mathrm{~cm}$ & $5 \mathrm{~cm}$ & $10 \mathrm{~cm}$ & $15 \mathrm{~cm}$ \\
\hline 1 & 36 & 0,65 & 2,27 & 4,30 & 14,44 & 17,07 & 16,06 \\
\hline 2 & 1 & 25,59 & 27,62 & 33,70 & 30,66 & 19,10 & 26,60 \\
\hline 3 & 24 & 6,93 & 9,98 & 16,06 & 25,59 & 15,45 & 26,60 \\
\hline 4 & 12 & 19,10 & 26,40 & 26,60 & 30,66 & 17,48 & 27,21 \\
\hline 5 & 31 & 19,10 & 20,52 & 35,73 & 28,63 & 23,56 & 21,53 \\
\hline 6 & 20 & 31,27 & 34,31 & 20,52 & 25,59 & 21,13 & 15,45 \\
\hline 7 & 12 & 11,40 & 16,46 & 26,60 & 37,75 & 33,70 & 26,60 \\
\hline
\end{tabular}




\begin{tabular}{|c|c|c|c|c|c|c|c|}
\hline 8 & 27 & 28,63 & 23,97 & 20,52 & 23,56 & 27,21 & 30,66 \\
\hline 9 & 18 & 4,30 & 11,40 & 16,46 & 3,29 & 18,49 & 22,14 \\
\hline 10 & 1 & 17,48 & 19,10 & 17,07 & 31,67 & 21,53 & 19,10 \\
\hline 11 & 30 & 11,40 & 18,49 & 9,37 & 14,03 & 20,11 & 17,48 \\
\hline 12 & 4 & 13,42 & 12,41 & 19,10 & 30,66 & 15,04 & 19,51 \\
\hline 13 & 10 & 5,72 & 7,34 & 7,75 & 19,51 & 17,48 & 10,38 \\
\hline 14 & 6 & 24,57 & 20,52 & 19,51 & 25,59 & 26,60 & 20,11 \\
\hline 15 & 3 & 22,55 & 18,49 & 20,52 & 20,52 & 23,56 & 17,48 \\
\hline 16 & 19 & 13,83 & 22,14 & 24,57 & 25,59 & 28,22 & 25,99 \\
\hline 17 & 10 & 21,13 & 31,67 & 30,66 & 5,31 & 25,59 & 27,62 \\
\hline 18 & 17 & 7,75 & 25,59 & 25,59 & 21,13 & 20,52 & 30,05 \\
\hline 19 & 8 & 23,56 & 18,49 & 10,38 & 32,68 & 20,52 & 13,02 \\
\hline 20 & 19 & 7,34 & 12,00 & 28,63 & 30,05 & 19,51 & 22,55 \\
\hline 21 & 28 & 21,53 & 21,53 & 23,56 & 38,77 & 24,98 & 19,51 \\
\hline 22 & 4 & 10,99 & 10,99 & 16,46 & 25,59 & 23,97 & 10,38 \\
\hline 23 & 19 & 13,42 & 15,45 & 21,53 & 28,63 & 15,45 & 14,44 \\
\hline 24 & 36 & 15,45 & 15,45 & 14,03 & 33,29 & 33,70 & 28,63 \\
\hline 25 & 13 & 21,53 & 17,48 & 20,52 & 33,70 & 23,56 & 26,60 \\
\hline 26 & 21 & 36,74 & 18,49 & 10,38 & 38,77 & 25,99 & 23,56 \\
\hline 27 & 28 & 11,80 & 30,25 & 32,28 & 33,70 & 20,52 & 30,66 \\
\hline 28 & 17 & 8,35 & 5,31 & 4,30 & 17,48 & 22,55 & 19,51 \\
\hline 29 & 35 & 23,56 & 23,56 & 26,60 & 26,60 & 22,55 & 21,53 \\
\hline 30 & 28 & 17,48 & 18,49 & 19,51 & 21,53 & 14,44 & 14,44 \\
\hline 31 & 20 & 33,70 & 19,51 & 25,59 & 45,86 & 45,86 & 45,86 \\
\hline 32 & 22 & 35,73 & 18,49 & 15,45 & 32,68 & 21,53 & 17,48 \\
\hline 33 & 12 & 8,35 & 8,35 & 13,42 & 23,56 & 24,57 & 19,51 \\
\hline 34 & 3 & 8,35 & 8,35 & 8,35 & 23,56 & 17,48 & 16,46 \\
\hline 35 & 11 & 1,26 & 13,42 & 21,53 & 27,62 & 23,56 & 19,10 \\
\hline 36 & 2 & 3,29 & 5,31 & 16,46 & 24,57 & 14,44 & 15,04 \\
\hline 37 & 8 & 1,87 & 16,46 & 27,62 & 28,63 & 26,60 & 24,57 \\
\hline 38 & 21 & 22,14 & 31,67 & 25,18 & 26,20 & 22,55 & 17,48 \\
\hline 39 & 15 & 6,93 & 13,42 & 15,45 & 24,17 & 22,55 & 21,53 \\
\hline 40 & 11 & 27,62 & 22,14 & 14,03 & 26,20 & 28,22 & 24,17 \\
\hline 41 & 25 & 32,68 & 32,68 & 24,57 & 41,81 & 34,71 & 21,53 \\
\hline 42 & 2 & 25,59 & 22,55 & 22,55 & 32,28 & 25,59 & 23,16 \\
\hline 43 & 36 & 20,52 & 20,52 & 19,51 & 29,64 & 25,59 & 23,16 \\
\hline 44 & 6 & 9,37 & 6,33 & 16,46 & 17,48 & 23,56 & 29,64 \\
\hline 45 & 17 & 24,57 & 19,51 & 26,60 & 30,66 & 20,52 & 22,14 \\
\hline 46 & 2 & 21,53 & 20,52 & 23,56 & 22,55 & 19,51 & 16,46 \\
\hline 47 & 31 & 5,92 & 11,40 & 9,98 & 29,64 & 25,18 & 24,57 \\
\hline 48 & 26 & 4,70 & 16,46 & 19,51 & 24,57 & 23,16 & 20,52 \\
\hline & & & & & & & \\
\hline
\end{tabular}




\begin{tabular}{|c|c|c|c|c|c|c|c|}
\hline 49 & 15 & 5,31 & 30,66 & 29,64 & 14,03 & 19,51 & 15,04 \\
\hline 50 & 1 & 4,91 & 3,29 & 6,33 & 24,57 & 22,55 & 21,53 \\
\hline 51 & 26 & 6,33 & 5,31 & 5,31 & 21,53 & 23,56 & 9,98 \\
\hline 52 & 14 & 4,30 & 29,64 & 32,68 & 21,53 & 20,52 & 16,46 \\
\hline 53 & 24 & 6,93 & 16,06 & 15,04 & 34,31 & 18,49 & 6,33 \\
\hline 54 & 4 & 2,88 & 9,37 & 15,04 & 32,68 & 21,53 & 15,04 \\
\hline 55 & 29 & 29,24 & 22,14 & 19,10 & 6,93 & 19,10 & 17,48 \\
\hline 56 & 25 & 39,78 & 31,67 & 18,49 & 40,79 & 7,34 & 8,35 \\
\hline 57 & 15 & 15,04 & 15,45 & 14,03 & 14,03 & 21,53 & 19,51 \\
\hline 58 & 24 & 15,45 & 15,45 & 18,09 & 24,57 & 25,59 & 24,57 \\
\hline 59 & 29 & 1,26 & 1,26 & 9,37 & 16,46 & 15,45 & 13,42 \\
\hline 60 & 28 & 5,31 & 14,44 & 15,04 & 12,41 & 9,37 & 8,96 \\
\hline 61 & 32 & 9,98 & 27,62 & 26,20 & 27,62 & 33,70 & 33,70 \\
\hline 62 & 22 & 1,26 & 18,09 & 12,00 & 23,16 & 23,16 & 17,48 \\
\hline 63 & 20 & 0,24 & 9,98 & 23,56 & 23,56 & 19,51 & 19,51 \\
\hline 64 & 5 & 0,85 & 7,95 & 13,42 & 17,48 & 19,10 & 23,16 \\
\hline 65 & 27 & 26,60 & 36,33 & 35,32 & 31,67 & 35,32 & 32,28 \\
\hline 66 & 16 & 39,78 & 23,56 & 12,81 & 27,62 & 25,59 & 25,18 \\
\hline 67 & 25 & 7,95 & 16,06 & 14,03 & 26,20 & 21,53 & 17,48 \\
\hline 68 & 6 & 10,99 & 4,30 & 9,98 & 7,34 & 18,49 & 20,11 \\
\hline 69 & 9 & 1,87 & 20,11 & 23,56 & 20,11 & 13,42 & 19,51 \\
\hline 70 & 19 & 3,29 & 16,06 & 23,16 & 25,18 & 30,66 & 30,25 \\
\hline 71 & 5 & 15,45 & 16,46 & 21,53 & 15,45 & 20,52 & 8,35 \\
\hline 72 & 22 & 1,26 & 0,85 & 4,91 & 25,59 & 19,10 & 17,48 \\
\hline 73 & 18 & 5,31 & 12,41 & 23,56 & 35,73 & 31,67 & 30,25 \\
\hline 74 & 35 & 6,33 & 13,02 & 15,45 & 34,71 & 30,66 & 18,49 \\
\hline 75 & 7 & 7,34 & 9,98 & 12,41 & 23,16 & 17,48 & 12,41 \\
\hline 76 & 30 & 1,26 & 2,27 & 4,91 & 24,57 & 22,55 & 18,09 \\
\hline 77 & 14 & 6,93 & 9,98 & 12,00 & 14,44 & 16,46 & 13,02 \\
\hline 78 & 10 & 10,38 & 3,29 & 7,34 & 13,42 & 23,56 & 19,51 \\
\hline 79 & 9 & 5,92 & 16,46 & 8,35 & 23,56 & 32,68 & 16,46 \\
\hline 80 & 2 & 4,91 & 7,34 & 13,42 & 29,64 & 24,17 & 19,10 \\
\hline 81 & 5 & 4,30 & 1,26 & 0,85 & 17,48 & 10,99 & 15,45 \\
\hline 82 & 22 & 5,31 & 7,34 & 27,62 & 14,44 & 14,44 & 14,44 \\
\hline 83 & 6 & 9,37 & 12,41 & 16,46 & 13,42 & 17,07 & 20,52 \\
\hline 84 & 36 & 36,74 & 27,62 & 22,55 & 25,59 & 16,46 & 13,42 \\
\hline 85 & 13 & 10,99 & 13,02 & 9,37 & 20,52 & 17,48 & 16,46 \\
\hline 86 & 34 & 13,02 & 15,45 & 16,06 & 30,66 & 32,68 & 25,59 \\
\hline 87 & 15 & 39,78 & 26,60 & 17,48 & 19,51 & 14,44 & 13,42 \\
\hline 88 & 7 & 14,44 & 34,71 & 35,73 & 36,74 & 26,60 & 23,56 \\
\hline 89 & 20 & 3,29 & 4,91 & 13,42 & 25,59 & 28,63 & 36,33 \\
\hline
\end{tabular}




\begin{tabular}{|c|c|c|c|c|c|c|c|}
\hline 90 & 32 & 15,04 & 12,00 & 10,99 & 28,22 & 19,51 & 18,09 \\
\hline 91 & 1 & 18,49 & 25,59 & 34,31 & 18,49 & 21,53 & 19,51 \\
\hline 92 & 25 & 9,37 & 17,48 & 10,38 & 28,22 & 17,48 & 13,42 \\
\hline 93 & 3 & 9,37 & 10,99 & 8,35 & 20,52 & 15,45 & 13,42 \\
\hline 94 & 17 & 15,45 & 18,49 & 24,57 & 26,60 & 20,52 & 15,45 \\
\hline 95 & 13 & 3,89 & 21,53 & 25,59 & 24,17 & 18,09 & 33,70 \\
\hline 96 & 21 & 13,42 & 19,51 & 33,29 & 23,56 & 23,56 & 23,56 \\
\hline 97 & 27 & 15,04 & 17,48 & 26,20 & 22,55 & 13,02 & 6,33 \\
\hline 98 & 18 & 3,89 & 16,46 & 16,06 & 29,24 & 21,53 & 24,57 \\
\hline 99 & 33 & 19,51 & 11,40 & 16,46 & 12,00 & 15,45 & 13,42 \\
\hline 100 & 18 & 36,74 & 39,38 & 34,71 & 19,51 & 24,17 & 16,46 \\
\hline 101 & 21 & 16,46 & 14,03 & 19,51 & 17,48 & 15,45 & 12,41 \\
\hline 102 & 23 & 7,34 & 14,44 & 22,14 & 42,82 & 37,75 & 34,71 \\
\hline 103 & 30 & 14,03 & 13,42 & 11,40 & 21,53 & 17,48 & 14,44 \\
\hline 104 & 31 & 5,31 & 6,33 & 6,33 & 19,51 & 20,52 & 15,45 \\
\hline 105 & 7 & 12,00 & 12,41 & 25,59 & 44,85 & 27,62 & 14,44 \\
\hline 106 & 35 & 21,13 & 18,49 & 22,14 & 41,81 & 35,73 & 32,28 \\
\hline 107 & 29 & 6,33 & 5,31 & 8,96 & 23,56 & 27,62 & 28,63 \\
\hline 108 & 34 & 4,30 & 11,40 & 6,33 & 24,57 & 17,48 & 28,63 \\
\hline 109 & 12 & 7,95 & 22,14 & 27,62 & 23,56 & 19,51 & 18,49 \\
\hline 110 & 24 & 22,55 & 21,13 & 15,45 & 25,18 & 15,45 & 13,42 \\
\hline 111 & 31 & 7,34 & 15,45 & 18,49 & 32,68 & 35,73 & 19,51 \\
\hline 112 & 33 & 25,59 & 23,56 & 25,59 & 21,53 & 20,52 & 18,49 \\
\hline 113 & 26 & \multicolumn{7}{|c|}{ perdido } & & \\
\hline 114 & 8 & 6,33 & 19,51 & 19,51 & 13,02 & 13,02 & 13,42 \\
\hline 115 & 23 & 10,38 & 29,64 & 26,20 & 47,89 & 32,68 & 32,68 \\
\hline 116 & 30 & 15,45 & 10,38 & 15,45 & 20,11 & 20,52 & 13,42 \\
\hline 117 & 9 & 9,37 & 10,38 & 10,38 & 14,44 & 13,42 & 12,41 \\
\hline 118 & 23 & 8,35 & 9,98 & 14,44 & 47,89 & 36,74 & 20,52 \\
\hline 119 & 5 & 24,17 & 21,53 & 24,17 & 23,16 & 21,53 & 22,55 \\
\hline 120 & 3 & 32,28 & 27,21 & 28,63 & 19,51 & 16,06 & 25,18 \\
\hline 121 & 33 & 26,60 & 36,74 & 36,74 & 19,10 & 26,20 & 27,62 \\
\hline 122 & 34 & 4,30 & 25,59 & 30,25 & 16,46 & 31,67 & 30,66 \\
\hline 123 & 8 & 15,45 & 30,66 & 30,66 & 22,55 & 27,62 & 27,62 \\
\hline 124 & 32 & 10,38 & 27,62 & 27,62 & 36,74 & 34,71 & 33,70 \\
\hline 125 & 16 & 4,91 & 6,33 & 12,41 & 17,48 & 18,49 & 25,18 \\
\hline 126 & 27 & 21,53 & 27,62 & 31,67 & 34,71 & 33,70 & 31,67 \\
\hline 127 & 4 & 12,41 & 13,42 & 20,52 & 14,44 & 17,48 & 38,77 \\
\hline 128 & 32 & 14,44 & 18,09 & 27,62 & 18,49 & 21,13 & 28,22 \\
\hline 129 & 14 & 23,56 & 34,71 & 37,75 & 37,75 & 40,39 & 40,79 \\
\hline 130 & 11 & \multicolumn{7}{|c|}{ perdido } & & \\
\hline
\end{tabular}




\begin{tabular}{|c|c|c|c|c|c|c|c|}
\hline 131 & 29 & 6,33 & 6,33 & 12,41 & 30,66 & 29,64 & 23,56 \\
\hline 132 & 11 & 9,98 & 9,98 & 17,48 & 21,13 & 27,21 & 21,53 \\
\hline 133 & 16 & 39,38 & 33,70 & 27,62 & 30,66 & 19,51 & 25,59 \\
\hline 134 & 13 & 10,38 & 17,48 & 28,63 & 37,35 & 39,78 & 36,74 \\
\hline 135 & 33 & 10,38 & 7,34 & 24,57 & 19,51 & 15,45 & 20,52 \\
\hline 136 & 14 & 7,34 & 25,59 & 28,63 & 26,60 & 23,56 & 26,60 \\
\hline 137 & 23 & 0,24 & 27,62 & 37,35 & 15,04 & 24,17 & 25,59 \\
\hline 138 & 10 & 8,96 & 36,33 & 38,77 & 18,49 & 31,67 & 30,66 \\
\hline 139 & 16 & 18,49 & 24,57 & 29,64 & 28,22 & 24,17 & 26,60 \\
\hline 140 & 9 & 35,73 & 27,62 & 29,64 & \multicolumn{3}{|c|}{ perdido } \\
\hline 141 & 26 & 21,53 & 20,52 & 27,62 & 23,56 & 28,63 & 32,68 \\
\hline 142 & 35 & 20,52 & 30,66 & 31,27 & 20,52 & 23,56 & 22,14 \\
\hline 143 & 34 & 9,37 & 20,52 & 27,62 & 17,07 & 19,51 & 18,49 \\
\hline 144 & 7 & 35,32 & 30,66 & 31,67 & 38,36 & 37,35 & 35,73 \\
\hline & MÉDIA & 14,04 & 17,63 & 19,94 & 24,88 & 22,70 & 21,27 \\
\hline
\end{tabular}




\section{ANEXO B: Dados dos Ensaios de Campo}

Tabela B1: Dados referentes à calibração da Célula de Carga, com o amplificador ajustado para 3000 micro strain, correspondente à $36787,5 \mathrm{~N}$ (3750 kgf), para cada intervalo de ensaio especificado através dos seus números. (obs: tempo em segundos).

\begin{tabular}{|c|c|c:c|c:c|c:c|c:c|}
\hline de n. & até n. & tempo & pulsos & tempo & pulsos & tempo & pulsos & tempo & pulsos \\
\hline 1 & 7 & 10,1 & 54662 & 10,1 & 54839 & 10,2 & 55033 & 10,0 & 54131 \\
\hline 8 & 40 & 10,0 & 47671 & 10,1 & 48154 & 10,1 & 48625 & 9,8 & 46829 \\
\hline 41 & 58 & 9,8 & 48881 & 10,1 & 49483 & 10,1 & 49709 & 10,1 & 49980 \\
\hline 59 & 106 & 10,0 & 49434 & 10,0 & 48443 & 10,1 & 48765 & 10,0 & 48619 \\
\hline 107 & 146 & 10,1 & 47750 & 9,9 & 46463 & 10,0 & 47152 & 10,1 & 47424 \\
\hline
\end{tabular}

Tabela B2: Dados referentes à calibração do equipamento de medição do patinamento instalado em cada roda do trator, onde se tem o número de pulsos para um deslocamento de 40 metros do trator, com patinamento considerado nulo. Total de ensaios: 5.

\begin{tabular}{|l|c|c|c|c|c|}
\hline \multicolumn{1}{|c|}{ ensaio } & 1 & 2 & 3 & 4 & 5 \\
\hline TE (traseira esquerda) & 501 & 482 & 489 & 492 & 486 \\
\hline TD (traseira direita) & 477 & 465 & 472 & 471 & 466 \\
\hline DE (dianteira esquerda) & 680 & 650 & 662 & 671 & 650 \\
\hline DD (dianteira direita) & 685 & 660 & 671 & 685 & 666 \\
\hline
\end{tabular}


Tabela B3: Dados referentes aos parâmetros medidos durante os ensaios. $\mathrm{Na}$ seqüência das colunas, tem-se: número do ensaio (cronológico); tipo do ensaio (de 1 a 36); tempo total do ensaio (segundos); pulsos das rodas traseira esquerda, traseira direita, dianteira esquerda, e dianteira direita; número de pulsos da célula de carga (cc); consumo de combustível (leitura da bureta central); tempo de consumo do combustível (segundos); temperatura do óleo diesel (em milivolts de um termopar tipo J); dia e mês, horário do ensaio.

\begin{tabular}{|c|c|c|c|c|c|c|c|c|c|c|c|c|}
\hline n. & is. & tp. & $\mathrm{TE}$ & TD & $\overline{\mathrm{DE}}$ & $\mathrm{DD}$ & $\mathrm{cc}$ & is & $\begin{array}{l}\text { tp. } \\
\mathrm{cb}\end{array}$ & $\begin{array}{c}\text { tp. } \\
\text { Dies }\end{array}$ & is & hora \\
\hline 1 & 36 & 3,0 & 3 & 30 & 769 & 81 & 52367 & 5 & 21,8 & & 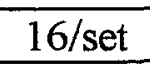 & 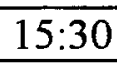 \\
\hline 2 & 1 & 3,4 & $\overline{8}$ & 90 & 687 & 703 & & 5 & 23,8 & 1 & /set & $15: 35$ \\
\hline 3 & 24 & 0,6 & 79 & 566 & 784 & 778 & 91 & 18,5 & 56,8 & 1,1 & /set & $15: 45$ \\
\hline 4 & $\overline{12}$ & 74,0 & 68 & 563 & 776 & 780 & 251252 & 15,9 & 60,8 & 1,1 & $/$ set & $15: 50$ \\
\hline 5 & 31 & 33,6 & 56 & 557 & 762 & 773 & 6052 & 15,4 & 33,8 & 1,1 & /set & $16: 00$ \\
\hline 6 & 0 & 44,4 & 40 & 526 & 731 & 733 & & $\overline{4,2}$ & 44,6 & & & $16: 10$ \\
\hline 7 & 2 & 74,3 & 64 & 552 & 768 & 767 & 23 & 18,3 & 73,2 & 1,1 & & $16: 20$ \\
\hline 8 & 27 & 28,9 & 81 & 573 & 796 & 796 & 104 & 15,6 & 23,7 & 1,1 & & $8: 30$ \\
\hline 9 & 18 & 42,8 & 698 & 649 & 933 & 931 & 189 & 24,7 & 35,7 & 1,3 & set & $8: 37$ \\
\hline 10 & 1 & 3,9 & 05 & 89 & 686 & 683 & & o, & 35,0 & 1, & & $: 40$ \\
\hline 11 & 30 & 35,1 & 88 & 593 & 817 & 817 & 126 & 17,6 & 30,2 & 1,1 & & 45 \\
\hline 12 & - & 39,7 & 21 & 500 & 704 & 703 & 67 & 9,6 & 32,9 & $\overline{1,1}$ & set & $8: 49$ \\
\hline 13 & 10 & 54,5 & 766 & 754 & 1035 & 035 & 246 & 34,2 & 48,5 & 1,1 & & $8: 55$ \\
\hline 14 & 6 & 55,3 & 711 & 697 & 973 & 974 & 25 & 29,2 & 47,4 & 1, & & $8: 59$ \\
\hline 15 & 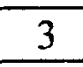 & 46,9 & 73 & 677 & 936 & 935 & & 29,8 & 40,2 & 1 & & $9: 02$ \\
\hline 16 & 19 & 42,0 & 511 & 498 & 694 & 691 & $\overline{45}$ & 6,8 & 38,1 & 1,3 & set & $9: 06$ \\
\hline 17 & 10 & 54,0 & 754 & 736 & 1023 & 1021 & 254 & 31,9 & 46,1 & 1 , & & $9: 08$ \\
\hline 18 & 17 & 36,1 & 577 & 557 & 784 & 786 & 126 & 15,7 & 28,3 & 1. & set & $9: 12$ \\
\hline 19 & - & 6,1 & 52 & 539 & 766 & 754 & 15 & 11,4 & 42,9 & 1, & & $9: 16$ \\
\hline 20 & 19 & 41,7 & 499 & 484 & 686 & 679 & 39 & 6,4 & 34,5 & 1,4 & set & $9: 20$ \\
\hline 21 & 28 & 22,0 & 510 & 497 & 696 & 694 & 27648 & 6,2 & 17,2 & 1,4 & $/$ set & $9: 23$ \\
\hline 22 & 4 & 38,4 & 588 & 566 & 798 & 797 & 12 & 18 & 30,6 & 1 , & set & $9: 25$ \\
\hline 23 & 19 & 41,4 & 513 & 498 & 698 & 699 & & 8,4 & 36,4 & 1, & & $9: 30$ \\
\hline 24 & 36 & 44,0 & 564 & 550 & 766 & 766 & 141709 & 15,8 & 36,3 & 1, & & $9: 35$ \\
\hline 25 & 13 & 26,9 & 508 & 489 & 689 & 686 & & 5,9 & 21,8 & 1,4 & $18 /$ set & $9: 39$ \\
\hline 26 & 21 & 50,6 & 618 & 602 & 843 & 844 & 199076 & 20,4 & 44,6 & 1,5 & $18 /$ set & $9: 45$ \\
\hline
\end{tabular}




\begin{tabular}{|c|c|c|c|c|c|c|c|c|c|c|c|c|}
\hline 27 & 28 & 22,1 & 509 & 498 & 679 & 698 & 29868 & 5,9 & 16,0 & 1,5 & $18 /$ set & $9: 50$ \\
\hline 28 & 17 & 37,8 & 614 & 578 & 823 & 822 & 132321 & 17 & 30,7 & 1,5 & $18 /$ set & $9: 57$ \\
\hline 29 & 35 & 40,9 & 530 & 510 & 718 & 718 & 82062 & 10,1 & 34,5 & 1,5 & $18 /$ set & $10: 00$ \\
\hline 30 & 28 & 22,2 & 508 & 493 & 693 & 693 & 27557 & 6,3 & 17,4 & 1,5 & $18 /$ set & $10: 05$ \\
\hline 31 & 20 & 45,5 & 541 & 532 & 741 & 744 & 130595 & 9 & 31,8 & 1,5 & $18 /$ set & $10: 07$ \\
\hline 32 & 22 & 51,1 & 504 & 487 & 683 & 686 & 56115 & 6,5 & 44,7 & 1,5 & $18 /$ set & $10: 12$ \\
\hline 33 & 12 & 76,4 & 571 & 553 & 775 & 777 & 260905 & 17,8 & 66,5 & 1,5 & $18 /$ set & $10: 15$ \\
\hline 34 & 3 & 47,8 & 704 & 679 & 953 & 950 & 270906 & 29,4 & 36,5 & 1,6 & $18 /$ set & $10: 20$ \\
\hline 35 & 11 & 69,8 & 531 & 512 & 723 & 721 & 151603 & 12,9 & 64,4 & 1,6 & $18 /$ set & $10: 25$ \\
\hline 36 & 2 & 38,8 & 562 & 551 & 771 & 769 & 120891 & 18,9 & 34,0 & 1,6 & $18 /$ set & $10: 27$ \\
\hline 37 & 8 & 55,8 & 546 & 534 & 753 & 746 & 160255 & 14,8 & 48,3 & 1,6 & $18 /$ set & $10: 30$ \\
\hline 38 & 21 & 50,3 & 599 & 597 & 829 & 827 & 198700 & 20,7 & 45,5 & 1,6 & $18 /$ set & $10: 32$ \\
\hline 39 & 15 & 38,7 & 708 & 670 & 950 & 950 & 162137 & 24,7 & 32,2 & 1,6 & $18 /$ set & $10: 35$ \\
\hline 40 & 11 & 71,1 & 541 & 521 & 732 & 736 & 150182 & 12 & 62,4 & 1,6 & $18 /$ set & $10: 38$ \\
\hline 41 & 25 & 18,9 & 499 & 483 & 679 & 680 & 10361 & 4,1 & 13,6 & 1,6 & $18 /$ set & $11: 00$ \\
\hline 42 & 2 & 38,9 & 574 & 554 & 782 & 781 & 130572 & 20,5 & 34,8 & 1,6 & $18 /$ set & $11: 02$ \\
\hline 43 & 36 & 43,6 & 574 & 556 & 781 & 783 & 152532 & 17,3 & 36,5 & 1,6 & $18 /$ set & $11: 04$ \\
\hline 44 & 6 & 55,1 & 701 & 691 & 964 & 966 & 246549 & 26,7 & 45,4 & 1,6 & $18 /$ set & $11: 07$ \\
\hline 45 & 17 & 40,6 & 659 & 634 & 893 & 899 & 144050 & 16 & 30,0 & 1,6 & $18 /$ set & $11: 10$ \\
\hline 46 & 2 & 38,8 & 578 & 550 & 780 & 781 & 120449 & 16,6 & 29,9 & 1,6 & $18 /$ set & $11: 12$ \\
\hline 47 & 31 & 29,2 & 517 & 499 & 703 & 703 & 46048 & 7,8 & 23,8 & 1,6 & $18 /$ set & $11: 15$ \\
\hline 48 & 26 & 21,5 & 547 & 539 & 749 & 749 & 63449 & 12,8 & 17,3 & 1,6 & $18 /$ set & $11: 24$ \\
\hline 49 & 15 & 37,1 & 679 & 666 & 931 & 930 & 166938 & 26,9 & 32,4 & 1,6 & $18 /$ set & $11: 26$ \\
\hline 50 & 1 & 33,9 & 509 & 489 & 690 & 689 & 28275 & 9,8 & 28,0 & 1,6 & $18 /$ set & $11: 28$ \\
\hline 51 & 26 & 22,3 & 562 & 537 & 761 & 761 & 63789 & 13,6 & 17,9 & 1,6 & $18 /$ set & $11: 30$ \\
\hline 52 & 14 & 29,8 & 553 & 533 & 747 & 753 & 86532 & 14,3 & 24,5 & 1,6 & $18 /$ set & $11: 32$ \\
\hline 53 & 24 & 62,9 & 578 & 560 & 786 & 786 & 204449 & 16,7 & 54,9 & 1,6 & $18 /$ set & $11: 35$ \\
\hline 54 & 4 & 38,8 & 510 & 499 & 697 & 694 & 64042 & 12,1 & 35,3 & 1,6 & $18 /$ set & $11: 38$ \\
\hline 55 & 29 & 25,9 & 568 & 559 & 776 & 778 & 83397 & 13,2 & 20,2 & 1,6 & $18 /$ set & $11: 40$ \\
\hline 56 & 25 & 19,3 & 497 & 480 & 673 & 685 & 10840 & 5,2 & 16,2 & 1,6 & $18 /$ set & $11: 45$ \\
\hline 57 & 15 & 38,5 & 700 & 668 & 945 & 949 & 173708 & 27,6 & 33,3 & 1,6 & $18 /$ set & $11: 48$ \\
\hline 58 & 24 & 64,0 & 605 & 589 & 823 & 821 & 236257 & 20,2 & 57,7 & 1,6 & $18 /$ set & $11: 52$ \\
\hline 59 & 29 & 25,9 & 568 & 550 & 774 & 773 & 84788 & 15,5 & 22,3 & 1,6 & $18 /$ set & $13: 10$ \\
\hline 60 & 28 & 21,8 & 502 & 489 & 683 & 683 & 24973 & 6,2 & 17,9 & 1,6 & $18 /$ set & $13: 13$ \\
\hline 61 & 32 & 31,9 & 540 & 525 & 734 & 741 & 80917 & 11,6 & 27,3 & 1,6 & $18 /$ set & $13: 15$ \\
\hline 62 & 22 & 51,1 & 505 & 489 & 688 & 688 & 39568 & 6,2 & 46,2 & 1,6 & $18 /$ set & $13: 18$ \\
\hline 63 & 20 & 46,0 & 549 & 532 & 744 & 746 & 124940 & 12,5 & 40,1 & 1,6 & $18 /$ set & $13: 20$ \\
\hline 64 & 5 & 44,6 & 575 & 556 & 786 & 783 & 151429 & 18,6 & 38,2 & 1,6 & $18 /$ set & $13: 23$ \\
\hline 65 & 27 & 28,4 & 583 & 566 & 795 & 794 & 99805 & 16,1 & 23,9 & 1,6 & $18 /$ set & $13: 27$ \\
\hline 66 & 16 & 31,0 & 504 & 489 & 685 & 786 & 33834 & 7,1 & 26 & 1,6 & $18 /$ set & $13: 30$ \\
\hline 67 & 25 & 18,9 & 498 & 479 & 676 & 680 & 9847 & 4,4 & 15,7 & 1,6 & $18 /$ set & $13: 32$ \\
\hline
\end{tabular}




\begin{tabular}{|c|c|c|c|c|c|c|c|c|c|c|c|c|}
\hline & & 6 & 715 & 698 & 74 & 970 & & 29,2 & 49,4 & 1,0 & 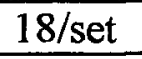 & \\
\hline 69 & 7 & & 612 & 584 & 26 & & & & 5 & 16 & & \\
\hline 70 & 19 & 4 & 517 & 497 & 699 & 0 & & 7,7 & 5,5 & 1,6 & & - \\
\hline 71 & 5 &, 4 & 592 & 577 & 806 & 08 & & 9,1 & 38,9 & 1,6 & & $3: 42$ \\
\hline 2 & 22 &, 7 & 499 & 486 & 681 & 84 & & 5,2 & 44,6 & 1,6 & & 44 \\
\hline 73 & 18 & & 690 & 699 & 967 & 63 & & 6,5 & 37,6 & 1,7 & & 4 \\
\hline 74 & 35 & 9 & 533 & 510 & 719 & 721 & & 9,2 & 33,4 & 1,8 & 4 & $3: 49$ \\
\hline 75 & 7 &, 1 & 511 & 489 & 690 & 695 & & 8,1 & 44 & 1,8 & set & $3: 51$ \\
\hline 76 & 30 & 3 & 595 & 573 & 806 & 813 & & 18,5 & 27,9 & 1,8 & & $3: 59$ \\
\hline 77 & 14 & ,4 & 560 & 549 & 761 & 765 & & 5,2 & 25,6 & 1,8 & set & $4: 03$ \\
\hline 78 & 10 & 4 & 515 & 499 & 702 & 703 & & 9 & 7,6 & 1,8 & & 5 \\
\hline 79 & 0 & 1,0 & 610 & 603 & 841 & 841 & & 22,0 & 59,9 & 1,8 & - & 08 \\
\hline 80 & 2 &, 6 & 569 & 536 & 765 & 770 & & 16,4 & 30 & 1,8 & set & $: 11$ \\
\hline 2 & 5 & 24 & 592 & 572 & 804 & 810 & & 17,2 & 33,6 & 1,5 & set & $5: 07$ \\
\hline 82 & 2 & ,4 & 2 & 483 & 692 & 01 & & 0 & 41,1 &, 0 & & 08 \\
\hline 8 & & 0 & 9 & 713 & 1013 & 998 & & 7,4 & 6,9 & 1,6 & & $: 13$ \\
\hline 84 & 36 & 3 & 3 & 559 & 792 & 779 & & 15,7 & 5,9 & 1,6 & & $: 15$ \\
\hline 85 & 1 & 4 & 495 & 485 & 683 & 680 & & 6,1 & 1,9 & 1,6 & set & $5: 22$ \\
\hline 86 & 32 & 5 & 512 & 500 & 706 & 699 & & 7,3 & 1,8 & 1,6 & & $5: 24$ \\
\hline 87 & & & 4 & 652 & 39 & 92 & & 3,2 & 29,2 & 1,0 & & 29 \\
\hline 88 & $\pi$ & 8 & 520 & 499 & 714 & 703 & & 7,4 & 40,5 & 1,6 & & 31 \\
\hline 89 & 20 &, 9 & 554 & 533 & 765 & 753 & & 10,4 & 34,8 & 1,6 & & $5: 35$ \\
\hline 90 & 32 & 2 & 498 & 483 & 686 & 68 & & 11,2 & 25,6 & 1,6 & et & $5: 37$ \\
\hline 91 & 1 & & 3 & 50 & 720 & 71 & & 10,4 & 28,5 & 1,6 & & $5: 39$ \\
\hline 92 & 25 & & 495 & 492 & 684 & - & & 6,3 & 20 & 16 & & $: 41$ \\
\hline 93 & 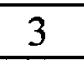 &, 2 & 661 & 660 & 934 & 912 & & 24,3 & 37,3 & 1,6 & set & $5: 43$ \\
\hline 94 & 17 & 36,1 & 580 & 570 & 805 & 799 & & 18,2 & 30,2 & 1,8 & & $5: 48$ \\
\hline 95 & 13 & 26,5 & 495 & 480 & 680 & 674 & & 6,0 & 20 & 1,8 & set & $5: 53$ \\
\hline 96 & 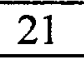 & & 602 & 585 & 828 & 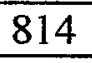 & & 15,2 & 39,4 & 1,8 & et & $5: 55$ \\
\hline 97 & 27 & 7 & 572 & 546 & 784 & 772 & & 15,6 & 20,2 & 1,8 & & $5: 57$ \\
\hline 98 & 18 & 44,1 & 719 & 696 & 992 & 993 & & 26,0 & 35,8 & 1,8 & set & $6: 01$ \\
\hline 99 & 33 & 38,6 & 614 & 599 & 854 & 848 & & 17,5 & 32,1 & 1,8 & set & $6: 08$ \\
\hline & 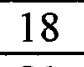 & - & 706 & 689 & 977 & 962 & & 24,5 & 36,8 & 1,8 & & $6: 10$ \\
\hline & 21 & & 0.1 & 622 & 867 & 864 & & 18,0 & 41,8 & 1,8 & et & $6: 12$ \\
\hline & 23 & & 526 & 520 & 731 & 728 & & 6,8 & 37,4 & 1,6 & set & $6: 15$ \\
\hline 103 & 30 & 35 & 621 & 602 & 861 & 862 & 41 & 20,2 & 32,1 & 1,6 & set & $16: 19$ \\
\hline 10 & 31 & 32 & 554 & 538 & 764 & 767 & & 5,2 & 23,2 & 1,6 & set & $6: 21$ \\
\hline & - & & 515 & 509 & 720 & 713 & & 6,9 & 36,7 & 1,6 & & $16: 23$ \\
\hline 106 & 35 & & 531 & 521 & 735 & 725 & & 10,2 & 32,1 & 1,6 & $8 / \mathrm{set}$ & $16: 25$ \\
\hline 107 & 29 & 24,8 & 642 & 628 & 676 & 649 & & 13,9 & 22,9 & 1,1 & set & $8: 28$ \\
\hline 108 & 34 & 38,6 & 511 & 497 & 673 & 649 & 19209 & 4,5 & 31,6 & 1. & $19 / \mathrm{set}$ & $8: 30$ \\
\hline
\end{tabular}




\begin{tabular}{|c|c|c|c|c|c|c|c|c|c|c|c|c|}
\hline & & & 570 & 558 & 808 & 782 & & 16,4 & 64,7 & 1,2 & & \\
\hline 110 & - & & & 546 & 791 & & & 4,0 & 518 & & & \\
\hline 11 & 31 & 1 & 503 & 489 & 693 & & & 3,1 & 23,2 & & & \\
\hline & 2 & 7 & 602 & 579 & 837 & & & 6,9 & 30 & 14 & & \\
\hline & 20 & 4 & 562 & 542 & 777 & & & 2,1 & 17 & & & \\
\hline & & & 0 & 536 & 61 & & & 2,2 & 45,5 & & & \\
\hline & 23 & & 7 & 504 & 30 & & & 7,6 & & & & \\
\hline 116 & 30 & 7 & 500 & 489 & 690 & 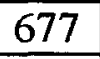 & & 3,1 & 15,2 &, 5 & & 34 \\
\hline 117 & 0 & 9 & 628 & 590 & 865 & 41 & & 19,0 & 54 & 5 & & 56 \\
\hline & 23 & & 543 & 524 & 762 & & & 9,4 & 4 & 6 & & 59 \\
\hline & & & 1 & 564 & 17 & 8 & & 8,3 & 5,3 & & & 05 \\
\hline 120 & 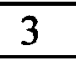 & 3 & 93 & 672 & 72 & 5 & & 9,7 & 0,0 &, 0 & & 12 \\
\hline 121 & 33 & 1 & 601 & 589 & 846 & 24 & & 17,2 & 1,5 & $\epsilon_{1}$ & - & $: 14$ \\
\hline 122 & 34 & & 512 & 492 & 717 & 08 & & 5,3 & 061 & 1,5 & & 18 \\
\hline 123 & 8 & 4 & 532 & 523 & 749 & 721 & &, 8 & 3,1 & 1,5 & & 20 \\
\hline 124 & & & 40 & 527 & - & & & 2,6 & 4 & 2 & & 24 \\
\hline 125 & 16 & & 11 & 497 & 717 & -1 & & 6,6 & 24 & 1,5 & & 27 \\
\hline 126 & 27 & 3 & 77 & 582 & 840 & 20 & & 15,6 & 3,3 & 5 & t & 29 \\
\hline 127 & - & & 6 & 480 & 711 & $\overline{26}$ & & 8,5 & 1,9 & -7 & & 31 \\
\hline 128 & 32 & & 53 & 51 & 742 & 44 & & 11,7 & 25,4 & , & & 34 \\
\hline 129 & 14 & & & 5 & 78 & & & & 24 & & & 36 \\
\hline 130 & 11 & 8 & 534 & 516 & 750 & 31 & & 11,0 & 58,2 & 1,6 & set & $: 38$ \\
\hline 131 & 29 & & 575 & & 810 & 97 & & 13,5 & 19 & 1, & & 41 \\
\hline 170 & 11 & & & 5 & 740 & 71 & & 10,5 & 8 & 1, & & $: 43$ \\
\hline & 16 & & & 1 & 71 & & & $\sigma$ & 24,1 & 1,6 & & 46 \\
\hline 134 & 13 & 7 & 494 & 444 & 693 & 108 & & 3,7 & 20,5 & - & & $: 48$ \\
\hline 135 & 33 & 36,7 & 603 & 58 & 844 & 5 & & 17,8 & 31 & 1,7 & set & 9.51 \\
\hline 136 & 14 & & 561 & 54 & 789 & 767 & & 14,3 & 23, & 1, & set & $9: 56$ \\
\hline 13 & 23 & & 52 & 51 & 742 & 724 & & 10,1 & 48,5 & 1,1 & set & $9: 58$ \\
\hline$\sigma_{2}$ & 10 & & 514 & 498 & 721 & 700 & & 8,6 & 57,6 & 1,1 & set & $0: 0$ \\
\hline 139 & 16 & & 516 & 498 & 717 & 724 & & 8,7 & 24,9 & 1,7 & $9 / \mathrm{set}$ & $0: 05$ \\
\hline 140 & 9 & 63,9 & 607 & 584 & 852 & 827 & & 19,7 & 56,2 & 1, & set & $0: 13$ \\
\hline 141 & 26 & & 546 & 52 & 752 & 750 & & 12,1 & 16 & 1, & et & $0: 1$ \\
\hline $1 A^{\prime}$ & 35 & & 52 & 50 & 735 & 713 & & 9,7 & 33,6 & 1,8 & & $10: 18$ \\
\hline 143 & 34 & & 516 & 498 & 724 & 710 & & 6,1 & 31,5 & 1,8 & IJSE & $10: 20$ \\
\hline 144 & 7 & 52,0 & 501 & 484 & 705 & 688 & & 7,6 & 44,1 & 1,8 & $/$ set & $10: 23$ \\
\hline 145 & 3 & 5,6 & 78 & 654 & 42 & 934 & 200587 & 9,2 & 40,7 & 1,8 & $/ /$ set & $0: 2$ \\
\hline
\end{tabular}

OBS: o ensaio número 34 foi repetido e substituído pelo de número 145 , devido ao fato de ter sido executado erroneamente. 
ANEXo C: Cálculo dos Valores de Rendimento, Força, Velocidade, Potência e Patinamento das rodas.

Tabela C1: Cálculo dos Parâmetros Dinâmicos.

\begin{tabular}{|c|c|c|c|c|c|c|c|c|c|c|}
\hline n. & ens. & $\eta_{\mathrm{t}}$ & Força & Veloc & Pot Corrig & \multicolumn{4}{|c|}{ Patinamento(\%) } \\
\hline & & $(\%)$ & $(\mathrm{kgf})$ & $(\mathrm{km} / \mathrm{h})$ & $(\mathrm{kw})$ & TE & TD & DE & DD & média \\
\hline 2 & 1 & 13,05 & 938,17 & 4,31 & 11,54 & 3,7 & 4,2 & 3,7 & 4,6 & 4,0 \\
\hline 10 & 1 & 8,64 & 442,18 & 4,25 & 5,07 & 3,1 & 4,0 & 3,5 & 1,6 & 3,0 \\
\hline 50 & 1 & 8,62 & 633,28 & 4,25 & 7,41 & 3,9 & 4,0 & 4,1 & 2,5 & 3,6 \\
\hline 91 & 1 & 12,46 & 964,64 & 4,16 & 11,16 & 6,7 & 7,4 & 8,7 & 6,4 & 7,3 \\
\hline 36 & 2 & 18,19 & 2443,34 & 3,71 & 24,82 & 14,7 & 17,2 & 16,4 & 14,4 & 15,7 \\
\hline 42 & 2 & 17,91 & 2548,55 & 3,70 & 25,90 & 17,1 & 17,8 & 18,0 & 16,2 & 17,3 \\
\hline 46 & 2 & 17,62 & 2357,02 & 3,71 & 24,01 & 18,0 & 17,0 & 17,7 & 16,2 & 17,2 \\
\hline 80 & 2 & 19,66 & 2470,55 & 3,83 & 26,30 & 16,1 & 14,0 & 15,5 & 14,5 & 15,0 \\
\hline 15 & 3 & 16,49 & 3620,44 & 3,07 & 30,15 & 37,3 & 44,0 & 41,3 & 39,1 & 40,4 \\
\hline 145 & 3 & 16,70 & 3428,56 & 3,09 & 29,32 & 38,4 & 39,1 & 42,2 & 38,9 & 39,6 \\
\hline 93 & 3 & 17,72 & 3269,93 & 3,12 & 28,34 & 34,9 & 40,4 & 41,0 & 35,7 & 38,0 \\
\hline 120 & 3 & 16,45 & 3479,61 & 3,11 & 29,54 & 41,4 & 42,9 & 46,7 & 40,6 & 42,9 \\
\hline 12 & 4 & 18,17 & 1333,95 & 3,63 & 13,12 & 6,3 & 6,3 & 6,2 & 4,6 & 5,9 \\
\hline 22 & 4 & 17,87 & 2533,63 & 3,75 & 25,89 & 20,0 & 20,4 & 20,4 & 18,6 & 19,8 \\
\hline 54 & 4 & 15,22 & 1253,21 & 3,71 & 12,81 & 4,1 & 6,1 & 5,2 & 3,2 & 4,7 \\
\hline 127 & 4 & 13,48 & 860,59 & 3,74 & 8,82 & 3,3 & 4,0 & 7,3 & 3,5 & 4,5 \\
\hline 64 & 5 & 19,62 & 2614,96 & 3,23 & 23,45 & 17,3 & 18,2 & 18,6 & 16,5 & 17,7 \\
\hline 71 & 5 & 19,42 & 2657,37 & 3,17 & 23,41 & 20,8 & 22,7 & 21,6 & 20,2 & 21,3 \\
\hline 81 & 5 & 19,23 & 2742,18 & 3,17 & 24,21 & 20,8 & 21,7 & 21,3 & 20,5 & 21,1 \\
\hline 119 & 5 & 20,45 & 2758,47 & 3,19 & 23,99 & 18,6 & 19,9 & 23,3 & 18,7 & 20,1 \\
\hline 14 & 6 & 17,03 & 3664,47 & 2,60 & 25,88 & 45,1 & 48,2 & 46,8 & 44,9 & 46,3 \\
\hline 44 & 6 & 16,88 & 3397,38 & 2,61 & 24,37 & 43,1 & 47,0 & 45,5 & 43,7 & 44,8 \\
\hline 68 & 6 & 16,99 & 3426,82 & 2,59 & 24,65 & 45,9 & 48,4 & 47,0 & 44,3 & 46,4 \\
\hline 83 & 6 & 16,55 & 3376,02 & 2,53 & 23,74 & 48,8 & 51,6 & 52,9 & 48,5 & 50,4 \\
\hline 75 & 7 & 13,89 & 814,56 & 2,76 & 6,26 & 4,3 & 4,0 & 4,1 & 3,4 & 4,0 \\
\hline 88 & 7 & 18,76 & 1088,67 & 2,78 & 8,41 & 6,1 & 6,1 & 7,8 & 4,6 & 6,1 \\
\hline
\end{tabular}




\begin{tabular}{|c|c|c|c|c|c|c|c|c|c|c|}
\hline 105 & 7 & 21,24 & 1252,92 & 2,82 & 9,80 & 5,1 & 8,3 & 8,7 & 6,1 & 7,0 \\
\hline 144 & 7 & 12,34 & 679,28 & 2,77 & 5,21 & 2,2 & 2,9 & 6,4 & 2,4 & 3,5 \\
\hline 19 & 8 & 23,01 & 2163,57 & 2,57 & 15,06 & 12,7 & 14,6 & 15,6 & 12,2 & 13,8 \\
\hline 37 & 8 & 21,15 & 2252,16 & 2,58 & 15,91 & 11,4 & 13,6 & 13,6 & 11,0 & 12,4 \\
\hline 114 & 8 & 21,71 & 2024,94 & 2,59 & 14,32 & 10,2 & 14,0 & 14,9 & 10,4 & 12,4 \\
\hline 123 & 8 & 20,98 & 1822,20 & 2,55 & 12,75 & 8,6 & 11,2 & 13,0 & 7,3 & 10,0 \\
\hline 69 & 9 & 19,49 & 2698,26 & 2,26 & 16,92 & 24,9 & 24,2 & 24,7 & 23,2 & 24,2 \\
\hline 79 & 9 & 19,94 & 2865,41 & 2,25 & 17,92 & 24,5 & 28,2 & 26,9 & 25,1 & 26,2 \\
\hline 117 & 9 & 20,62 & 2946,03 & 2,22 & 17,84 & 28,2 & 25,5 & 30,5 & 25,1 & 27,3 \\
\hline 140 & 9 & 21,40 & 2961,15 & 2,25 & 18,39 & 23,9 & 24,2 & 28,6 & 23,0 & 24,9 \\
\hline 13 & 10 & 14,59 & 3552,83 & 2,64 & 25,46 & 56,3 & 60,4 & 56,2 & 54,0 & 56,7 \\
\hline 17 & 10 & 15,68 & 3701,50 & 2,67 & 26,77 & 53,9 & 56,5 & 54,4 & 51,9 & 54,2 \\
\hline 78 & 10 & 18,65 & 1242,02 & 2,27 & 7,84 & 5,1 & 6,1 & 5,9 & 4,6 & 5,4 \\
\hline 138 & 10 & 18,37 & 1101,42 & 2,22 & 6,72 & 4,9 & 5,9 & 8,8 & 4,1 & 5,9 \\
\hline 35 & 11 & 19,56 & 1703,23 & 2,06 & 9,62 & 8,4 & 8,9 & 9,1 & 7,3 & 8,4 \\
\hline 40 & 11 & 19,45 & 1656,42 & 2,03 & 9,18 & 10,4 & 10,8 & 10,5 & 9,5 & 10,3 \\
\hline 130 & 11 & 23,10 & 1868,95 & 2,09 & 10,72 & 9,0 & 9,7 & 13,2 & 8,7 & 10,2 \\
\hline 132 & 11 & 22,09 & 1595,14 & 2,08 & 9,08 & 7,8 & 8,5 & 11,7 & 6,5 & 8,6 \\
\hline 4 & 12 & 20,16 & 2352,18 & 1,95 & 13,05 & 15,9 & 19,7 & 17,1 & 16,0 & 17,2 \\
\hline 7 & 12 & 19,36 & 2171,24 & 1,94 & 11,98 & 15,1 & 17,4 & 15,9 & 14,1 & 15,6 \\
\hline 33 & 12 & 20,94 & 2678,00 & 1,88 & 13,78 & 16,5 & 17,6 & 17,0 & 15,6 & 16,7 \\
\hline 109 & 12 & 19,49 & 2395,12 & 1,88 & 12,21 & 16,3 & 18,7 & 21,9 & 16,3 & 18,3 \\
\hline 25 & 13 & 8,07 & 368,92 & 5,35 & 5,38 & 3,7 & 4,0 & 4,0 & 2,1 & 3,4 \\
\hline 85 & 13 & 7,82 & 352,77 & 5,45 & 5,35 & 1,0 & 3,1 & 3,1 & 1,2 & 2,1 \\
\hline 95 & 13 & 6,64 & 322,02 & 5,43 & 4,87 & 1,0 & 2,1 & 2,6 & 0,3 & 1,5 \\
\hline 134 & 13 & 6,83 & 203,72 & 5,39 & 3,03 & 0,8 & 0,8 & 4,6 & 5,3 & 2,9 \\
\hline 52 & 14 & 20,48 & 2204,72 & 4,83 & 29,35 & 12,9 & 13,4 & 12,7 & 12,0 & 12,7 \\
\hline 77 & 14 & 20,47 & 2259,03 & 4,74 & 29,75 & 14,3 & 16,8 & 14,9 & 13,8 & 14,9 \\
\hline 129 & 14 & 21,34 & 2259,40 & 4,75 & 29,42 & 14,1 & 14,2 & 17,9 & 13,5 & 14,9 \\
\hline 136 & 14 & 20,59 & 2382,87 & 4,74 & 31,11 & 14,5 & 16,1 & 19,1 & 14,1 & 15,9 \\
\hline 39 & 15 & 17,77 & 3285,43 & 3,72 & 33,46 & 44,5 & 42,5 & 43,4 & 41,3 & 42,9 \\
\hline 49 & 15 & 17,92 & 3416,44 & 3,88 & 36,53 & 38,6 & 41,6 & 40,5 & 38,4 & 39,8 \\
\hline 57 & 15 & 17,38 & 3425,72 & 3,74 & 35,36 & 42,9 & 42,1 & 42,6 & 41,2 & 42,2 \\
\hline 87 & 15 & 18,42 & 3373,79 & 3,83 & 35,93 & 39,6 & 38,7 & 41,7 & 37,8 & 39,4 \\
\hline 66 & 16 & 16,18 & 840,59 & 4,65 & 10,85 & 2,9 & 4,0 & 3,4 & 16,9 & 6,8 \\
\hline 125 & 16 & 17,61 & 918,09 & 4,68 & 11,76 & 4,3 & 5,7 & 8,2 & 4,3 & 5,6 \\
\hline 133 & 16 & 18,39 & 968,03 & 4,71 & 12,55 & 4,3 & 6,1 & 8,1 & 4,6 & 5,8 \\
\hline 139 & 16 & 19,40 & 1289,32 & 4,68 & 16,61 & 5,3 & 5,9 & 8,2 & 7,7 & 6,8 \\
\hline 18 & 17 & 21,75 & 2751,01 & 3,99 & 29,76 & 17,8 & 18,5 & 18,3 & 16,9 & 17,9 \\
\hline 28 & 17 & 20,97 & 2745,10 & 3,81 & 28,55 & 25,3 & 22,9 & 24,2 & 22,3 & 23,7 \\
\hline 45 & 17 & 20,03 & 2693,89 & 3,55 & 26,23 & 34,5 & 34,8 & 34,8 & 33,7 & 34,5 \\
\hline
\end{tabular}




\begin{tabular}{|c|c|c|c|c|c|c|c|c|c|c|}
\hline 94 & 17 & 22,18 & 2945,88 & 3,99 & 32,72 & 18,4 & 21,2 & 21,5 & 18,9 & 20,0 \\
\hline 9 & 18 & 18,53 & 3480,91 & 3,36 & 31,63 & 42,4 & 38,0 & \begin{tabular}{|l|}
40,8 \\
\end{tabular} & 38,5 & 39,9 \\
\hline 73 & 18 & 18,35 & 3437,27 & 3,32 & 31,71 & 40,8 & 48,7 & 45,9 & 43,3 & 44,7 \\
\hline 98 & 18 & 17,70 & 3461,28 & 3,27 & 31,47 & 46,7 & 48,0 & 49,7 & 47,7 & 48,0 \\
\hline 100 & 18 & 19,14 & 3399,24 & 3,30 & 31,19 & 44,1 & 46,5 & 47,4 & 43,1 & 45,3 \\
\hline 16 & 19 & 17,83 & 844,44 & 3,43 & 7,85 & 4,3 & 5,9 & 4,7 & 2,8 & 4,4 \\
\hline 20 & 19 & 15,23 & 739,40 & 3,45 & 6,96 & 1,8 & 2,9 & 3,5 & 1,0 & 2,3 \\
\hline 23 & 19 & 17,78 & 1066,35 & 3,48 & 10,11 & 4,7 & 5,9 & 5,3 & 4,0 & 5,0 \\
\hline 70 & 19 & 17,91 & 1027,84 & 3,34 & 9,54 & 5,5 & 5,7 & 5,5 & 4,1 & 5,2 \\
\hline 6 & 20 & 20,78 & 1771,18 & 3,24 & 16,37 & 10,2 & 11,9 & 10,3 & 9,0 & 10,4 \\
\hline 31 & 20 & 27,94 & 2250,80 & 3,16 & 19,45 & 10,4 & 13,1 & 11,8 & 10,7 & 11,5 \\
\hline 63 & 20 & 23,77 & 2091,87 & 3,13 & 18,19 & 12,0 & 13,1 & 12,3 & 11,0 & 12,1 \\
\hline 89 & 20 & 27,24 & 2291,26 & 3,14 & 19,99 & 13,1 & 13,4 & 15,5 & 12,0 & 13,5 \\
\hline 26 & 21 & 21,27 & 3085,25 & 2,85 & 23,92 & 26,1 & 28,0 & 27,2 & 25,6 & 26,7 \\
\hline 38 & 21 & 21,73 & 3097,79 & 2,86 & 24,27 & 22,2 & 27,0 & 25,1 & 23,0 & 24,3 \\
\hline 96 & 21 & 22,59 & 2707,55 & 2,83 & 21,33 & 22,9 & 24,4 & 25,0 & 21,1 & 23,3 \\
\hline 101 & 21 & 22,22 & 2948,95 & 2,85 & 23,41 & 26,7 & 32,3 & 30,8 & 28,5 & 29,6 \\
\hline 32 & 22 & 18,53 & 861,15 & 2,82 & 6,63 & 2,9 & 3,6 & 3,1 & 2,1 & 2,9 \\
\hline 62 & 22 & 14,17 & 596,37 & 2,82 & 4,67 & 3,1 & 4,0 & 3,8 & 2,4 & 3,3 \\
\hline 72 & 22 & 18,15 & 671,55 & 2,79 & 5,20 & 1,8 & 3,4 & 2,8 & 1,8 & 2,4 \\
\hline 82 & 22 & 14,21 & 554,84 & 2,75 & 4,24 & 2,4 & 2,7 & 4,4 & 0,9 & 2,6 \\
\hline 102 & 23 & 27,11 & 1621,00 & 2,68 & 12,10 & 7,3 & 10,6 & 10,3 & 8,3 & 9,1 \\
\hline 115 & 23 & 22,96 & 1325,88 & 2,60 & 9,41 & 5,5 & 7,2 & 10,2 & 5,2 & 7,0 \\
\hline 118 & 23 & 23,63 & 1734,62 & 2,62 & 12,42 & 10,8 & 11,4 & 15,0 & 10,2 & 11,9 \\
\hline 137 & 23 & 24,72 & 1754,95 & 2,61 & 12,62 & 7,1 & 8,9 & 12,0 & 7,7 & 8,9 \\
\hline 3 & 24 & 19,17 & 2279,43 & 2,38 & 15,45 & 18,2 & 20,4 & 18,3 & 15,7 & 18,1 \\
\hline 53 & 24 & 20,84 & 2467,89 & 2,29 & 15,56 & 18,0 & 19,1 & 18,6 & 16,9 & 18,2 \\
\hline 58 & 24 & 20,25 & 2802,83 & 2,25 & 17,40 & 23,5 & 25,3 & 24,2 & 22,1 & 23,8 \\
\hline 110 & 24 & 22,99 & 2456,83 & 2,30 & 15,33 & 15,5 & 16,1 & 19,4 & 15,0 & 16,5 \\
\hline 41 & 25 & 11,76 & 416,23 & 7,62 & 8,71 & 1,8 & 2,7 & 2,5 & 1,2 & 2,0 \\
\hline 56 & 25 & 11,12 & 426,45 & 7,46 & 8,76 & 1,4 & 2,1 & 1,6 & 1,9 & 1,7 \\
\hline 67 & 25 & 12,34 & 401,27 & 7,62 & 8,49 & 1,6 & 1,9 & 2,0 & 1,2 & 1,7 \\
\hline 92 & 25 & 12,54 & 455,51 & 7,66 & 9,70 & 1,0 & 4,6 & 3,2 & 0,7 & 2,4 \\
\hline 48 & 26 & 22,76 & 2240,67 & 6,70 & 41,34 & 11,6 & 14,6 & 13,0 & 11,4 & 12,7 \\
\hline 51 & 26 & 20,71 & 2171,87 & 6,46 & 38,63 & 14,7 & 14,2 & 14,9 & 13,2 & 14,2 \\
\hline 113 & 26 & 22,65 & 2280,14 & 6,43 & 39,70 & 14,7 & 15,3 & 17,3 & 13,5 & 15,2 \\
\hline 141 & 26 & 23,29 & 2327,84 & 6,73 & 43,17 & 11,4 & 11,4 & 13,5 & 11,6 & 12,0 \\
\hline 8 & 27 & 23,44 & 2837,03 & 4,98 & 38,18 & 18,6 & 21,9 & 20,1 & 18,4 & 19,7 \\
\hline 65 & 27 & 23,05 & 2706,61 & 5,07 & 38,12 & 19,0 & 20,4 & 20,0 & 18,1 & 19,4 \\
\hline 97 & 27 & 21,45 & 2699,32 & 5,39 & 40,53 & 16,7 & 16,1 & 18,3 & 14,8 & 16,5 \\
\hline 126 & 27 & 24,16 & 2853,30 & 5,09 & 39,78 & 21,8 & 23,8 & 26,8 & 22,0 & 23,6 \\
\hline
\end{tabular}




\begin{tabular}{|c|c|c|c|c|c|c|c|c|c|c|}
\hline 21 & 28 & 9,80 & 985,51 & 6,55 & 17,58 & 4,1 & 5,7 & 5,0 & 3,2 & $\overline{4,5}$ \\
\hline 27 & 28 & 20,79 & 1059,83 & 6,52 & 18,85 & 3,9 & 5,9 & 2,5 & 3,8 & 4,0 \\
\hline 30 & 28 & 19,36 & 973,42 & 6,49 & 17,24 & 3,7 & 4,8 & 4,6 & 3,1 & 4,1 \\
\hline 60 & 28 & 19,00 & 882,28 & 6,61 & 16,16 & 2,4 & 4,0 & 3,1 & 1,6 & 2,8 \\
\hline 55 & 29 & 23,34 & 2444,80 & 5,56 & 37,44 & 15,9 & 18,9 & 17,1 & 15,7 & 16,9 \\
\hline 59 & 29 & 22,77 & 2521,31 & 5,56 & 38,86 & 15,9 & 17,0 & 16,8 & 15,0 & 16,2 \\
\hline 107 & 29 & 21,06 & 2011,98 & 5,81 & 31,64 & 31,0 & 33,6 & 2,0 & $-3,5$ & 15,8 \\
\hline 131 & 29 & 23,47 & 2687,21 & 5,56 & 40,94 & 17,3 & 18,2 & 22,2 & 18,6 & 19,1 \\
\hline 11 & 30 & 21,73 & 2828,81 & 4,10 & 31,35 & 20,0 & 26,1 & 23,3 & 21,5 & 22,7 \\
\hline 76 & 30 & 23,21 & 3227,43 & 4,20 & 37,67 & 21,4 & 21,9 & 21,6 & 20,9 & 21,5 \\
\hline 103 & 30 & 5,04 & 2771,80 & 4,02 & 30,95 & 26,7 & 28,0 & 29,9 & 28,2 & 28,2 \\
\hline 116 & 30 & 14,35 & 397,38 & 6,64 & 7,20 & 2,0 & 4,0 & 4,1 & 0,7 & 2,7 \\
\hline 5 & 31 & 21,45 & 1980,43 & 4,29 & 24,19 & 13,5 & 18,5 & 15,0 & 15,0 & 15,5 \\
\hline 47 & 31 & 20,14 & 1197,35 & 4,93 & 16,21 & 5,5 & 6,1 & 6,1 & 4,6 & 5,6 \\
\hline 104 & 31 & 16,77 & 750,23 & 4,43 & 9,23 & 13,1 & 14,4 & 15,3 & 14,1 & 14,2 \\
\hline 111 & 31 & 14,50 & 36 & 4,78 & 4,78 & 2,7 & 4,0 & 4,6 & 3,2 & 3,6 \\
\hline 61 & 32 & 23,44 & 1953,62 & 4,51 & 24,45 & 10,2 & 11,7 & 10,8 & 10,2 & 10,7 \\
\hline 90 & 32 & 25,48 & 1995,79 & 4,93 & 27,37 & 1,6 & 2,7 & 3,5 & 2,1 & 2,5 \\
\hline 124 & 32 & 24,20 & 2375,39 & 4,65 & 30,23 & 10,2 & 12,1 & 13,8 & 9,6 & 11,4 \\
\hline 128 & 32 & 23,99 & 2118,35 & 4,68 & 27,14 & 9,2 & 9,1 & 12,0 & 10,7 & 10,2 \\
\hline 99 & 33 & 21,61 & 2776,45 & 3,73 & 28,84 & 25,3 & 27,4 & 28,9 & 26,2 & 26,9 \\
\hline 112 & 33 & 21,32 & 2858,95 & 3,82 & 29,58 & 22,9 & 23,1 & 26,3 & 21,8 & 23,5 \\
\hline 121 & 33 & 21,77 & 2828,34 & 3,78 & 29,18 & 22,7 & 25,3 & 27,7 & 22,6 & 24,5 \\
\hline 135 & 33 & 23,67 & 3080,39 & 3,92 & 33,31 & 23,1 & 24,0 & 27,4 & 24,2 & 24,7 \\
\hline 86 & 34 & 22,37 & 1181,02 & 3,84 & 12,61 & 4,5 & 6,3 & 6,5 & 4,0 & 5,3 \\
\hline 108 & 34 & 11,36 & 396,38 & 3,73 . & 4,00 & 4,3 & 5,7 & 1,6 & $-3,5$ & 2,0 \\
\hline 122 & 34 & 25,72 & 1054,97 & 3,79 & 10,95 & 4,5 & 4,6 & 8,2 & 5,3 & 5,7 \\
\hline 143 & 34 & 27,34 & 1235,52 & 3,79 & 12,96 & 5,3 & 5,9 & 9,3 & 5,6 & 6,5 \\
\hline 29 & 35 & 21,01 & 1573,40 & 3,52 & 15,12 & 8,2 & 8,5 & 8,4 & 6,8 & 8,0 \\
\hline 74 & 35 & 21,25 & 1499,57 & 3,44 & 14,33 & 8,8 & 8,5 & 8,5 & 7,3 & 8,3 \\
\hline 106 & 35 & 23,49 & 1833,29 & 3,60 & 18,32 & 8,4 & 10,8 & 10,9 & 7,9 & 9,5 \\
\hline 142 & 35 & 22,61 & 1647,86 & 3,50 & 15,98 & 6,7 & 8,0 & 10,9 & 6,1 & 7,9 \\
\hline 1 & 36 & 24,30 & 2454,80 & 3,35 & 23,45 & 14,9 & 17,0 & 16,1 & 16,2 & 16,0 \\
\hline 24 & 36 & 21,01 & 2525,61 & 3,27 & 22,52 & 15,1 & 17,0 & 15,6 & 14,0 & 15,4 \\
\hline 43 & 36 & 20,69 & 2656,24 & 3,30 & 24,08 & 17,1 & 18,2 & 17,9 & 16,5 & 17,4 \\
\hline 84 & 36 & 21,79 & 2586,01 & 3,25 & 23,40 & 16,9 & 18,9 & 19,5 & 15,9 & 17,8 \\
\hline
\end{tabular}




\section{REFERÊNCIAS BIBLIOGRÁFICAS}

ALMEIDA, E. M. Rendimento global de tratores em pista de concreto. Campinas, 1990. 111 p. Dissertação (Mestrado) - Faculdade de Engenharia Agrícola, Universidade Estadual de Campinas.

AMERICAN SOCIETY OF AGRICULTURAL ENGINEERS. ASAE standards 1983: standards, engineering practices data. 30.ed. St. Joseph, 1983. p.233: Soil cone penetrometer - ASAE S313.1

AMERICAN SOCIETY OF AGRICULTURAL ENGINEERS. ASAE standards 1995: standards, engineering practices data. 42.ed. St. Joseph, 1995. p.335-340: Agricultural machinery management data - ASAE D497.2

ASSOCIAÇÃO BRASILEIRA DE NORMAS TÉCNICAS. Motores alternativos de combustão interna de ignição por compressão (Diesel) ou ignição por centelha (Otto) de velocidade variável - método de ensaio: NBR 5484. Rio de Janeiro, 1985. 23p.

BALASTREIRE, L.A. Máquinas Agrícolas. São Paulo: Manole, 1987. 307p.

BURT, E.C.; LYNE P.W.D. Velocity effects on traction performance. Transactions of ASAE, v.28, n.6, p.1729-1730, Nov./Dec. 1985.

BRIXIUS, W.W. Traction prediction equations for bias ply tires. St.Joseph: ASAE, 1987. 9p. (ASAE Paper, 87-1622).

CHANCELLOR, W.J.; THAI, N.C. Automatic control of tractor transmission ratio and engine speed. Transaction of ASAE, v.27, n.3, p.642-646, May/June 1984. 
HANSEN, A.C.; WALKER, A.J.; LYNE, P.W.; MEIRING, P. Power demand mapping of tractor operations. Transactions of ASAE, v.29, n.3, p.656-660, May/June 1986.

HERMANN, P.R.; KRAUSE, R.; MATTOS, P.C. Parâmetros para a seleção adequada de tratores agrícolas de rodas. Boletim Técnico - Ano 1, n.1, Suplemento do Informativo CENEA. Out./Nov./Dez., 1982. CENEA - Centro Nacional de Engenharia Agrícola. 4p.

KHALILIAN,A.; BATCHELDER,D.G.; SELF, K.; SUMMERS,J.D. Revision of fuel consuption equations for diesel tractors. St. Joseph: ASAE, 1984. 16p. (ASAE Paper, 84-1077).

KIEHL, E. J. Manual de edofologia. Piracicaba: Ed. Agronômica “Ceres”, 1979. $262 \mathrm{p}$.

KOTZABASSIS, C; WIEDEMANN, H.T; SEARCY, S.W. Tractor energy conservation. College State: Texas Agricultural Extension Service. 1994. 5 p.

LAFLEN, J.M; AMEMIYA, M; HINTZ, E.A. Measuring crop residue cover. Journal of Soil and Water Conservation, v. 36, p. 341-343. Nov./Dec. 1981.

LEVITICUS, L.I.; REYES, J.F. Tractor performance on concrete. Transactions of ASAE, v.28, n.5, p.1425-1429, Sept./Oct. 1985.

LIMA, J.S. de S.; SOUZA, E.G. de; MILANEZ, L.F. Avaliação do rendimento global de um trator em um tipo de solo agrícola. In: CONGRESSO BRASILEIRO de ENGENHARIA AGRÍCOLA, 22., Campinas, 1993, p.17411755.

LYNE, P.W.L.; BURT, E.C.; MEIRING,P. Effect of tire and engine parameters on efficiency. Transactions of ASAE, v.27, n.1, p.5-7, Jan./Feb. 1984.

MIALHE, L.G. Análise das características e desempenho de tratores. Piracicaba: Fundação de Estudos Agrários Luiz de Queiroz. 1985. 145p.

MIALHE, L.G. Máquinas agrícolas: ensaios \& certificação. Piracicaba, SP: Fundação de Estudos Agrários Luiz de Queiroz. 1996. 722p. 
PACEY,D.A.; SCHROCK,M.D. Modeling of tractor fuel use. St.Joseph: ASAE, 1982. 7p. (ASAE Paper, 82-1521).

SCHROCK, M.; MATTESON, D.; BLUMANHOURST, M. THOMPSON, J. A device for aiding gear selection in agricultural tractors. Transactions of ASAE, v.29, n.5, p.1232-1236, Sept./Oct.1986.

SCHROCK, M.D.; LIU, Y. Simulation of control schemes for agricultural tractor engines and transmissions. Transactions of ASAE, v.33, n.6, p.1785-1789, Nov./Dec. 1990.

SOUZA, E.G. de Simulação do desempenho de tratores em pista de concreto. Campinas, 1989. 117p. Tese (Doutorado) - Faculdade de Engenharia Agrícola, Universidade Estadual de Campinas.

SOUZA, E.G. de; MILANEZ, L.F. Indirect evaluation of the torque of diesel engines. Transactions of ASAE, v.31, n.5, p.1350-1354, Sept./Oct. 1988.

SOUZA, E.G. de; MLANEZ, L.F. Efficiency analysis of diesel engines. Transactions of the ASAE, v.33, n.1, p.8-14, Jan./Feb. 1990.

SOUZA, E.G. de; ALMEIDA, E. M; MILANEZ, L.F. Overall efficiency of tractors on concrete. Transactions of ASAE, v.34, n.6, p.2333-2339, Nov./Dec. 1991.

SOUZA, L.F.C.de Trator agrícola: outra proposta de uso. Maquinaria Agrícola , v.4, n.3/4, p.2, Jul./Dez. 1989.

STEINKAMPF, $\mathrm{H}$ Possibilities of saving energy during tractor use. Federal Center of Agriculture, Braunschweig, 1981, 9p.

TAYLOR, C.F. Análise dos motores de combustão interna. 2.ed. São Paulo: Edgard Blücher, 1971. v.1, cap. 12-13: Desempenho de motores sem supercarregamento.

WANG, G.; ZOERB, G.C. Determination of optimum working points for diesel engines. Transactions of ASAE, v.32, n.5, p.1519-1522, Sept./Oct. 1989. 